Illinois State University

ISU ReD: Research and eData

Theses and Dissertations

$10-25-2018$

\title{
A Pokébalancing Act: The Management Of Japanese Cultural "odor" In Pokémon
}

Nicholas Raes

Illinois State University, nickraes@gmail.com

Follow this and additional works at: https://ir.library.illinoisstate.edu/etd

Part of the Communication Commons

\section{Recommended Citation}

Raes, Nicholas, "A Pokébalancing Act: The Management Of Japanese Cultural "odor" In Pokémon" (2018). Theses and Dissertations. 1022.

https://ir.library.illinoisstate.edu/etd/1022

This Thesis is brought to you for free and open access by ISU ReD: Research and eData. It has been accepted for inclusion in Theses and Dissertations by an authorized administrator of ISU ReD: Research and eData. For more information, please contact ISUReD@ilstu.edu. 


\section{A POKÉBALANCING ACT: THE MANAGEMENT OF JAPANESE CULTURAL “ODOR”}

IN POKÉMON

\section{NICHOLAS RAES}

\section{Pages}

In this project, I analyzed two seasons of the Pokémon anime to discover patterns of cultural "odor" management employed by the show's producers and editors. In the first season of Pokémon, the producers of the anime included many symbolic representations of Japanese cultural artifacts within the visual features of the show. However, between the Japanese and US versions of the season, most instances of Japanese linguistic text were either "scrubbed" from scenes entirely or replaced with English text. These techniques struck a careful balance between including and excluding Japanese specificity within the first season, subtly expressing to nonJapanese audiences the Japanese origin of the show. However, in the twentieth season, producers removed symbolic representations of Japanese culture almost entirely - replacing these instead with symbols indicative of Hawaiian culture. This study traced the patterns of techniques used within these two seasons to manage this cultural "odor" to implicate the ways in which aspects of culture in television shows can prompt audiences toward developing interests in other cultures. KEYWORDS: anime; cultural odor; Japan; Japanese culture; Pokémon 


\title{
A POKÉBALANCING ACT: THE MANAGEMENT OF JAPANESE CULTURAL "ODOR"
}

IN POKÉMON

\author{
NICHOLAS RAES
}

\author{
A Thesis Submitted in Partial \\ Fulfillment of the Requirements \\ for the Degree of \\ MASTER OF SCIENCE \\ School of Communication \\ ILLINOIS STATE UNIVERSITY
}

2018 
(C) 2018 Nicholas Raes 


\section{A POKÉBALANCING ACT: THE MANAGEMENT OF JAPANESE CULTURAL “ODOR”}

IN POKÉMON

NICHOLAS RAES

COMMITTEE MEMBERS

Phil Chidester, Chair

John Baldwin

Lauren Bratslavsky 


\section{ACKNOWLEDGMENTS}

I would first like to thank my parents, Charlie and Mary Raes and Marjorie Mayer, without them none of this would be possible. I would also like to thank my committee members: Dr. Chidester, Dr. Baldwin, and Dr. Bratslavsky, for all of the hard work they have done in helping me get this project finished. Also - Nichole, Haley, and Alyssa thank you for your support as well as your understanding toward my multitude of stresses and thank you Jorgi for being a great mentor. I'd also like to thank Gerard and Jeremy for keeping me focused and sane during the rough patches. To Justin, Travis, and Griffin thank you for keeping me in good spirits for most of this process. To my undergraduate advisors, Trudi Peterson and Kate ZittlowRogness, thank you very much for believing in my ability and motivating me to take the plunge into grad school. Furthermore, thank you to Satoshi Tajiri, whose dream project influenced me to explore cultures outside of my comfort zone. Without any of you, I doubt I would be in the spot I am today. Thank you very much.

N.R. 


\section{CONTENTS}

Page

ACKNOWLEDGMENTS

CHAPTER I: INTRODUCTION 1

A Survey of Existing Research $\quad 8$

Globalization and Localization $\quad 9$

$\begin{array}{ll}\text { Orientalism } & 13\end{array}$

$\begin{array}{ll}\text { Anime } & 15\end{array}$

$\begin{array}{ll}\text { Cultural Odor } & 17\end{array}$

$\begin{array}{ll}\text { Pokémon } & 21\end{array}$

$\begin{array}{ll}\text { Methodology } & 25\end{array}$

$\begin{array}{ll}\text { Thesis Outline } & 27\end{array}$

CHAPTER II: REVIEW OF LITERATURE $\quad 28$

Globalization and Localization 28

$\begin{array}{ll}\text { Glocalization } & 35\end{array}$

$\begin{array}{ll}\text { Orientalism } & 39\end{array}$

$\begin{array}{ll}\text { Cultural Odorless-ness } & 49\end{array}$

$\begin{array}{ll}\text { Anime } & 62\end{array}$

History of Anime $\quad 63$

Defining of Anime $\quad 66$

Anime's Cultural Influence and its Japanese Specificity 68

$\begin{array}{ll}\text { Anime in the Local and the Global } & 70\end{array}$

$\begin{array}{ll}\text { Pokémon } & 73\end{array}$ 
$\begin{array}{ll}\text { History of Pokémon } & 74\end{array}$

$\begin{array}{ll}\text { Pokémon as Transmedia } & 77\end{array}$

$\begin{array}{ll}\text { Pokémon as a Social Phenomenon } & 78\end{array}$

Pokémon as Japanese $\quad 83$

$\begin{array}{lr}\text { Conclusion } & 89\end{array}$

CHAPTER III: METHODS 91

Background of Anime's Broadcast in the United States 91

Background of Pokemon's Broadcast $\quad 92$

What are Pokémon? 94

Description of the First Season's Setting 96

First Season Character Summary $\quad 97$

Description of the Twentieth Season's Setting 99

$\begin{array}{ll}\text { Twentieth Season Character Summary } & 100\end{array}$

$\begin{array}{ll}\text { Episode Analysis } & 100\end{array}$

$\begin{array}{ll}\text { Japanese Content } & 101\end{array}$

$\begin{array}{ll}\text { Selection of Episodes } & 102\end{array}$

$\begin{array}{ll}\text { Conclusion } & 103\end{array}$

$\begin{array}{ll}\text { CHAPTER IV: ANALYSIS } & 104\end{array}$

$\begin{array}{ll}\text { Background of Season One } & 104\end{array}$

Management of Cultural "Odor" 105

$\begin{array}{ll}\text { Analysis of Episodes } & 107\end{array}$

$\begin{array}{ll}\text { Landscape } & 109\end{array}$

Japanese-ness in Clothing, Architecture, and Food 112 
$\begin{array}{ll}\text { Japanese Cultural Knowledge } & 126\end{array}$

$\begin{array}{ll}\text { Diegetic Text } & 137\end{array}$

$\begin{array}{ll}\text { Names and Puns } & 146\end{array}$

Background of Season Twenty 152

$\begin{array}{ll}\text { Analysis of Episodes } & 154\end{array}$

$\begin{array}{ll}\text { Landscape } & 154\end{array}$

Japanese-ness of Food, Clothing, and Architecture 155

$\begin{array}{lr}\text { Japanese Cultural Knowledge } & 158\end{array}$

$\begin{array}{ll}\text { Polynesian-ness } & 163\end{array}$

$\begin{array}{ll}\text { Conclusion } & 164\end{array}$

CHAPTER V: DISCUSSION 167

$\begin{array}{ll}\text { Implications } & 180\end{array}$

$\begin{array}{ll}\text { Future Research } & 182\end{array}$

$\begin{array}{ll}\text { Conclusion } & 184\end{array}$

$\begin{array}{ll}\text { REFERENCES } & 187\end{array}$

APPENDIX: LIST OF EPISODES EXAMINED 215 


\section{CHAPTER I: INTRODUCTION}

As a fan of the Pokémon franchise, I have continued to be interested in the globalized aspects of the production and marketing of this pop cultural phenomenon. I wanted to discover whether, if over time, the anime Pokémon was deliberately edited or otherwise altered to reflect “international taste" in conforming with extra-cultural notions concerning children's television shows. As this program has been on the air for over 20 years, I investigated whether there have been perceivable differences in the amount and type of editing between the Japanese and the English versions of the program between its first season and its most recent season (Season 20).

In the late 1990s through the early 2000s, the popular cable network Cartoon Network ran a programming block consisting primarily of Japanese anime. This block known as Toonami was presented during the after-school hours between four and seven o'clock on weekdays and consisted of a rotating schedule of translated shows from Japan such as Mobile Suit Gundam Wing and Dragon Ball $Z$ alongside American shows like Batman: The Animated Series and Thundercats. As an avid television watcher during the height of the block's popularity, I could tell the difference between the Japanese anime and the Western animated television shows, but I could not articulate how I knew the difference or why I preferred the anime over the other shows. Furthermore, as animated programming did not, and does not, have to concern itself with matching dubbed voice acting over the lip movements of its actors, it is one of the most ubiquitous genres that have been localized around the world. As Western conventions of animation "state" that cartoons are for children, this localization and dubbing mostly affected children who watched these shows.

When watching shows such as Pokémon on other channels, I could also tell that this anime contained alterations from its original Japanese language to the Westernized translation. 
For instance, in one episode of Pokémon a character mentioned his affinity for jelly doughnuts but held up an armful of rice balls as emphasis.

The localization of lingual references for a Western audience indicates an identifiable difference between the two cultures. Per Katsuno and Maret (2002), localization is "the process of adapting a global product for a specific market" in which translation is a key component (p. 82). The Westernized translation indicates a lack of confidence with American audience's ability to conceive of cultural differences in an animated medium. However, other cultural signifiers such as text on signs, specifically Japanese flags, and other food products gave the impression of difference to me. While watching these entertainment programs, this perceived difference between cartoons from my own culture and animation from abroad made me feel like I was discovering something about another land far from my own experiences.

This feeling of discovery was consistently extended every time I watched or re-watched an episode of an anime. It was more salient when I watched series with subtitles but was nonetheless present in anime that was "dubbed" in the English language as well. In consuming a program that was not produced through the American cultural context, my experience with translated media from Japan inspired me to uncover the ways in which these transmediated programs were adapted for Western audiences. Although these programs were initially produced for the consumption of Japanese audiences, they nevertheless found their way around the world, translated for other cultural audiences. However, during the processes of translation, linguistic subtleties and iconographs are inevitably altered for the purpose of Western consumption. What remains to be found, however, is the level, frequency, and intentionality with which these changes occur amongst the industries and individuals that translate these programs. 
As an avid watcher of anime, I still prefer to watch these programs in their original language alongside subtitles rather than dubbed with English voices because I believe that subtleties in linguistic and cultural references are lost in the translation process and therefore "lose" some of the artistic intent behind the programs' production. Furthermore, because I watch these programs in their original language without edits made by an intermediating distributor I am more aware of cultural-specific references, thereby giving the shows a "more authentic" feel. Furthermore, I believe that this investment in authenticity stems from my peripheral awareness of, and subsequent disinterest in, Japanese live-action films such as Godzilla from the 1950s and 1960s that were dubbed over in English. Because of the difference in mouth movements and what was said in these films, I was skeptical toward their accuracy in conveying the original intent of the films and was therefore disinterested in the translated versions. My interest in the original Japanese versions of anime consequently results from this ambivalence because I am more confident that the content has not been altered by Western distributors who think that less diverse content is more profitable.

While I was initially neutral toward these old Japanese films, they nevertheless informed me that there were different countries and cultures that produced film which influenced my habits to find entertainment outside of my "boring" American upbringing. When I was growing up in the 1990s, aside from several sitcoms featuring Black families and characters, most of the content I saw portrayed on television included White-American lifestyles that I eventually perceived to be boring and repetitive. I then made active attempts to find shows and movies outside of this familiarity which culminated in my fanaticism with the Pokémon franchise. Therefore, authenticity in products outside of my immediate cultural familiarity is important to me due to my preference for consuming culturally diverse products that can, at least partially, 
provide me with the type of entertainment unique to the other cultures. If programs are continuously and consistently "scrubbed" in order to more closely align with my "American" tastes, I become bored with the "sameness" of these programs. When I can perceive culturally specific and authentic qualities in themes and aesthetics different than what I have grown accustomed to, I become much more invested in that product because I believe that attending to programs from different backgrounds than my own can help erase insular, exclusive attitudes toward people from different cultures.

Furthermore, culturally diverse television programming with intact, perceivable, culturalness is important because of the underrepresentation of non-U.S. cultures in American television. This lack of representation homogenizes the type of media to which people, particularly children, are exposed. If American children are primarily exposed to cross-cultural programming that has been intentionally edited for the removal of cultural-specific references, language, and artifacts, then they may not be aware of the diversity of cultures found in the world. This becomes important in today's increasingly globalized world when individuals are able to freely choose from a vast number of programs to watch because if they are not aware of distinct cultures and their uniqueness, they may "stick to what they know" which are the familiar, domestic programs with which they are accustomed. This insulation from other cultures becomes problematic as developing cross-cultural awareness and intercultural competence becomes ever more important in an increasingly globalized world.

Within the last twenty years, technology has rapidly changed the globalized landscape. The rise of the internet from niche-usage to ubiquity in almost every country, for example, has drastically impacted the ways people have communicated within their respective cultures as well as with individuals in disparate cultures. The United States, which is commonly presumed to be 
the hegemonic center of globalization, has also been influenced by technological advancements. Due to these recent advancements, individuals are exposed to, and develop interest in, other cultures. It could also be argued that interest in other cultures has simultaneously incentivized technological advancements in the realm of communication. The internet has facilitated this interest in other cultures with its ability to transmit information quickly. Cultural products such as television shows are now able to be uploaded, downloaded, shared, and streamed at a moment's notice. These technological advances also influence the ways in which producers target particular demographics. No longer can these producers fashion products with only specific audiences in mind, as these products can "leak" into other audiences who will interpret the product in their own ways. Producers of these products are additionally able to use the internet to monitor feedback from their consumers, thereby becoming more attuned to the tastes of the publics with regards to the programs they choose to watch. The preferences that consumers hold in terms of diverse programming and products from other cultures might indicate American culture's attitude toward diversity and intercultural interaction in the media. As the Japanese Pokémon multimedia franchise has consistently been globally successful over 20-year period since its initial conception, it exists as a prime example of the globalization of media programming from "peripheral" countries outside of the American "domination" of globalized entertainment products.

This prompts the question as to whether we, as a nation, are truly extending ourselves to diverse cultures. If the extra-cultural products we receive and consume are scrubbed of their culturally-specific attributes, can it really be said that we are becoming more sensitive to other cultures? Or are we merely presenting a façade of diversity for the purpose of seeming diverse? 
With over 1000 episodes, 22 animated movies, and 8 TV specials to date, Pokémon has been successful in terms of longevity and reach. Furthermore, the franchise has cemented its cultural relevancy in an age when videogames are growing to comprise a significant part of many cultures. The first generation of Pokémon games released in 1998 in America, (Pokémon Red, Pokémon Blue, and Pokémon Yellow) sold a combined total of nearly 15 million units in the United States alone. The next generation released in 2000 (Pokémon Gold, Pokémon Silver, and Pokémon Crystal) sold 9.25 million units. The sales figures of these games successfully communicated the franchise's popularity in America to Japan (US platinum videogame chart, 2007). Furthermore, the franchise has multiple other peripheral, but nonetheless successful, products. including a trading card game whose existence stretches back to before the anime, board games, manga, and various toys (Pokémon in figures, 2017). The Pokémon brand itself makes $\$ 1.5$ billion annually (GOBankingRates, 2017).

The Pokémon anime is one of the very few non-American entertainment programs that has lasted for over 20 years within an American market while continuously supporting its suprafranchise with its consistent additions of characters and creatures that incentivize audiences to stay invested in the story of the anime as well as the commodified franchise itself. As a program that has been adapted to 98 countries and regions (Pokémon in figures, 2017). Pokémon has been able to reach a multitude of audiences that it previously could not with the assistance of advances in technological distribution via the internet (Pokémon in figures, 2017), The longevity of this franchise in multiple cultural contexts presented an opportunity to research the methods through which media producers and distributors adapt a television program to multiple different audiences over an extended period of time. 
This project furthered insight toward how adaptation choices made by producers and distributors change over time and within different contexts through the process of globalization. Furthermore, this project revealed that choices made by those in charge influence the way that the producing culture is perceived in other cultures. For example, if programs from one country are heavily edited and altered for consumption in another country, consumers in that culture may receive a cultural-product that may not represent an accurate, or authentic, vision of the producing culture in question. When a culture's commodities are altered for the sake of the tastes in another culture, the inclusion of this product into the receiving culture does not necessarily authentically produce cultural diversity within that culture as the editing process "deodorizes" cultural specificity in order to orient that product according to the receiving culture's tastes.

Whereas the Pokémon franchise contains much more than just the anime under its umbrella, in relation to its other media, the anime presents a more robust opportunity to determine the extent to which the cultural odor of the franchise has been managed over the course of its history. While an examination toward the linguistic localization of the video games and card game would provide valuable insight toward The Pokémon Company's management strategies, it would require someone much more accomplished in the Japanese language to parse out the cultural specificities maintained, edited, and replaced in the games.

Concerning products from Japan, global audiences' perceptions of these products may be influenced by the orientalization of Japan and Japanese products on the part of the producers and global distributors. While Pokémon as Japanese product is incredibly popular, marketable, and profitable, the mere "hint" of Japanese-ness may indicate a commodification of the Japanese culture, edited for global audiences to "fit" with their preferences. This indicates that the Japanese-ness of the program may be judged to be unwanted or un-needed by distributors for 
their audiences. Instead, aspects of the Japanese-ness may have served as distinguishing features that contrasted the anime from other, familiar cartoons. I theorized, and later concluded, that a "balancing act" was undertaken by the distributors of the Pokémon anime by endeavoring to appeal to Western preferences and not having an apparent Japanese "cultural odor" while simultaneously using its "Japanese-ness" to its advantage in portraying a unique "exotic" program for Western children to view. These considerations led to the following research questions which informed this project:

RQ1: How have the producers and distributors of Pokémon altered the anime for American consumption during the 20 years of the program's existence?

RQ2: How have these producers and distributors achieved the "balancing act" of maintaining a particular Japanese style in the Pokémon anime texts without making these texts "too Japanese" for American audiences?

\section{A Survey of Existing Research}

Existing research related to the Pokémon franchise, while expansive, has left some gaps which this thesis was designed to address. This research has examined the series in terms of the globalized nature of Pokémon as well its relationship with localization methods, its nature as an animated television show and the Orientalist nature of the anime medium itself, and through the concept of "cultural odorless," which purports that cultural specificity is reduced in certain products to better appeal to wider audiences. However, none have combined these concepts toward an examination of the management of Pokémon's cultural "odor" over the course of the franchise's history. 


\section{Globalization and Localization}

In an increasingly connected global society, cultural commodities are able to be imported and exported more easily than ever before. Distribution networks allow products such as television programs to be efficiently delivered to nations and cultures all over the world. Because of this networking, individuals are much more easily able to access television programs produced outside of their own culture. The United States has previously been regarded as the center of this network, sending its media to influence cultures abroad. As Olson (2000) states, "Hollywood is a global aesthetic, and that in a nutshell sums up its transnational appeal" (p. 4). Lorenzen (2007) explicates that "last century's internationalization of the film industry has been a tale of the dominance of a very limited number of countries on export markets" (p. 351). He states that Hollywood, in the $20^{\text {th }}$ century, was uniquely capable of shouldering the burdens of production and distribution of films in the United States and exporting them abroad as well as importing foreign films for translation into the U.S. This, however, ignores the influence that media productions in other cultures have on each other and on the United States itself in the $21^{\text {st }}$ century.

Previously thought of as a force that standardizes or homogenizes cultures into a similar, overarching orientation, globalization is now conceptualized as an intricate web of processes that is not so linear. The term "globalization" no longer refers to the idea that, through a series of processes, one particular culture overrides localities to becomes the dominant force toward which peripheral cultures orient toward (Albrow, 1990; Ferguson, 1992; Robertson, 1995) Instead, Pieterse (1994) emphasizes that although many processes combine to shape globalization's power to create a more unified world, globalization creates a hybridization of cultures and their artifacts rather than enforcing a dominant "Westernized" tone to which the 
world must adapt. Pieterse further states that this hybridization "intensifies" and "accelerates" when certain conditions are met, particularly that of technological and industrial advancements as well as with the increasing socio-cultural relations that follow these advancements (p. 163 $164)$.

Kriesi (2013) defines globalization as a challenge to the granted imperialistic forces of the pre- $20^{\text {th }}$ century expansionist forces. He argues that "advancing economic, cultural, and political globalization leads to an expansion, deepening, and acceleration of global interdependencies across the borders of nation-states" (p. 3). Kriesi utilizes Held's (2006) ideas of "symmetries" and "congruencies" of previously held notions of the relationships of governments and cultures to argue that the interactions within these relationships within nations, and across their borders, are no longer clear-cut but are "breaking down" in the face of increasing globalization forces that "challenge" democracy. Here, globalization is no longer thought of as an affective path from a hegemonic center to peripheral countries, but as a composite interplay of regions, nations, ethnicities, and cultures as affective on one another (Crane, 2002).

Many authors view globalization as a series of processes. These processes can influence and alter our understanding of nationality and the nation-state (Steger, 2009), socially link together cultures, corporate entities, organizations, and individuals (Wise, 2008), and inform the methods in which cultures translate extra-cultural products into their own cultural contexts (Ivy, 1995). Wise (2008) and Ivy (1995) distinguish globalization from internationalization in that rather than reducing the global transfer of meaning and relations to that of the relationship between nations and ethno-states, globalization encompasses a wider set of enmeshments between cultures. 
In current conceptions of globalization unbound to strictly Western hegemony, countries such as Japan partake in globalization through cultural assimilation, Ivy (1995) states that these Japanese tendencies to assimilate foreign products as an "otherization" that as an interaction with the foreign, "operate[s] as a commodified sign of reassurance" (p. 2). By consuming and assimilating the "foreign," Ivy argues that the Japanese reify their status as a unique culture within the world. Here, then, the term "globalization" may be more appropriate in analyzing the cross-cultural production, dissemination, "domestication," and consumption of foreign products within a national context as the processes implicated in these terms does not necessarily imply the inherent relation of nations-to-nations, but rather a process of cultures "translating" foreign products into their own culture through a variety of means.

In each of these definitions, globalization is turned away from stress of Westernization as a globally hegemonic force to which nations and cultures must adapt. Instead, it becomes a network of political, industrial, cultural, and social processes that interrelate in an increasingly interconnected world. Included within the concept of globalization is the role of media in creating and sustaining these connections between cultures.

Barnlund (1975) argues that individuals must become more aware of the "rulebooks of meaning" that cultures have in order for individuals to better adapt to an increasingly globalized world. This globalized world, what Marshall McLuhan (1964) describes as the "global village," is a digitally interconnected world in which geographic proximity is diminished by the role of technology in individuals' and cultures' everyday lives. This diminishment is brought upon by the mediatization of globalization, which is defined as the centralizing processual force of media in individuals' and cultures' social lives that facilitate, organize, and interpret cultural experience (Hjarvard \& Peterson, 2013; Waisbord, 2013). 
According to Barnlund (1975), it is necessary to identify these "rulebooks of meaning" that characterize distinct cultures from one another in order to further understand the distinguishing factors of culture thereby becoming more interculturally competent within the "global village" (p. 6). These rulebooks inform the ways texts are produced, disseminated, and consumed, and by accessing these, it "enable[s] us to maintain the constructive relationships with societies that operate according to a different logic than our own" (p. 6). Individuals from disparate cultures will differ in their attribution of meanings to texts and objects and so texts are interpreted differently in relation to the frame of reference that the receiver holds. Furthermore, Hjarvard and Peterson (2013) assert that the increasing relevance of media within people's lives influences socio-cultural change. Through the utilization of Giddens' (2008) definition of globalization as the "acceleration of interconnected parts of the world," Waisbord (2013) argues that this mediatization comprises an important aspect of the globalization process.

Global localization, or "glocalization" refers to the process of localizing content in certain cultural contexts while keeping an overarching international appeal. Per Iwabuchi (2002a), glocalization “does not seek to impose a standard product or image, but instead it's tailored to the demands of the local market" (p. 46). It is a strategy that producers utilize to appeal to as many markets as possible while remaining its particular style of aesthetic but tailoring it enough to cater to the tastes of particular audiences.

As a globalized product, Pokémon has been localized into many countries over the past decades. Language translation and dubbing are the most apparent localization methods that distributors use to alter the program for local audiences. However, content may also be edited to better suit the cultural values into which the anime is being exported. This project explores these 
methods for the purpose of determining the extent to which distributors altered the original text for the tastes of American audiences.

\section{Orientalism}

The fetishization and commodification of Asian aesthetics and culture-specific products have been extensively noted in the past decades due to the growing influence of globalization. Although it can be perceived at surface level as an "appreciation" for these cultures by those who consume these cultural products, it has been argued that this "appreciation" can manifest itself as a reductive, essentializing force in which Western cultures exotify these cultures and their respective cultural products for the purpose of capitalistic gain.

In his book Orientalism, Edward Said (1978) purports that the cultures of the "East" have been, in modern times, commodified for "Western" consumption through the exotifying representations of the "Other." Through "Orientalism," Westerners "could perceive the trajectory of their own culture by constructing an 'Other' with diametrically opposed values" (Hill, 2000, p. 177; Said, 1979). The Orientalist lens has been applied, for example, to the works of American authors (Bresnahan, 1983), and representations of China and Chinese peoples in fictional works (Graham, 1983). Here, Graham concentrates on the power behind the imposition of a world view through otherization rather than the simple West-to-East exotification.

Asian values and Asian exceptionalism have been examined in different ways in terms of Orientalism, (Hill, 2000; Shirong Lu, 2008; Wei et al., 2017). Of particular note to Hill (2000) is the "reverse Orientalism" embodied in Singaporean leadership in the $20^{\text {th }}$ century that served to entrench nationalistic values of anti-Western sentiment and encroachment upon their Asian identity. Here, the ruling party of Singapore intentionally facilitated "reverse Orientalism" by fueling the exceptionality of the "Asian values" of Singaporean identity while otherizing the 
West (188). Shirong Lu (2008) argues that "self-orientalized internationalization," as an extension of Orientalism, functions through cultural products in a global landscape to "Orientalize" the producing culture within the international sphere. Asian cultures are argued to produce artifacts that one, mark their culture as unique in relation to other cultures, and two, represent the economic, social, and political identities of these respective cultures. Furthermore, Orientalized identities are often negotiated and are "rendered relative" to contextual factors that can, at times, empower these workers to resist alternative worldviews through "mediated resistances," (Wei et. al, 2017, p. 97).

Through the concept of nihonjinron, Ivy (1995) states that Japan asserts its cultural uniqueness and exceptionality and distinguishes itself from the West through an embracement of its unique cultural artifacts. Iwabuchi (2002a) argues that this perceived exceptionality functions in conjunction with Western Orientalism to differentiate Japan from other Asian countries. Iwabuchi further argues that Japan exists as both Western and Asian.

Iwabuchi (2002a) asserts that "the development of international communications has made transnational media consumption a site where an Orientalist gaze upon a dehumanized, cultural Other is invariably reproduced" (pp. 165-166). By this argument, globalization therefore facilitates further orientalism rather than promoting holistic understanding of other cultures. McKevitt (2010) states that the consumption of anime by fans perpetuates this orientalization, stating that it allows fans to reduce cultures to what is seen on screen without consideration of the depth of Japanese culture. Orientalism in the twenty-first century, therefore, functions through the transmediated process of representation of cultures as consumed by individuals who "pick out" aspects of these cultures to use as representative markers for that culture without attending holistically to the cultures themselves. 
"Techno-orientalism" refers to the shift from the Western "fetishization" of traditionally Japanese art forms to the commodities that are commonly thought to "represent" Japan in the twenty-first century. These commodities include anime, video games, pachinko gambling parlors, and other technological, globalized products (Paulk, 2011). Sato (2004) refers to technoorientalism it as the tendency to imagine Japan through both the "traditional" stereotype and the "technologically oriented" stereotype (p. 355). In any case, advances in technology have contributed to orientalism through the ideological shift of non-Japanese audiences becoming familiarized with the cultural properties that "represent" Japan or Japanese-ness.

As an Asian product rooted in Japan but distributed throughout the world, Pokémon has been promoted as such to these global audiences. Whether the appeal of the series rests within the Japanese qualities of its origins or the sanitized version that was distributed to other countries remains in question. I suggest that, although anime such as Pokémon have been edited to remove certain Japanese qualities, an inherent "Japanese-ness" remains that appeals to Western audiences' sense of novelty-seeking through the presentation of exotic difference, thereby essentializing the Japanese culture to that of "anime." This implies that part of Pokémon's popularity is caused by the appeal of the exotic "Other" that is suggested by the anime's Japanese origin.

\section{Anime}

Japanese animation, as well as the comic industry (manga) have long held a long place at the forefront of Japanese media culture. Scholars have recognized these the ubiquity of these industries, stating that they are interrelated (Condry, 2013; Ito \& Crutcher, 2014) and interdependent (Pusztai, 2015). Pusztai (2015) states that the creative production qualities of these industries allow them to borrow heavily from each other in that storylines, characters, and 
aesthetic stylistics are often interchangeably "recycled" between productions (p. 141). The creative collaboration between the two industries indicates their relevancy and saliency within Japanese culture. Furthermore, since anime incorporates the cultural personae of manga, taking on and reflecting the stories and themes that resonate with Japanese people, animation should be regarded as cultural artifacts that represent the given culture in which they are produced (Hubka, 2002; Price, 2001; Wells, 2002).

Much has been researched concerning the stories and themes surrounding the most popular anime production company in Japan, Studio Ghibli, as well as its creator, Miyazaki Hayao, which was credited with much of anime's international popularity (Boyd \& Nishimura, 2004; Darling-Wolf, 2016; Denison, 2007; Denison, 2015; Hagiwara, 2006; Napier, 2005ab; McKevitt, 2010; Wu, 2016). Miyazaki films are accessible to a variety of audiences including children (Hubka, 2002; Napier, 2005a). Because animation can be easily edited, translated, and dubbed over with new voices, it is an ideal product to export to new cultures and languages. Furthermore, for these reasons, anime provides a gateway toward understanding the methods though which programming is altered for international audiences (Hubka, 2002). McKevitt (2010) notes that while animation in Japan has never been "pigeonholed" as exclusively for children as it has in America "allowing" multiple demographics to partake in the medium, there are nevertheless multitudes of children-oriented anime.

However, what constitutes children-oriented in Japan does not necessarily match with what Americans view as child-friendly. Denison (2015) states that the child-friendly quality found in many of the first anime television series allowed them to be exported overseas to the American market, with some alterations. In order for many exported anime to be shown in the United States, producers and distributors forced or made alterations to the original version, 
sometimes altering the storyline and the themes therein entirely. The most critically egregious example of this alteration was the English version of Nausicaa and the Valley of the Wind which Ruh (2010) notes fans to have said that it was "mutilated," "wretched," and a "horrendously mangled version" of the original (p. 32). Ruh further states that, at times, entire storylines, character deaths, and action sequences were removed from the English version which caused confusion on the part of the viewers.

As a genre that has become more prevalent in America over the last decades, anime has become a rare example of a form of cultural product that has found its way into US culture outside of Hollywood importation. While Japanese karate and monster films were imported by Hollywood into the United States explicitly as foreign novelties in the 1950s, 1960s, and 1970s as popular B-movie features (Noriega, 1987), anime has much less explicit Japanese "foreign" connotations. As anime is a genre of television and film that has been popularized globally outside of Western production, its central production and distribution lies outside of the Western media apparatus. This is significant because Hollywood and associated American companies are often thought to hold the dominant modes of production, distribution, and representation in terms of television entertainment (Olson, 2000; Lorenzen, 2007).

\section{Cultural Odor}

It is assumed that a program that is produced in a particular culture reflects, and is informed by, the culture's attitudes, beliefs, and values. However, not all of these programs that are financially successful domestically are as successful globally. In an era where the exportation of television programs has been streamlined by technological advances in production and distribution, more television programs from other cultures are open for broadcast on American television. Structural limitations, however, remain to how many programs can be broadcast in a 
given day so choices are likely to be made by producers and distributors as to which programs are chosen for broadcast. Presumably, particular programs are chosen due to their potential appeal for the demographics that broadcasters are targeting. Ergo, programs with the most perceived appeal to audiences are aired. In the attempt to create more appealing programs for American audiences, editors alter the programs' qualities to better suit the tastes of the audience to which they want to appeal.

Hoskins and Mirus (1988) propose a cultural discount theory as a method of explaining how certain types of objects and media produced in one culture do not have the same sort of appeal in another culture. Iwabuchi (2002b) asserts that this "discount" explains the low number of Japanese media exports with which distributors engage. He argues that both Japanese producers and global distributors are aware of the limited appeal to culturally-specific popular media in the Western markets. Presuming that due to the "dominance" of Hollywood, the United States is insulated from the global-cultural media ecology, they assume that because viewers from the United States are not as exposed to exported media as other cultures, they do not "appreciate" foreign media that are either subtitled or dubbed. Because of this "discount," Hoskins and Mirus (1988) theorize that a fewer people will consume this media in the exported culture than those in the producing culture.

Iwabuchi (2002a) expands upon the concept of "cultural discount" with his definition of "cultural odorless-ness" as a product's ability to mask the roots of its production within a given culture. He states that while a product may be able to hide their cultural "odor", there is nevertheless traces of cultural residue that remain as indicators suggestive of the culture of origin. In other words, any given product inherently contains traces of the culture from which it originates. Other scholars have examined internationally successful products with diminished 
"Japanese-ness" and theorized that Japanese goods do not rely on representing the "Japanese way of life" the way certain American products such as McDonald's and Coca-Cola do for the “American way of life" (Du Gay et al., 1997, Featherstone, 1996; Iwabuchi, 2002b).

According to Iwabuchi (2002b), any given product from a country contains a "cultural odor" from the context within which it was created. He conceptualizes "cultural odor" as "the way in which cultural features of a country of origin and images or ideas of its national, in most cases stereotyped, way of life are associated positively with a particular product in the consumption process" (p. 27, emphasis in the original). This "odor" calls upon the originating country to become the allure of the product. He amends this by stating that features related to Japan or "Japanese-ness" are de-emphasized for international consumption in order to better appeal to international audiences. He relates products and commodities that are produced with this in mind to the term mukokuseki, meaning "stateless," or as Napier (2005) puts it, "without a national identity" (p. 24). This is related to Sato's (1997) notion of "ethnic bleaching" in which anime productions are "de-Japanized" through the application of representative Caucasian characteristics to Japanese characters in order to achieve the perceived ideal of the "modern" Westernized body (Arnold, 2004; Hairston, 1999).

Ethnic bleaching, and the related concepts of cultural discount and cultural odorless-ness have been studied in relation to the anime and manga industries' (Brienza, 2009; Levi, 2013; McKevitt, 2010; Patrickson \& Young, 2013; Shirong Lu, 2006, 2008; Yoshida, 2008), representations of race and gender (Darling-Wolf, 2006; Kovacic, 2014; Yoshida, 2008), and national cuisine (Cwiertka, 2006). However, little attention has been afforded to examining the concept of cultural odor in relation to global pop cultural phenomena such as Pokémon. Iwabuchi (2004) touches upon Pokémon's cultural "odorless-ness" insofar as it is a globalized media 
phenomenon that has been produced and distributed for an international and domestic audiences alike, but no research thus far has examined how this "odor" has been managed since Pokémon's inception.

Brienza (2009) used the concept of cultural odorless-ness to examine the alteration of Japanese material for American audiences in the manga industry, (Brienza, 2009). Furthermore, Denison (2015) utilized cultural odorless-ness to problematize the notion of a "correct" way to represent Japanese culture in a globalized world. Daliot-Bul (2009) further utilized this concept to examine Japan's attempt to brand a commodified cultural identity through the promotion of popular culture for the purposes of tourism and "soft-power." Additionally, Levi (2013) applies the concept to manga and anime's appeal in North America. Shirong Lu (2008) applies it to the development of anime's internationalization and Napier (2005) states that the flexibility of the "stateless" properties of anime in terms of representation and international appeal demonstrates anime's cultural odor-less properties. In some ways, anime therefore carries the burden of representing the national cultural consciousness of Japan as a paragon of popular culture because of its aesthetic and reproductive properties characteristic of the medium.

Scholars have pointed to the physical features of anime characters as the most common point of discussion regarding cultural odor and "stateless-ness." Rather than appearing as nonJapanese, as characters are abstracted representations dependent on the genre and type of show within which they exist rather than intentionally accurate depictions of an ethnicity (Ruh, 2014). Shirong $\mathrm{Lu}(2008)$ notes that many anime characters appear Caucasian and when there are characters specifically noted to be Asian, they are clearly signified by indicators of their respective ethnic culture. 
Cultural odorless-ness becomes apparent in certain types of cultural products that have been intentionally and obviously altered for the purpose of being more appealing, relevant, or relatable to extra-cultural audiences' preferences. Within anime, where dubbing a new language over existing footage is simple, other considerations are made (and some overlooked) to edit the footage to more closely conform with a targeted audience's experiences. American distributors, namely 4Kids Entertainment, edited the footage to be more aligned with American children's experience thereby muting (or at least attempting to mute) the Japanese-ness of the show. This type of modification seems to be common in the production of Pokémon, one of the most successful globally distributed products in Japanese history.

\section{Pokémon}

Referred to as a "craze" or a "phenomenon," Pokémon exists as a franchise that has received much attention due to its status as a global sensation in the late 1990s and early 2000s (Buckingham \& Sefton-Green, 2004). Although the franchise is not as popular as it was at its peak, it still maintains consistent sales numbers, having sold a combined 56.24 million copies of the last four installments of the videogame series since 2013 and has taken the second, third, fourth, and ninth spots on the all-time best-selling Nintendo 3DS games (Top selling title sales units, 2017). Furthermore, the anime has been aired in 98 countries and has generated 22 movies, which themselves have grossed a combined \$736 million (Pokémon in figures, 2017).

Pokémon has been studied in a number of ways including the media franchise's interactiveness (Sapach, 2017) and the second order localization wherein children transliterate the localized anime into classroom and playground settings (Bromley, 2004) In these ways, Pokémon becomes an artifact where the known and the unknown are joined to form a site where cultural capital can be generated and exchanged between people; children in this particular case. 
Bainbridge (2014a) examines Pokémon and its products as facilitative commodities that allow people to "connect" to "Japanese" ideas concerning such things as materialism and the environment. He argues that because of Pokémon's inherent themes of socialization and networking, it permits "analysis of the textual nuances of Pokémon and the way it uses its media power to articulate $[\ldots]$ the popular imaginary and the national concerns of Japan" (p. 12). The Pokémon franchise is not, therefore, only a product of the globalized sphere of marketing and consumerism, but also an artifact that has inherently Japanese roots.

Iwabuchi (2004) discusses this inherent "Japanese-ness" of Pokémon, asserting that the "Pokémonization" of the world is evidence of the "acceleration of transnational corporate partnerships in deploying localization strategies, particularly between Japanese and American media industries" in order to more successfully market the show toward the local audiences in each respective culture (p. 55). Consequently, Iwabuchi asserts that it is difficult to ascertain Pokémon's "Japanese-ness" as it is inherently a globalized product constructed, at least in part, with global audiences in mind.

Furthermore, Condry (2009) argues that anime is connected to larger cultural contexts, "the world-settings of anime and contemporary worlds in which we live are necessarily connected, through language, imagery, symbolism, to larger cultural worlds and not simply to the requirements of merchandising" (p. 27). Similarly, Tobin (2004b) states that Pokémon is Japan's "most successful entry...in the business of globally marketing a global product" and that it "is/was not just any globally circulating children's product - it is a product from Japan," (p. 257). So, while Pokémon is in fact a globalized product comprised of multiple mainline and peripheral products and merchandise, it nevertheless exists as a product from Japan. 
The popularity of Pokémon games and merchandise suggests that the success of the franchise stretches beyond its anime. According to Tobin (2004), Pokémon's multidimensionality as an “interrelated set of products and activities" provides it strength in remaining relevant and marketable (p. 10). According to Bainbridge (2014b), Pokémon is "one of the best-known examples of transmedia storytelling youth media today" (p. 399). Furthermore, this "transmedia storytelling is not unique to Pokémon, but is a common element of the anime industry. Per Condry (2011), the anime industry not only produces television shows, but also, "fictional characters and dramatic premises that can be parlayed across diverse media" (p. 72) He further argues that this can best be seen in the "explosion of interest" in the Pokémon franchise and the characters therein (p. 72). In relation to its “textuality," Bainbridge (2014a) argues that the Pokémon franchise's products work in conjunction to encourage the audience to think differently about nature and the environment. Here, the features of the Pokémon franchise suggest something for the audience.

Other contexts in which the Pokémon franchise has been studied include the field of health communication in which Clark and Clark (2016) and Kaczmarek, et al. (2017) examine how Pokémon Go, an augmented reality cellphone game, incentivizes changes in health behavior through the promotion of social and physical activity in conjunction with the familiarized "Pokémon." Additionally, Pokémon has been examined from a pedagogical standpoint (Buckingham \& Sefton-Green, 2004; Vasquez, 2003) and from a gender studies perspective (Ogletree et al, 2004).

Other scholars focus on how the Pokémon anime was localized for American audiences. Katsuno and Maret (2004) examine how the Pokémon anime was adapted for Western audiences through the localization of its dialogue, music, and facial expressions. They note that as the show 
shifted from the Japanese "genre" of anime into the more narrowly defined and limited definition of a Western "cartoon," many of the "elements of the Japanese series were modified or eliminated, and new points of reference, new associations, and sometimes entirely new meanings were imposed on the text" (p. 83). Furthermore, they conclude that a reason for the franchise's success is due to its ability to be localized into different contexts through selective editing. They assert that since Pokémon is "embedded" in the cultural medium of anime, it preserves "a certain Japanese aesthetic and cultural odor" (p. 104). Even though Pokémon has been localized into a variety of international markets, Katsuno and Maret (2004) purport that it nevertheless contains elements that are recognizably "Japanese-ness" in nature.

For these reasons, I examined the Pokémon anime series through the lens of cultural odorless-ness in terms of "de-odorization" strategies used by distributors to appeal to an American audience across its broadcast history. Anime has grown in popularity over the last decade, to the point where Walmart, a distinctly American company, has a DVD and Blu-Ray section devoted to the genre. This popularity may be a side-effect of Pokémon's global acclaim at the end of the $20^{\text {th }}$ century, going into the $21^{\text {st }}$ century. Pokémon therefore serves as a prime avenue of research toward the methods that producers and distributors localize, and culturally “de-odorize,” anime for American audiences. Furthermore, Pokémon's status as a long-running anime spanning twenty years presents an opportunity for research into how one anime's cultural "odor" is managed throughout its years of broadcast. Therefore, this study augments Katsuno and Maret's (2004) study by examining whether the cultural odor of the Pokémon anime has diminished over time by the management techniques of Pokémon's producers (The Pokémon Company) and distributors (4Kids Entertainment and The Pokémon Company International). 


\section{Methodology}

The Pokémon media franchise became a global phenomenon at the turn of the millennium. As a multi-media product from Japan, the franchise was produced within a Japanese context that gave it what Iwabuchi (2002) would claim to be a "cultural odor," or an imprint of particular cultural context in which it was produced and distributed. However, at the beginning of the new millennium when globalization was beginning to accelerate due to increased access to other cultures through digital means, the producers of Pokémon made intentional choices to appeal more broadly to an international audience. While the anime was localized for Western audiences with the input of Western distributors, the series nonetheless appealed to a sense of "difference" in that it was unlike other Western cartoon shows on the air during that period. The production of the anime, therefore, consisted of a balancing act of attempting to appeal to a Western sense of taste by not having an obvious "cultural odor" while also utilizing its uniquely Japanese nature to its advantage in portraying a distinctive program to entice Western children to watch. I presumed that the unaltered Japanese version of the show consists of much more recognizably "Japanese" elements that were edited or removed from the translated version. If this is the case, the Japanese producers present a particular "self-orientalized" version that is especially catered for their domestic audience in comparison to an internationalized version that has been scrubbed of this cultural "odor." In order to discover how the producers and distributors of the television show, Pokémon, oriented the program for different audiences, I analyzed the content of Pokémon Seasons One and Twenty to determine whether there were differences in the management of the cultural "odor" of these seasons.

Although Katsuno and Maret (2004) noted specific examples from the first seasons of Pokémon of the removal of this cultural odor, little research has been done examining whether 
this "scrubbing" has changed since the anime's peak of popularity. As the anime is still being broadcasted around the world, it is worthy of expansion through the analysis of episodes that have been broadcasted since Katsuno and Maret's (2004) study. Therefore, this project examined episodes in both Season One and Season Twenty to determine whether producers have, in any way, altered the way they managed the cultural "odor" of the anime. The first season and the most recent season were examined for differences in localization strategies to discover whether the strategies employed by these producers have changed over time.

Two seasons of the program were compared and contrasted through loose, thematic textual analysis in order to determine the extent to which producers changed the program to "fit" with the globalized international audience. The present study examined the first season of Pokémon produced and distributed beginning in 1998 in relation to the most recent season of Pokémon in 2017 for the purpose of understanding how they differed in the representation of Japanese cultural "odor."

In this textual analysis, I searched for instances of artifacts that emblemize Japanese culture and lifestyles and constitute aspects of its cultural odor. Examples where Japanese-ness manifested itself through symbols such as representations of Japanese food, Japanese building architecture, and Japanese apparel alongside other examples of Japanese-ness were noted and analyzed. Other textual artifacts such as linguistic references, on-screen text, and audio and visual iconography specific and familiar to the Japanese were noted as well. The seasons were then compared to determine whether there was more "cultural odor" in the first season than the more recent, twentieth season. 


\section{Thesis Outline}

This study clarifies some methods that media producers and distributors use to capitalize on facets and characteristics of cultures through the transliteration of cultural products within globalized spheres of production typically thought to be dominated by US cultural hegemony. As the Pokémon anime has consistently been broadcasted in 98 countries for over 20 years, it exists as a unique artifact with which to study how production and distribution choices may change over time and within different cultural contexts. Investigating the ways in which producers and distributors "de-odorize" Pokémon for US audiences revealed how globalized programs from countries not considered to be a part of the "dominant" global entertainment sphere are adapted to and for this dominant culture through the management of these programs' cultural "odor."

In the second chapter of this project, I discuss the relevant literature to globalization and localization, anime, cultural odorless-ness, anime, and Pokémon. In the third, I delineate the methods that I will use to examine the Pokémon anime along with detailing the lens with which I implemented. Then, in the fourth chapter, I analyzed the English versions of the first and twentieth seasons of Pokémon for the purpose of examining the localization strategies used by distributors to balance the unique aesthetics of the Japanese anime with the need to market to Western sensibilities and preferences. Additionally, in select instances I also examined the Japanese versions of episodes in order to discover how editors altered the program for US audiences. I discuss the significance of the findings in terms of cultural "odor" in the fifth chapter alongside a discussion of the implications this holds in relation to intercultural awareness in terms of the reception of cultural "odor" through entertainment television. I will finally summarize the project and discuss directions for further research. 


\section{CHAPTER II: REVIEW OF LITERATURE}

In this chapter, I review existing research in various subjects that relate to my study of the Pokémon anime and how this series has been adapted for Western audiences. Because Pokémon media products have been produced and transported around the world for over twenty years, literature concerning globalization and localization is discussed in terms of their impact on media production, consumption, and distribution in the $20^{\text {th }}$ and $21^{\text {st }}$ centuries. Furthermore, the various Pokémon videogames, television shows, and related merchandise constitute a transmedia franchise that has achieved massive success throughout the world. Therefore, transmedia research is also examined and applied within the scope of this project.

As Pokémon is a franchise created within the Japanese context and consumed throughout the world, Said's (1978) concept of "orientalism" is applied for the purpose of discovering whether the franchise is exoticized as a Japanese cultural product by extra-cultural audiences. The relevant concept of "cultural odor" is also discussed in this section as a lens through which to examine the "Japanese-ness" of the Pokémon anime and whether this "Japanese-ness" has been altered over the course of its broadcast history. Additionally, as Pokémon's popularity is due in no small part to its cartoon anime, research concerning anime's history and salience as a cultural product is also examined. Finally, previous research concerning the Pokémon franchise itself is examined in this section.

\section{Globalization and Localization}

Previously, scholars conceived of globalization as synonymous with modernity (Giddens, 1990) and a compressing process in which nations coalesce to form a single cultural "world" (Albrow, 1990; Robertson, 1992). Rather than a direct and definite path from a hegemonic center to peripheral countries, globalization is currently viewed as a series of processes that connect 
cultures and nations, as well as their constitutive individuals, to each other (Crane, 2002; Steger, 2009). Robertson (1995) adds that the idea of a culture overriding a "locality" ignores the transmediated influence between cultures. Furthermore, rather than there being a central "Western" orientation toward which cultures align, Pieterse (1994) argues that cultures "hybridize" when they become more connected. This "hybridization" accelerates when sociocultural and socioeconomic conditions such as advancements in technology, industry, production and consumption are met.

Kriesi (2013) applies Held's (2006) notions of the congruent and symmetric relationships between governments and cultures to argue that, in an increasingly globalized world, these relationships within and between nations and cultures are becoming less clear in the face of “challenging" globalization that confronts imperialistic ideas of pre- $20^{\text {th }}$ century expansionism. Kriesi (2013) purports that “advancing economic, cultural, and political globalization” cause increasingly expansive and deep connections and interdependencies between cultures and nations (p. 3). Here, cultures, co-cultures, and individuals are no longer definitively restricted to the topdown influence of governments upon their day-to-day lives, but are now also influenced by extra-national forces (Wise, 2008). Furthermore, these globalization processes can influence how cultures import and make sense of products produced outside of their culture (Ivy, 1995). As globalization affects our understanding of nationality and that of the nation-state, it also makes individuals more aware of the growing interconnection of nations and cultures (Steger, 2009).

Wise (2008) distinguishes globalization from internationalization. Rather than reducing the global transfer of meaning and relations to that of the relationship between nations and ethnostates (internationalization), globalization encompasses a wider set of social processes in which cultures, corporate entities, organizations, and individuals are all capable of forming and 
maintaining links with groups around the world unbound by the strict limitations of national boundaries. Ivy (1995) likewise iterates that internationalization implies a "cosmopolitan expansiveness," allowing foreign products into a nation while keeping the "national frame" of reference through which to view these products. She acknowledges the Japanese form of "internationalization," which assimilates these foreign products and incorporates them into the national culture thereby creating a "domestication of the foreign" (p. 3). Ivy argues that this assimilation of foreign products function as an "otherization" that "operate[s] as a commodified sign of reassurance" (p. 2). By consuming and assimilating the "foreign," the Japanese reify their status as culturally distinct from other cultures and nations. Rather than "internationalization," then, the term "globalization" is more appropriate in analyzing the cultural production of meaning constructed through the cross-cultural production, dissemination, "domestication," and consumption of foreign products within national-cultural contexts.

While actual processes of globalization predate the appearance of traditional media, authorship concerning the subject has nevertheless concluded that media have facilitated the expansion of these processes in the $20^{\text {th }}$ and $21^{\text {st }}$ century (Chalaby, 2003; Chen, 2014; Lee, 2000; Pogorel, 2000; Wang \& Servaes, 2000). Media perform a significant role in connecting these processes to, and between, nations and cultures. By becoming more "mediatized," globalization becomes more apparent and significant to the function of cross-cultural processes of production, dissemination, and consumption.

Hjarvard and Peterson (2013) define mediatization as the "various processes through which culture is influenced by the modus operandi of the media (i.e. the media's technological, institutional, and aesthetic modes of operation)" (p. 2). Waisbord (2013) discusses the influence of mediatization upon globalization, asserting that the ubiquity of media in individuals' social 
lives influences, and is influenced, by the process of globalization. He argues that these processes facilitate, organize, and interpret cultural experience due to their centrality in today's digital era. Furthermore, Hjarvard and Peterson (2013) assert that the increasing presence of media in people's lives influences socio-cultural change. Through the utilization of Giddens' (2008) definition of globalization as the accelerating processes of interconnection of multiple parts of the world, Waisbord (2013) argues that this mediatization comprises an important aspect of the globalization process.

Furthermore, rather than the previously conceived definition of globalization as a standardization of cultures from a hegemonic center, it becomes a composite interplay of regions, nations, ethnicities, and cultures influenced by the media. In order for audiences to become more interculturally competent with respect to culturally distinguishing features, it is important to understand the significance of the role of media in, and between, these cultures. Globalization is facilitated, in part, through practices of localization of media, which Kraidy (2001) argues is the "flip side" of the processes of globalization (p. 264). Furthermore, Kraidy purports that television programming is an important point of convergence between the local and the global, arguing that television is "the site in which global modernity and local tradition struggle to define national values and identity" (p. 261). As globalization functions to build economic and cultural connections between nations, it stands to reason that the methods through which globalization accomplishes this occur partly by way of distributing cultural products across national boundaries. However, not all cultural products are identified by their distributors as economically advantageous to sell as is, so for some products, these distributors alter the product in such a way that it becomes theoretically more familiar to an audience and therefore 
more profitable. Here, the processes of globalization are comprised in part by the process of localization of foreign products for a particular culture.

Localization functions as a "process of modifying products or services to account for differences in distinct markets" (Local Industry Standards Association, 2011). Furthermore, Adelia and Subiyanto (2006) distinguish translation from localization in that translation is merely the aspect of localization in which the written or oral language is converted to another language while localization incorporates translation along with specific strategies to acclimate particular products into another culture by adapting them to the culture's "locale" - or the tastes, preferences, and standards (p. 1). Localization is therefore critical toward understanding the processes of globalization that connect cultures through media. Much has been written concerning the localization of particular television show formats and how they are adapted from first- and second-order originating countries to new audiences (Esser, 2010; Jensen, 2009; Larkey, 2009; Lewis, 2009; Moran, 2008, 2009a, 2009b; Moran \& Aveyard, 2014; Ndlela, 2011; Waisbord \& Jalfin, 2009). In these cases, programs' aesthetics, narratives, and humors are deliberately transformed from a previous culture through the translation of both language and content to another culture's sensibilities. Here, program "templates" from television franchises are shipped around the world and modified for the consumption of the local audience, thereby demonstrating not only the propensity of television to be demonstrative of the processes of globalization and localization, but the ability for programs outside of the U.S. to receive localization into U.S. markets.

Localization has also been studied in the context of video games (Carlson \& Corliss, 2010; Di Marco, 2007). Heemsbergen (2016) defines "successful localization" of video games as the "mixture of domestication and foreignization strategies" that "makes the game enjoyable and 
evaluable in the target language while preserving its 'essence'" (Heemsbergen, 2016, p. 34). As video games and anime have a close relationship (Kinder, 1991; O'Hagan, 2006; Picard, 2007; Heemsbergen, 2016), it may be argued that these standards of localization success can be applied to the medium of Japanese animation. Heemsbergen (2016) argues that the media of anime and videogames are closely related where localization is concerned, stating that the "two mediums run parallel in that they require translators to traverse the same pathways of cultural negotiation as part of the localization process" (p. 32). In both cases, the cultural idiosyncrasies of Japanese must be skillfully managed in order to retain the "sense" that the medium is trying to convey.

McKevitt (2010) purports that anime is a "tangible illustration of the impact of cultural globalization on the United States in the last quarter of the twentieth century" (p. 894). He argues that anime illustrates how "non-elites" have used foreign cultural goods to create and maintain new social groups within the United States. Adelia and Subiyanto (2006) refer to the process of the localization of Japanese programs as "Americanization" when they are specifically tailored to, and distributed within, the United States. Here, producers "may cut out vast quantities of the story, remove any controversial materials, modify the setting and the characters, and then remake it in a manner more suitable to the standard and requirement of its new locale" (Adelia \& Subiyanto, 2006, p. 1). As Japanese and American audiences have different standards and beliefs about what is acceptable to be seen by children on television (Adelia \& Subiyanto, 2016; Close, 2017; Patten, 2004; Ladd \& Deneroff, 2009) and in video games (Di Marco, 2007; Mandiberg, 2015), the localization of these media is perceived as necessary by content producers. When localizing anime programs for American audiences, Adelia \& Subiyanto (2006) found that two common themes in distribution were present, particularly that of the acknowledgement, and 
subsequent management, of cultural difference and the financial motivation of distributors to manage this difference "correctly" (Adelia \& Subiyanto, 2006, p. 3). The authors conclude that, "while localization may be a good idea into bringing a product closer to its new audiences...the adjustments may turn out to be less interesting and less colorful in its quest to comply with the customs of the new culture (p. 9)." According to them, if an anime is adjusted too much to more closely resemble American cartoons and heroes, then it may lose its appeal as a cross-cultural product.

Di Marco (2007) refers to "cultural deterritorialization" as the method in which a product (particularly a video game in her study) is "deprived of its signs and logos and globalized in order to be more palatable for the American and European audience" (p. 3). Many times, this occurs at the onset of production when Japanese producers intentionally create a product that can be easily localized into other cultures' contexts and can therefore be accessible by many customers. Furthermore, scholars have noted that localizing content from Japan to the United States is not a simple task of translating the language word-for-word, but requires creativity in contextualizing particularities in cultural parlance and reference (Borbély, 2014; Di Marco, 2007; Heemsbergen, 2016; Huang \& Archer, 2014) and at times, its music (Roedder, 2014). For example, puns, idioms, and cultural-specific references usually require an inventive touch to adapt these into another cultural context as they may seem alien to a consumer. However, this runs the risk of losing the tone of the original thereby reimagining (possibly dismantling) part of the product's aesthetic in the process.

At the same time, Di Marco (2007) recognizes that this same creativity can bring something new to the product: "Accepting a possible loss in localization also means accepting the possibility of adding to and improving a text during translation" (p. 7). She argues that 
localization should do as much to "compensate" for potential loss by retaining as much as the original intention as possible, citing Eco's (2003) idea of "functional equivalence" in translation to make sure that the localized product functions as the original does to "generate the same effect to which the original aspires, offering an interpretive hypothesis as regards that effect and remaining faithful not to the text itself but to its intention" (Di Marco, 2007, p. 73). The interpretation therefore becomes important as method of translating the "feeling" of the original rather than the literal semantics.

\section{Glocalization}

While localization refers primarily to the modification of programs specifically to the tastes of local audiences, global localization, or "glocalization" suggests the process of localizing content in certain cultural contexts while keeping an overarching international appeal. Robertson (1995) roots glocalization "dochakuka" or "living on one's land" (p. 25). Essentially meaning adapting one's own farming techniques to fit the needs of the community. The term came to prominence in the 1980s in relation to Japanese business practices becoming more sensitized to marketing products globally and locally simultaneously (Robertson, 1995). Problematizing the reductionist thinking pertaining to the "global" and the "local," Robertson (1995) offers a method of becoming more aware of the subtleties of cultural production, consumption, and dissemination toward global and local markets with "glocalized" strategies. According to Iwabuchi (2002a), glocalization "does not seek to impose a standard product or image, but instead its tailored to the demands of the local market" (p. 46). Glocalized products are therefore manufactured with both the global and the local markets in mind. Glocalization is a strategy that producers utilize to apply programs with traditionally universal concerns (such as love and family) with the "capacity for localization through translation" (Patrickson \& Young, 2013, p. 
48). Producers utilize this strategy in order to appeal as many markets as possible while retaining its particular style of aesthetic but tailoring it enough to cater to the tastes of particular audiences (Lu, 2009). Monden (2008) applies this definition to the "glocalization" of the fashion industry in Japan, which assimilates styles of fashion from other countries and infuses them with their own cultural "flavor" to create hybridized products that appeal to individuals both in the domestic and international spheres (p. 21). Thompson and Arsel (2004) similarly examine the "cultural hetero-hybridization" facilitated by glocalization strategies that Starbucks uses to develop ideas concerning "what coffee shops should be" in markets around the world (p. 638).

Chen (2014) asserts that videogames illustrate the logics of successful glocalization. Instead of standardizing the content of videogames, as had been the case for years to middling success, Japanese producers "absorbed and adopted foreign (western) ideas for use in their own cultural products, and then adapted them to fit other cultures" (Chen, 2014; Iwabuchi, 2002; Straubhaar, 2007). By becoming more sensitized toward the tastes and preferences of markets in other cultures, Japanese video game companies were able to gain economic foothold and influence in these cultures. In this case, Japan was able at least partially to enter into "dominant" globalization cultures such as America through the glocalization of its cultural products.

Barnlund (1975) states that individuals from different cultures will differ in their attribution of meanings to texts and objects. With different frames of reference with regards to cultural production and consumption, the individuals who receive messages interpret them from differing perspectives, influencing them to focus on some aspects and disregard others. This is significant when considered alongside the circuit of culture model, wherein cultural meaning manifests itself through the articulation of the production, consumption, regulation, representation, and identities of artifacts (du Gay et al., 1997). Through considering the 
"rulebooks" of these cultures alongside this circuit, we become "able to maintain the constructive relationships with societies that operate according to a different logic than our own" (Barnlund, 1975, p. 6).

Because television is a cultural product (Hall, 1975) it serves as a gateway to understanding the "rulebooks of meaning" through which cultures, and consequently cultural production, operate. As television programs reflect the cultural values of the contexts in which they are produced (Cho et al., 1999), they offer a glimpse into the ways that these cultures produce meaning. For instance, Patrickson and Young (2013) argue that Japanese animation functions as Japan's "performed, global face" as a distinct art form that has an "identifiably Japanese style" (p. 48). Likewise, Allison (2000) states that children who interact with Japanese cultural products - such as "character goods" and television shows - have "a greater openness towards, and awareness of, Japan" (p. 87). Being exposed to at least a superficial level of culture may therefore lead to further interest to that culture.

In an increasingly globalized world, producers of media content are able to increase their market by reaching past national borders to advertise to, and cater toward, the interests of international audiences. However, differences in cultural values, beliefs, and attitudes suggest that these media products will not be received as intended as they would in their domestic market. Producers therefore make decisions to localize these products to align more closely with foreign audiences' tastes for the goal of profiting from international success. The localization of these products therefore provides economic incentive for media producers in a globalized era to create and/or alter their products so as to increase their profit margins. For products that have been consciously created within this era, producers may have the international audience in mind from the outset of their products' conception and so they may "glocalize" the product by limiting 
the "cultural odor" that the product retains and making it more "neutral" for international taste and consumption. By doing this, producers minimize the need to alter the text, saving on costs, and maximize the potential for the product to sell well in other cultures. In order to gauge how glocalization processes transpires, it is necessary to compare a product tailored for a local audience to a transliterated version of the same product made for a global audience.

As a franchise informed by the logics of globalization, the Pokémon anime, video game series, and its related peripheral products have all been localized into many countries over the last twenty years. As the Japanese culture from which Pokémon was spawned differs in cultural values from many of the cultures to which it was exported, it is natural that edits were made to more closely "glocalize" the anime into these cultures. As an artifact produced outside of the traditionally defined hegemonic notion of globalization (the "top-down" approach of distributing cultural products from a central position to peripheral cultures), the Pokémon franchise reversed this trajectory as a product that intruded into that presumed center from the periphery. Distributors of the anime both translated and dubbed Pokémon into the English language in order for audiences to better understand the narrative plots of the episodes. Furthermore, content was also edited for "appropriateness" the extent of this editing remains in question, however. This project therefore explores these methods for the purpose of determining the extent of the alteration of the original text for the preferences of American audiences.

The localization of cultural products such as anime within a globalized world has implications for the ways in which these products are received and interpreted by individuals from cultures outside of the product's domestic culture. In an era of increased connection between cultures via technology, cultural products are able to be quickly and easily transmitted abroad. Between their creation and their extra-cultural transmission, these products may undergo 
a number of alterations to make them more "palatable" for the receiving-culture's tastes. This is significant as products within a particular culture contain - to varying degrees - an essence or "odor" of the culture in which they were produced. By scrubbing these products of their "odor," implications of how individuals and audiences consume intercultural content and become aware of cross-cultural differences become salient.

In the case of anime, if the particular "Japanese-ness" of these programs is scrubbed for audiences in the United States, can it be said that these audiences are exposed to a truly "Japanese" product - or to a "North Americanized" Japanese product? By examining the patterns in which producers and distributors localized an anime like Pokémon's content over the course of twenty years, it is possible to discover how these producers altered their patterns of production to audiences who, at first, were not aware of its status as a Japanese product to its status twenty years later as a recognizably Japanese franchise. For instance, have these producers consistently reduced the amount of "Japanese-ness" in episodes or have they "allowed" more Japanese-ness to remain as the anime has already found its international success, thereby providing reason to believe that audiences are amenable to the "Japanese-ness?"

\section{Orientalism}

As Pokémon is a product from Japan, audiences who are aware of its "Japanese-ness" may interpret this status through the social-historic lens of orientalism. While processes of localization or "glocalization" may hide this "Japanese-ness," the way Pokémon was discussed during the height of its popularity may have been informed by orientalist thinking influenced by years of compounded perceptions concerning Japan and the Japanese people as, according to Paulk (2011), commodities such as anime, video games, pachinko, and other technological, globalized products have come to represent Japan in the late- $20^{\text {th }}$ and early- $21^{\text {st }}$ centuries. This 
representation occurs at a point where a history of discourse concerning the "exotic" aspects of Japan has influenced international audiences' perceptions of the country. Whereas localization and "glocalization" seek to hide the cultural particularities of cultural products, orientalist discourse emblemizes and exotifies the cultural specificity of these products. In the case of Pokémon, the distribution of the localized anime into the United States was accomplished within the context of audiences (with the exception of the children demographic) having years of preconceived ideas concerning Japan and "Japanimation." Therefore, research concerning the contextual factors influencing the reception of Pokémon in the United States requires consideration of Orientalism and its related concepts.

Although globalization presents many opportunities to be open to a variety of different cultures, media products continue to present essentialist and stereotypical notions of cultures (DeKeseredy et al., 2014; Hancock et al, 2013; McGaha, 2015). Said (1978) argues that "Eastern" cultures (by which he is referring to what the West calls the "Middle East") have been exotified and commodified for "Western" audiences who perceive these cultures as alien or "Other" in relation to their own lived experiences. Developed by Said as "orientalism," the concept refers to Westerners' perceptual triangulation of their own identity in relation to the cultural identities of the "Other." (Hill, 2000, p. 177). Meaning, through orientalism, Western cultures identify who they are by who they are not.

While glocalization provides an avenue for media content to be ingrained into multiple cultures simultaneously, there remains micro-level individual conceptions of a product's culture of origin that affects its reception. Identifiably "Orientalist" discourses of the $20^{\text {th }}$ century therefore continue to affect how individuals perceive products from Asian cultures. These competing homogenizing and heterogenizing forces therefore must be balanced by producers of 
cultural products such as anime if the show is to be successful in a culture that has historically held particular ideas about their culture. So, while anime such as Pokémon attempt to glocalize themselves to many cultures through the use of universally accepted themes of friendship, collection, and triumph, they also do so through particular aesthetics that can be recognized as emblematic of Japanese anime by those already familiar with the style. Here, the notion of what Japanese anime look like shapes the perception and reception of the product.

Orientalism rests in the interplay of ideas of power in relation to the "Other" in which cultures hold reductive imaginings and stereotypes concerning these cultures. Per Schirato (1994), Orientalism manufactures the "Other" so that Western identities can be "guaranteed" or reaffirmed (p. 45). By doing this, the "Orient defines the West by what it is not through the contrasting images that are discursively represented (Said, 1985, p. 2). These discursive productions exist within institutionally distributed forms such as novels and tourist guides along with other media (Schirato, 1994). Through these texts, ...the 'Orient' becomes accessible to the West precisely because the West invests resources in acquiring knowledge (details about institutions, languages, religions, history, customs) and telling stories (novels, dramas, scientific treatises, anthropological works, business borchures) about the Oriental 'object' (Schirato, 1994, p. 46).

Central and East Asian cultures are commonly stereotyped by this exotifying "orientalism." (Said, 1978; Semati, 2001; Schirato, 1994; Hill, 2000). Here, the "Orient" can only be represented in relation to the "Occident" or else these "Oriental" cultures may be considered by their own terms, thereby forcing Western powers to "give up claims to knowledge and the right of explanation" in relations of power and control (Schirato, 1994, p. 46). The Western control 
over the representation of Middle- and East-Asian cultures is therefore critical to the propagation of Orientalist ideas.

Constructed in terms of being not-the-Occident, essentialized notions of Eastern cultures constitute Oriental ideas "invented and appreciated by Westerners who have little actual knowledge of the Orient...but have some prejudice and curiosity" (Ning, 1997, p. 58). Napier (2007) notes, for instance, that interest in Japanese culture dates as far back as the $19^{\text {th }}$ century with French Impressionists' fascination with "Oriental” aesthetics and traditions. Here, Japan was exotified as an alien, yet alluring, natural country with a "fascinating" culture.

Said's (1978) Orientalism primarily addressed the essentialist notions of Middle-Eastern cultures. However, much of the stereotypical, essentializing, and commodifying ideas Said spoke of can also be applied to the reduction of Japan as "exotic" (Gerbert, 2008). Western views of the Japanese have traditionally been born from spectacle and decoration rather than a true respect for the culture (Noh, 2016). According to Lie (2001), Ruth Benedict's ethnographic book The Chrysanthemum and the Sword (1946) played a critical role in shaping perceptions of Japan and the Japanese in the United States in the years following World War II. Ivy (1997) notes that although it was a book produced with anti-racist intentions, Ivy (1997) notes how "shifting historic-political terrain can lead to reversed readings" that transformed Chrysanthemum into a condescending exotification of the Japanese nation and culture (p. 11n20). According to Lie, by essentializing Japan as a homogenous culture in contrast to the United States, Benedict reifies "the cultural configuration as a coherent whole [and] she ignores the considerable diversity" of the identities of Japan (p. 254). Here, orientalist thinking toward Eastern cultures" "strangeness" reduces the Japanese to an essentialist caricature that belies the complexity of identities found within this culture. This "strangeness" has been noted by scholars such as Ning (1997) as a cause 
for Western curiosity toward Japanese culture. Examples of this include fascination with Japanese cultural traditions such as tea ceremony, Zen Buddhism and geisha (Akita, 2006; Nishihara, 2005). Through media, images of Japanese culture are distilled and offered as representative of the culture in question. The commodification of Asian identities and aesthetics as well as cultural products has been extensively noted in the past decades due to the growing influence of globalization (Consalvo, 2007; Kovacic, 2014; Morley \& Robins, 1995; Posadas, 2014). Although it can be perceived as an "appreciation" for these cultures, this "appreciation" may, att times, be conflated with the commodification of Asian identities and cultural products for Western markets.

The analysis of self-orientalization overlaps with Japanese exceptionality stemming from the imperialistic nationalism of Japan's late-Tokugawa and Meiji periods in which Japan began to exhibit colonialist ambitions (Buntilov, 2016; Iida, 2000; McLelland, 2008). Cultural theorists have argued that Japan distinguishes itself from the West through an embracement of unique cultural markers (Iida, 2000; Ivy, 1995). Nihonjinron defined by Iida (2000) as "the theory of Japanese uniqueness" (p. 448) refers to the Japanese ongoing conversation concerning national identity that informs the ways in which Japanese peoples see themselves in relation to the nation and the cultural traditions with which they identify (Buntilov, 2016; Ivy, 1997; McLelland, 2008; Sato, 2004; Zykas, 2009). Begun as a genre of literature in the late $19^{\text {th }}$ century, nihonjinron writings by academics, critics, and novelists pertained to themes of nationalism and the exceptionalism of Japanese tradition in the face of an industrializing, modernizing world (Hasegawa \& Hirose, 2005; Iida, 2000; Pinnington, 2001; McLelland, 2008; Morton \& Olenik, 2005). Authors have noted that nihonjinron writings were especially salient to the Japanese in the late $19^{\text {th }}$-early $20^{\text {th }}$ century, when the political and cultural contexts were foregrounded by 
several wars (McLelland, 2008), as well as in the 1960s and 1970s during the search for national identity post-World War II during a time of increasing globalization (Wahab et al., 2012). Here, during a time of international trade disputes and global tensions, nihonjinron ideas increased in presence in the Japanese cultural sphere as propagated by national media and entertainment programs.

Intent on "catching up" with the rest of the world in the late $19^{\text {th }}$ and early $20^{\text {th }}$ centuries, Japanese leaders intended to "modernize" the country through a variety of means. Modernization was "a main, calculated, and official aim" that sought to combine "Eastern ethics and Western science" under the umbrella of imperial rule (Morton \& Olenik 2005, p. 148). The leaders intentionally chose not to "Westernize" but to modernize while keeping the "soul of Old Japan" as the underlying foundation on which to build upon (p. 151). This modernization without Westernization is noted to have remained in effect to the contemporary era (Lewis, 2006; Varley, 2000). Here, Japan observed and assimilated Western attitudes of modernization and its methods for the purpose of becoming more influential within the global sphere (Te-jen, 1967; Morton \& Olenik, 2005; Varley, 2000). Lee (2017) notes that a "self-domestication" of the Japanese was "first imposed by the Meiji government on its own people, the Japanese, in relation to the Western powers and later, by the colonial authorities, on the colonizing Japanese, in relation to the colonized Taiwanese" (p. 32). Since the late $19^{\text {th }}$ century, then, Japan and consequently the Japanese people imported and transformed international ideas in conjunction with their own values for the purpose of developing as a nation in the face of quickly developing interconnections between countries and regions (Shin, 2010; Steele, 2012). 
Ivy (1997) argues that the perception of Japan as a homogenous society in the globalization context reveals how Japan reconciles the "Westernization" of their culture with its own traditions,

Repeated, fetishized assertions of Japanese cultural unity uncover the fragmenting processes of modern westernization itself and the necessity for Japanese subjects to bring together - to suture - those fragments. The residual protest of that suturing occurs most compellingly around moments of loss and their imaginary reconstitution as survivals. (p. 20) In the face of an increasingly globalized world, Japan asserts itself as $a$ culture, resisting perceptions of heterogeneity and internal difference (at times problematically with respect to the marginalized groups mentioned above). They do this with "intense preoccupations with essential national-cultural identity, continuity, and community that mark and remark it with the signs of totality" (Ivy, 1997, p. 26). Japanese peoples therefore have had a long history of identifying and therefore perceiving themselves and their singular, homogenous culture in relation to that of the "modern" West and in relation to other Asian cultures. Scholars have argued that local Japanese and Western elements work in conjunction to understand "Japanese-ness" as Japan exists in relation to the "West," other Asian cultures, and to itself (Lu, 2008; Napier, 2005; Sato, 2003; Wahab et al., 2012). As Japanese culture has been, and continues to be, hybridized through globalization elements that introduce, adapt, and assimilate "Western" ideas into Japanese culture, potential boundaries between what is and is not "Japanese" becomes increasingly more difficult to perceive (Darling-Wolf, 2000). In the modern era, Iwabuchi (2002a) argues that the Japanese appropriation of foreign cultures' characteristics emblemize Japan's cultural persona. By adapting foreign techniques of production and consumption, Japan continually reinvents itself 
as a national culture, thereby preventing particular definitions of what Japanese people "are" and what Japanese-ness “is" from arising.

Iwabuchi (2002a) argues that nihonjinron exceptionality and cultural unity also differentiates Japan from other Asian countries. This becomes apparent when 'Japan's peculiar position as the only modern, non-Western imperial/colonial power tends to be translated with a great skew toward Japan's relation with the West” (p. 7). Definitions of modernity aside, Iwabuchi (2002a) argues that Japan exists as both Western and Asian, therefore it Orientalizes itself in relation against Asia toward Western perception. Here, the "West" is/was the Other that whose modernity was to be strived toward with "Asia" representative of Japan's past from which the country wished to progress. Iwabuchi further argues that this type of Orientalism continues today in globalization discourses. Japanese culture therefore looks inward on its own history and traditions to assert its uniqueness as well as to situate itself as not necessarily resistant toward globalization, but adapting to globalization on Japan's terms.

Yasumoto (2011) identifies three "stages" of international interest of Japanese culture. The first came about in the 1860s with European fascination with "exotic" Japanese art and aesthetics; the second, in the early 1900s of Western interest (promoted by Benedict's (1946) Chrysanthemum) in traditions such as flower arrangement and tea ceremony; and the third, most recent, with the proliferation of anime and manga on the world stage. By comparing these “stages," Yasumoto (2011) directly implicates modern interest in Japanese media as an extension of orientalism.

Processes of globalization have increasingly presented modern Japan to other cultures. Per Iwabuchi (2002a), these processes can at times, perpetuate orientalism rather than promoting holistic understanding of other cultures. Scholars have argued that Western media tend to portray 
Japanese culture as an "alien society guided by strange incomprehensive mores (Gerbert, 2001, p. 100) and Japan itself as an exotic, sensual land (Akita, 2016). Gerbert (2001) states that that representations of Japan in the 1980s manifested as dark, technological dystopias exemplified by works such as Ridley Scott's Blade Runner (1982) and William Gibson's Neuromancer (1984). Paulk (2011) argues that Gibson's writings in the 1980s reflect the decade's concerns of Japan's "Economic Miracle" that propelled the nation into the role of an "economic superpower" (p. 479). Western anxiety toward Japan's success in the 1970s and 1980s therefore perpetuated particular ideas of Japan.

McKevitt (2010) states that the consumption of Japanese anime by extra-cultural fans perpetuates the orientalization of Japan, thereby "managing" it as a foreign threat upon Western culture, stating that it "enabled fans to adopt a representation of Japan at once unmediated by elite ideological structures of Western Orientalism yet mediated through a border-crossing technology of cultural representation" (p. 917). Orientalism in the twenty-first century therefore functions through the transmediated representation of cultures as products consumed by individuals who "pick out" aspects of these cultures to use as essentialized, representative markers for that culture. "Techno-orientalism" - coined by Morley and Robins (2002) and inspired by Japan's prowess in the technological arenas - refers to the shift from the Western "fetishization" of traditionally Japanese art forms such as Zen, flower arrangement and calligraphy to the commodities that are commonly thought to "represent" Japan in the twentyfirst century. Sato (2004) refers to techno-orientalism as the tendency to imagine Japan according to "two contrary stereotypes, which are, the premodern traditionalism and the supremacy of high-technology" (p. 355). 
Per Paulk (2011), "Pop culture is to contemporary Japan what computer chips and Toyotas were to Japan in the 1980s - a potent source of leverage on the world stage" (p. 495). McGray (2002) argues that a primary reason for Japan's pop culture popularity is its ostensible lack of Japanese authenticity. In an era heavily influenced by advancements in technology as well as increases of digital production and consumption, Japan could "no longer be dehumanized or condescended to in the traditional manner" due to the country's proficiency in these realms (Paulk, 2011, p. 480). Instead, fears of the nation-culture as a burgeoning economic superpower in the 1980 s influenced its stereotypical representations in the late $20^{\text {th }}-$ early $21^{\text {st }}$ centuries. Corbett (2009) suggests that this "techno-orientalism" acts as a sort of "Lacanian mirror stage' in which Japan has begun to recognize themselves through, thereby "leaning into" the perception of Japanese culture has a hyper-modern techno-scape rather than a "traditional" Asian society as it once was stereotyped. Morley and Robins (1995) state that Japan's association with the hypertechnological as representative of its identity on the world stage brings with it anxieties concerning the displacement of the West from its superior position in the world.

From these perspectives, worries concerning a historically exotified "primitive" nationculture intensified when this nation-culture grew into an economic technological superpower. In any case, advances in technology have contributed to orientalism through the ideological shift the cultural properties that "represent" Japan and Japanese-ness in the $20^{\text {th }}$ and $21^{\text {st }}$ centuries. The Japanese economic recession of the 1980s and 1990s led to a national re-conception of what can and should be profitably exported to the world. In these decades, popular cultural products such as anime and character merchandise (e.g., Hello Kitty) began to play a pivotal role in Japan's efforts to brand itself to the world for the purposes of tourism and exports (Choo, 2013; Posadas, 2014). Posadas (2014) argues that this promotion of cultural products contributed both to the 
reduction and fetishization of anime as representative of the Japanese natural culture in "popular and scholarly discourse" (p. 314).

Asian cultures and their respective products have a history of being exotified, fetishized, and otherwise "otherized" by hegemonic cultures that commodify these cultures; it therefore becomes salient to examine these historical tendencies through the globalized context as these habits have not "just disappeared" with the introduction of producers" increased ability to distribute cultural products abroad. As these producers localize and "de-odorize" the cultural specificity of these products, the actual "oriental" qualities of these artifacts become less immediate. However, the localization of products such as anime is never absolute as the news media and their audiences can refer to their Japanese origin in non-sanctioned, casual discussion. However, children who were introduced to anime through Pokémon would not be as aware of its origin as those adults mystified by its fad-like success in the late 1990s and early 2000 s.

Pokémon therefore has walked, and potentially continues to walk, the line between the localized, "de-odorized" content that has captivated children and the burden of being the emblemized representation of Japanese culture to those who understand Japan and Japanese people as an exotic "other."

\section{Cultural Odorless-ness}

As cultural products contain aesthetic elements from their originating culture, they are said to have a cultural "odor" about them that suggests their origin (Iwabuchi, 2002a). Twentieth century orientalist discourse concerning cultural products from Asia, for example, pinpointed the "exotic" and "refined" qualities of Chinese ceramics and silks and Japanese woodblock prints as characteristic of their respective cultures. The aesthetic characteristics that were fetishized and exoticized by other cultures were therefore conflated with the sociocultural qualities of the 
individuals within the cultures themselves through the same orientalist discourse. Therefore, the aesthetic products that cultures produce can, at times, have implications for the ways in which these cultures are perceived by those outside of these cultures.

As discussed in the previous section, the homogenizing force of glocalization and the fetishizing force of orientalism constitute a fine line that is walked by cultural products such as anime. Through glocalization, the producers of these programs manage the cultural "odor" so as to introduce and normalize these shows within a new cultural context for the purpose of maximizing international profit, but they also do so within a context defined by a history of orientalist thinking with regards to stereotypes regarding Japan and the Japanese people. Therefore, anime such as Pokémon both must resist stereotypes by ingraining its aesthetic into other cultures so as to familiarize these audiences to foreign entertainment but it must also consider prior perceptions of Japanese anime and culture and those who "appreciate" it so as to capture their attention as well.

Hoskins and Mirus' (1988) cultural discount theory purports how certain products may appeal in one culture, but not another. They explain, ...a particular programme rooted in one culture, and thus attractive in that environment, will have a diminished appeal elsewhere as viewers find it difficult to identify with the style, values, belief's institutions, and behavioural patterns of the material in question. (p. 500) This "discount" proposes that less people will purchase or consume the product in a foreign culture than what is typical in its originating culture as they will have more difficulty identifying with the underlying values, beliefs, and attitudes within the product (Lee, 2006). Iwabuchi (2002b) asserts that this "discount" explains the low number of Japanese media products distributors seek to export abroad. He argues that both Japanese producers and global distributors 
are aware of the limited appeal to culturally-specific popular media in the Western markets and therefore tailor some products to be more appealing for international consumption.

Iwabuchi (2002a) introduces "cultural odorless-ness" as a concept rooted in Hoskins and Mirus' (1988) cultural discount theory to explain a product's lack of inherent cultural specificity. He defines "cultural odor" as culturally stereotyped features are positively associated with a particular product while it is being consumed and relates the "fragrance" of Japan to stereotypically exotic images of Japan as a country of samurai, geisha, and tea ceremonies (Iwabuchi, 2002b, p. 27). The cultural fragrance is a symbolic image of a country that resonates from a product. In his view, any given product contains traces of the culture from which they originate, though particular products' cultural origin may be less overt.

Napier (2005) correlates cultural odorless-ness with mukokuseki, or the "statelessness / without a national identity" nature of cultural representation within anime programs (p. 24). This has also been examined in relation to "ethnic bleaching" wherein anime characters are "deJapanized" during production for a variety of reasons including making certain programs more appealing to international audiences (Arnold, 2004; Hairston, 199; Sato, 1997). However, scholars have criticized this essentialism of defining animated characters' ethnic identities primarily by their appearance, noting that many of these "ethnically bleached" characters also have characteristics of Japanese people, including dark hair and eyes (Arnold, 2004; Hairston, 1999). Close (2017) argues that, although anime characters were not intentionally portrayed as ethnically ambiguous in order to appeal to international audiences, this ambiguity nevertheless assisted anime's growth in popularity throughout the world. Lu (2008) argues that limited funding partially affects the limited variation of race and ethnicity found in anime, as its production is constrained not only by time, audience, and talent, but also by economics that 
necessitate quick and simplified features of characters that can easily be animated by multiple artists on a budget. Because of this, anime typically feature less distinctive facial features and ranges of motion than shows from Disney, which have significantly more funding. Lu further theorizes that the unrealistic features of characters (e.g., large colorful eyes and vibrant hair colors) along with simplified designs compound to produce racially and ethnically ambiguous characters. Furthermore, $\mathrm{Lu}$ (2009) concludes that due to this ambiguity, some audiences project their own ethnicities and races onto the characters in order to relate to them.

Naylor \& Helford (2014) argue that rather than the "stateless" nature of anime representing neutral cultures through its features, it rather displays "a collage of Japanese cultural markers with other Asian and western indicators" that mix and overlap with each other to represent a fictional culture that is comprised of features from multiple cultures (p. 311). Patrickson \& Young (2013) argue that the familiarity and difference found within texts and interpreted by audiences allow these audiences to explore alternate identities in the globalized context of cultural production. This statelessness gives anime the freedom to "explore and discuss indirectly, freely and playfully issues of Japanese identity, history and politics" (Naylor \& Helford, 2014, p. 311). Ruh (2014) points to the physical features of anime characters as the most common point of discussion regarding cultural odor and "stateless-ness." He states that rather than appearing as non-Japanese, as some scholars would argue, characters are abstracted representations dependent on the genre and type of show within which they exist rather than intentionally accurate depictions of an ethnicity. Here, anime can represent Japanese culture through caricature and exaggeration, sometimes through an idealized lens. According to Denison (2015), at times, discussions of anime's cultural specificity problematize the representation of Japanese culture on the world stage. She questions, however, whether there truly is a "correct" 
way for anime to represent Japanese culture abroad (p. 10). Patrickson \& Young (2013) argue that mere surface-level instances of "Japanese-ness" within anime can facilitate intercultural awareness and comprehension as "even possibly spurious fandom of Japan's performed global face can bridge cognitive dissonance and foster greater cultural familiarity over time” (p. 51). The indication that this is done "over time" suggests that cultural familiarity requires consistent attendance to programs from another culture.

Iwabuchi (2002a) muses that Western audiences may be "at long last coming to appreciate, and even yearn for, an animated race-less and culture-less, virtual version of Japan" due to repeated de-odorized representations of "Japanese-ness" within anime (p. 33). Here, it's not the actual Japan or Japanese culture that is being appreciated, but a virtual simulacrum that is intentionally produced both for capitalistic profit and for cultural "soft power" that selfexoticizes Japan to an international audience for further consumption. This soft power, coined by Nye (1990), refers to a form of global influence promotes favorable impressions of cultures through economic production. In this case, some of Japan's soft power lies in its distribution of entertainment media throughout the world. This is distinguished from "hard power" wherein countries spread their influence through military might and presence. Other scholars have examined internationally successful products with diminished "Japanese-ness."

Du Gay et al. (1997) examine the Sony Walkman as a cultural product that succeeded in the global market due to its lack of cultural specificity. However, they add that the Walkman emblemized many of the orientalist thoughts concerning Japanese technology during its lifetime. For example, the miniaturized tape player signified the common perception of Japan's tendency to capture efficiency through the miniaturization of its technological innovations. They note that this perception was disseminated partly due to the popularity and affordability of many small, 
Japanese products during the 1970s and 1980s including cars, radios, cooking appliances, and television sets. This perception that Japan innovates technological products by reducing their size for more efficiency continues today with the release of the Nintendo Switch - a video game console designed to be played both at home and on the go. While North American households typically hold more space for video game consoles, Japanese homes are more compact, limiting the amount of space individuals can afford for entertainment. Nintendo therefore capitalized upon both cultures' consumption habits by combining North Americans' habitual use of video game consoles attached to a television in a living room alongside Japan's predilection for mobile devices. Therefore, while the Sony Walkman and similar compact technology do not explicitly carry with them a particular "Japanese-ness," common perceptions of Japan and the Japanese are articulated, and reinforced, through the form of their cultural products thereby establishing them as "Japanese" in nature.

Other scholars theorized that Japanese goods do not rely on the "Japanese way of life" the way certain American products such as McDonald's and Coca-Cola do (Featherstone, 1996; Iwabuchi, 2002b). Featherstone (1996) notes that this may due to the fact that "Japanese consumer goods do not seek to sell on the back of a Japanese way of life" (p. 9) and therefore, these odorless products exist as "unthreatening" to other cultures.

In addition to cultural odor, theory of cultural discount has also been applied to many sorts of international products, many of them within the realm of mass media. For instance, it has been used to examine gendered and racial representation in fashion magazines (Darling-Wolf, 2007; Kovacic, 2014), localization of videogames (Carlson \& Corliss, 2010; Heemsbergen, 2016; Mandiberg, 2015), the localization and distribution of manga (Brienza, 2009; Patrickson \& Young, 2013) and anime (Allison, 2006; Levi, 2013; Lu, 2006, 2008, 2009; McKevitt, 2010; 
Napier, 2005). Other scholars have utilized the concept in reference to Japan's attempt to brand a cultural identity through the promotion of popular culture for the purposes of tourism and "softpower," (Daliot-Bul, 2009; Nye, 1990;). Brienza (2009) argues that the manga industry was not able to successfully develop in the United States due to American publishers' attempts to adhere to the publishing practices of their Japanese contemporaries that assumed that only products that have been altered to have had their "Japanese-ness" removed could succeed in the West, thereby reducing their potential product pool a significant amount.

Posadas (2014) argues that the shift in cognition of anime as a "denationalized cultural commodity" to representative cultural commodity of Japanese culture follows Hall's (1991) argument that the commodification of cultural markers of identity has replaced "modes of racial exclusion" in the postmodern era of consumption wherein novelty supersedes rejection of cultures (p. 316). Posadas therefore implicates the emblematic nature of Japanese anime as a distinct cultural product, indicating that there remains particularly "Japanese" aspects to the art form that are continually identified and embraced by international audiences. By this notion, anime therefore partially carries the burden of representing the national cultural consciousness of Japan as a paragon of popular culture because of its aesthetic and reproductive properties characteristic of the medium.

McGray (2002) introduced the concept of “Cool Japan” to examine Japan's burgeoning soft power being introduced to the international sphere through art, fashion, and technology. Since then, many scholars have examined the cultural implications about this sort of "national brand" (Condry, 2009; Daliot-Bul, 2009; Lam, 2007; Paulk, 2011; Yasumoto, 2011). Daliot-Bul (2009) examines the "Japan Brand Strategy" as an intentional policy utilized by the Japanese government to promote distinctly "Japanese" cultural products abroad in order to garner soft- 
power abroad through pro-Japanese sentiment. Rather than previous anime and manga export strategies to de-emphasize the Japanese nature of these texts in the 1980s and 1990s, the Japan Brand Strategy going forward from 2002 sought to signify the "Japanese-ness" of these products in order to "strengthen the symbolic value of the products it sells as Japanese" (Daliot-Bul, 2007; 2009). He argues that this served a variety of functions: one, to enlarge the market for their entertainment products abroad; two, to maintain a Japanese national identity following an abrupt recession during which people lost trust in the traditional institutions that previously provided a golden age of production; and three, to emblemize Japan's identity in a postmodern world signified by media consumption, production, and consumer-participation. Wong (2006) argues that the growing acceptance of Japanese media in America in recent years is due to the production and marketing strategies employed by Japanese producers in the 1990s that carefully considered products" "cultural odor" as well as the transmedia potential if these products,

Daliot-Bul (2009) cites participatory culture as another significant factor in this strategy, stating that the strategies employed in the promotion of the overarching "Japanese" narrative result from, and encourage, "ongoing interactions between local and international grassroots and corporate media in which the power of media producers and the media consumers intersect and sometimes collide in unpredictable ways" (p. 249). Jenkins (2006a) argues that an increasing "convergence culture" has begun to blur the distinctions between production and consumption in which the public becomes more invested and active in the consumption process thereby influencing production processes. Jenkins asserts that the modes of consumption of texts has become more complicated due to transmedia storytelling. Transmedia storytelling involves the extension of particular texts, such as films, into multimedia franchises containing novels, video 
games, comics, and websites that are each incorporated into the overarching "world" of the primary franchise text.

Fiske (2011), for instance, acknowledges the intertextuality managed by producers through the interrelation of texts through many forms of primary media texts and peripheral promotional products. These concepts are related to Kinder's (1991) notion of the “entertainment super-system" of children television franchises as transmedia that cut across several modes of image production; must appeal to diverse generations, classes and ethnic subcultures, who in turn are targeted with diverse strategies; must foster "collectability" through a proliferation of related products; and must undergo a sudden increase in commodification, the success of which reflectively becomes a "media event" that dramatically accelerates the growth curve of the system's commercial success. (p. 123).

In the entertainment super-system, the consumption and production modes of du Gay's (1997) circuit of culture are closely linked, each one informing the other through the consumer's "collection" of franchise artifacts that encourage producer's creation of new artifacts to meet demand. According to Kinder (1991) the super-system of entertainment encourages invested audiences to actively "complete" the overarching narrative of the franchise by attending to as many related media as possible. Jenkins (2006a) conceives of knowledge communities that share information and expertise about franchises amongst each other with social capital integrated with "affective economics" wherein "the ideal consumer is active, emotionally engaged, and socially networked" in the development of consumption and distribution of media texts as well as the production of fan works (p. 20).

In convergence culture, the logics of production are informed by how audiences consume media in the twenty-first century. Jenkins (2006a) points to The Matrix franchise as indicative of 
both convergence culture and transmedia storytelling as it involved the co-creation of videogames, animated short films, novellas, and comics alongside the main film trilogy from the onset of its production. Jenkins (2006a) explains that this transmediated storytelling strategy permitted the growth of a fictional world whose lore could be explored in multiple ways outside of the main films. In this case, the promotion of a "world" rather than a strict story limited to a single medium led to increased consumption by fans of the franchise.

Convergence culture - and consequently transmedia storytelling - encourages audiences to participate in the creation of meaning through the consumption of multiple modes of the story and through social activity with others in order to create, and maintain, an invested consumer base (Jenkins, 2006a). Convergence culture therefore signifies a "cultural shift" toward consumption as a collective, social process. Fans of transmedia stories further extend the "world" with fanfiction, fan art, and other fan activities that encourage others to contribute as well. Per Jenkins (2006a), convergence culture is "both a top-down corporate driven process and a bottomup consumer driven process" (p. 17). Scholari \& Ibrus (2014) explicate Jenkins' (2006a) notion of convergence culture as an "ongoing dispersal of media boundaries - between various media, between industries, between consumers and producers, and between those with power and those without" (p. 2192). According to Ferreira \& Fernandes (2014) convergence can be viewed through elements of du Gay et al.'s (1997) circuit of culture, particularly at the points of production, distribution, and reception. Ferreira \& Fernandes argue that new media (such as video games) blur the boundaries between these points and "renovate the media landscape" through alternate modes of each point of the process. For example, reception now includes active participation in communities as well as the production of fan works of media. Furthermore, these media are produced for as many platforms as possible in order to develop a profitable franchise. 
Transmedia storytelling therefore blurs the lines between production and consumption modes of du Gay et al's (1997) circuit of culture.

Whereas the Matrix franchise consisted of primary film texts and peripheral texts that contributed toward the understanding of the Matrix “world," Jenkins (2006a) suggests that "synergistic storytelling" in which movies, video games, comics, television shows, and other media formulate a "world" with different stories within them that co-create the "world's" narrative form (Jenkins, 2006a, p. 105). Jenkins (2006a) refers to co-creation as when "companies collaborate from the beginning to create content they know plays well in each of their sectors, allowing each medium to generate new experiences for the consumer and expand points of entry into the franchise" (p. 105).

He explains that audiences want works that "offer new insights and new experiences [and] if media companies reward that demand, viewers will feel greater mastery and investment" of the story and will therefore continue to buy into the transmediated world (p. 105).

Scholars such as Jenkins (2006a) and Picard (2007) have noted the admitted influence of Japanese anime on the Wachowski's development of The Matrix franchise, connecting transmedia storytelling to Japan's "media mix" franchising wherein "mass-media ecologies" are formulated through the integration of "in-home media such as television and game consoles, location-based media such as cinema and special events, and portable media as trading cars and handheld games" in audiences' lives (Ito, 2007). Per Ferreiro and Hernandez (2014), transmedia stories "presuppose the existence of a universe whose history can be told from multiple perspectives and authorships, taking advantage of as many platforms as possible, involving and encouraging a participatory, audience" (p. 5). They distinguish transmedia stories from transmedial worlds in that transmedial worlds do not focus on a single story, but are rather a 
construction comprised of the "rules" of the world (it's ethos), the world's physical context and setting (topos), and the multiple plots, stories, and characters present within the world (mythos) (Ferreiro \& Hernandez, 2014). Here, transmedial worlds contain transmediated stories as a vehicle to construct franchises. They further argue that to be successful, transmedia stories should be able to stand alone within the transmedia world, but also be connected by the world in other to facilitate recognition and expertise for audience members invested in the franchise. An example of this transmedial storytelling would be the Marvel Cinematic Universe in which the blockbuster movies play a centralized role in developing a story-world where television shows, comic books, videogames, and toys converge across channels through adjacent storylines and reoccurring characters.

Davis and Yeh (2008) argue that the primary medium for Japanese franchising is television and Steinberg's (2012) interpretation of Ito's (2007) Japanese “media mix” purports three defining features of the media mix that centrally features television. The media mix (1) must be implemented "across numerous media, among which anime plays a key role in popularizing the franchise" (2) it must rely upon "the dependence of other incarnations to sell works within the franchise;" and (3) it must utilize characters "as a means of connecting these media incarnations" (p. 148). Denison (2016) connects the transmedia potential of Japanese film through the entertainment super-system and its ability to cut across media to deliver narratives in primary and ancillary forms to an audience. Ahn (2002) argues that anime should be comprehended when the "media mix" strategy is examined in conjunction with the medium's particularities as anime simultaneously produce "various goods related to the manga and anime, including original soundtrack CDS, paperback books, fanzines, and numerous character merchandises" (p. 12). The networks involved in the anime-media mix as well as transmedial 
storytelling constitute Japan's mass media franchising stratagems that connect each medium (namely anime, videogames, and comics) to each other narratively and economically (Patrickson \& Young, 2013; Steinberg, 2012). Picard (2007) argues that an "indisputable bond" exists between video games, movies, and television (p. 293). The Japanese "media mix" takes full advantage of this relationship to foster franchised characters and transmedia worlds in order to build audience investment. Ōtsuka \& Steinberg (2010) purport that much of the appeal of Japanese transmedia stories comes from the "hunt" for fragments of a grand narrative. By this, audiences can access a limited amount of agency and participate in the world through the collection of franchise artifacts.

As Pokémon exists as a very obvious form of transmedia storytelling and emblematic of the very "media mix" that the aforementioned scholars explicate, it is a prime example of the Japanese-ness inherent to these media strategies. Here, much of the cultural "odor" of Pokémon lies within the strategies developed to market it domestically and global. The cultural "odor" of products is therefore rooted within the cultural persona that the culture believes about itself as well as how it wants this persona to be perceived by others. As far as anime is concerned, the producers typically choose not to sacrifice the visual aesthetic qualities of the programs (exceptions include gratuitous nudity and violence): instead, they alter the audio qualities so as to more closely resemble the cultures in which these programs are being marketed. Many localizers choose to use this method of transliteration: allowing most of the visually Japanese symbols to remain as such, but altering the verbal qualities through the "dubbing" of English voices over the animation so that the English-speaking audience can easily understand the program's exposition. However, some localizers also "scrub" the visual Japanese elements from anime - replacing them with blank space, alternative art, or in extreme examples, cutting the scene entirely. This 
sort of deletion may have a profound effect on how these programs are perceived by international audiences. As the Pokémon anime has been broadcasted for over twenty years, there is a strong likelihood that the distributors of this program engaged in efforts to localize and "de-odorize" it. This project therefore examines episodes of the show Pokémon to determine whether the producers and distributors have altered the localization methods to expand the franchise's popularity.

\section{Anime}

Pokémon is clearly an example of an anime text, a type of text that has been examined in depth by a number of researchers in a variety of ways. In this section, I identify what anime is, its historical and cultural roots, and offer a brief survey of how it has been researched before. This section establishes that anime, as a cultural product, qualitatively has a certain "cultural odor" derived from cultural specificity, historical origins, and its perception both inside and outside of Japan.

Anime and manga have been extensively studied as both domestic and global cultural products (Condry, 2013; Ito, 2005; Ito \& Crutcher, 2013; Napier, 2005; Otmazgin, 2014; Saito, 2017) as reflective of Japanese tradition and history (Levi, 1996; Sørensen, 2008) and as indicative of Nye's (2002) conception of “soft power” (Daliot-Bul, 2009; Lam, 2007; Lu, 2008). Others have written about gender and sexuality in anime (Saito, 2014; Schaub, 2001), anime as a teaching tool (Armour, 2011; Armour \& Iida, 2014;), and modernity and postmodernity represented in anime (Daliot-Bul, 2009; Lamarre, 2002; Stevens, 2010;). The history of anime in the global sphere has been extensively examined and traced (Ladd, 2009; MacWilliams, 2014) as well as the history of the transnational flow of anime into the United States (Drazen, 2002; Patten, 2007; Ladd, 2009). 


\section{History of Anime}

Japanese animation and the closely interrelated comic industry (manga) have held a constant interrelated ubiquity in Japanese popular culture (Condry, 2013; Ito \& Crutcher, 2014; Pusztai, 2015). Scholars have outlined the early influences on anime, from Japanese pictographic comic representations of caricatured animals to the "Animal Scrolls" and the Gaki Zoshi ("hungry ghost scrolls") drawn in the $11^{\text {th }}$ and $12^{\text {th }}$ centuries (Ito, 2005; Ito \& Crutcher, 2014) to the $19^{\text {th }}$ century delineating the significance of woodblock print artwork of Japanese culture during these periods (Schodt, 1988). Books containing cartoons for children as well as cartoons intended for adults with humor and satire have also been stated to be influential on the development of manga and consequently, anime into the twentieth century and beyond (Ito, 2005, Ito, 2008; Ito \& Crutcher, 2014; Schodt, 1988). Napier (2005) delineates several reasons for manga's ubiquity in, and importance to, Japanese culture, including the fact that the variety of themes and genres present in the industry makes it appealing to a wide range of ages and demographics. Per Schodt (1996), "Japan is the first nation on earth where comics have become a full-fledged medium of expression" rather than a niche subcultural art form as it has been considered in the West (p. 20).

In Post-War Japan, manga comics and animation grew concurrently as burgeoning media industries (Condry, 2013; Denison, 2015; Ito, 2005; Lu, 2008; Pusztai, 2015). During World War I and World War II, comics and animated movies were used by Japanese state industries as propagandist media to support the war efforts (Levi, 2013; Wahab et al., 2012). In the post-war period, these comics and animated films transitioned to be geared more toward children's entertainment and story manga became more popular than episodic comics (Ito, 2005). Furthermore, in the 1950s and 1960s, American comics were essential in the introduction of 
modern comics to Japan, and by extension, Asia (Wong, 2006). Osamu Tezuka, known as "the god of manga" was at the forefront of the popularization of both manga and anime in Japan in the Post-Occupation years (Ito, 2005). Considered to be the "founder of modern Japanese manga" (Ito, 2005, p. 466), Tezuka is argued to have been the most prolific and influential manga artist and anime producers in Japan, introducing many popular characters from his comics into the animated realm as well as creating the classic "anime look" (Drazne, 2003; Lu, 2008; Lu, 2009; Napier, 2005; Ruh, 2012).

Scholars have noted Walt Disney's influence upon Tezuka's comic and animated works (particularly upon the "big-eyed" aesthetic of character), who in turn, influenced a variety of Western cartoon animators in the 1990s, indicating the early "cross-pollination" of ideas within the globalized animation industry (Bakonyi, 2010; Consalvo, 2006; Kuwuhara, 1997; Napier, 2005; Naylor \& Helford, 2014; Ruh, 2012; Wahab, Anuar, \& Farhani, 2012; Wong, 2006). This cross-pollination of idea within media industries was also noted by Ito (2008) who suggests that during the 1920s and 1930s, Japanese artists borrowed ideas from American newspaper comics. Creative ideas concerning manga and anime were therefore not confined to the shores of Japan, but were partially affected by practices used in the West.

Influenced by Disney's aesthetics, Tezuka's Tetsuwan Atomu (known in the United States as Astro Boy) was arguably the first serialized cartoon based on a manga to be aired in Japan and then exported to the United States in the 1960s (Denison, 2015; Napier, 2005; Ladd, 2009). Cited by Denison (2015) as the "beginning of anime," Tezuka's program ushered in a variety of anime techniques and production conventions that exist to this day (p. 5). Wong (2006) argues that the transition of Tetsuwan Atomu_from comics to television marked a milestone in the Japanese multimedia industry and, according to Grigsby (1998), "reflected the movement to a mass 
society and the influence of American culture and marked the rise of the manga of contemporary Japan" (p. 68). Lu (2008) notes that Tezuka was the first animator to have featured anime characters with ambivalently Caucasian-looking characteristics. Lu further argues that through this "cultural blurring," "anime neutralized itself, which reflects a broader national desire to enter an extra-territorial stage of development" in which Japan modernizes itself toward global culture without confining itself to its borders. (p. 171). Many of these techniques continue in the production of anime as cultural products today (Denison, 2015; Lu, 2008; Wong, 2006). Denison (2016) notes the industrial mechanisms that emerged in Japan in the 1960s and 1970s that began the intertextual relationships between Japanese and media in franchises. Osamu Tezuka's production strategy in adapting manga to anime, for instance, relied upon franchised media and merchandise to sustain his business model. (Denison, 2016; Patrickson \& Young, 2013; Wong, 2006).

As anime and manga have had a long history and strong place within Japanese culture, they exist as interrelated cultural products. As Wells (2002) argues that animation should be regarded as cultural artifacts that represent the given culture in which they are produced, anime exists as a significant cultural commodity. Hirsch (1972) defines cultural products as "nonmaterial goods, directed at a mass public consumers, for whom they serve as esthetic, rather than a clearly utilitarian purpose" (p. 639). Levi (1996) connects anime inherently to Japan's cultural history, stating that to understand its aesthetics, themes, and theses, "requires a deeper knowledge of Japan's pre-history, its myths and legends, its religions, artistic traditions, and philosophies" as these are all tied together in the history of anime's development in Japan (p. 16). Through these ways, anime represents a distilled form of Japan's traditions, norms, history, and modernization through an animated medium. 


\section{Defining Anime}

Patten (2004) traces the term "anime" back to 1978 in early niche fan culture in the United States as a term by which people outside of Japan used to identify and admire Japanese animation where it soon overtook "Japanimation" as the preferred nomenclature due to the derogatory connotations that the phrase "Jap animation" provoked (Ruh, 2014; Yamato, 2012). Denison (2015) notes that anime is consistently defined as a type of animation. Anime has specific associated aesthetics that characterize the media, including large eyes for characters, distinct, sharp movement of scenes, and surreal imagery. Scholars have noted these features among others as distinctive of anime media and state its importance in innovating, and distinguishing, Japanese entertainment on the world stage (Close, 2017; Horno-López, 2016; Matsui, 2009; Yoshioka, 2008). Previously considered to be low-culture entertainment and "vulgar and infantile," anime and manga are now considered to be significant economically valued media products in the $21^{\text {st }}$ century (Daliot-Bul, 2009, p. 51). Often stereotyped as childish, violent, and pornographic, anime in fact contains multitudes of genre classifications and themes that present it as a complex form of representational and flexible storytelling (Denison, 2015; Drazen, 2003; Napier, 2005; Newitz, 1995; Newitz, 1997; Price, 2001; Ruh, 2014; Steinberg, 2011).

While McKevitt (2010) notes that anime typically refers to any kind of animation produced within Japan, Denison (2015) argues that anime is not just a genre any more than it is simply a kind of animation, or a product of only Japanese culture...[but that] anime needs to be understood more broadly as a cultural phenomenon whose meanings are dependent on context (p. 2). 
She argues that the various processes involved in the production, distribution, and consumption of anime, both within and outside of Japan, change what "anime" means to the various audiences it encounters. Many scholars agree with the idea that anime is an overarching pop cultural phenomenon, particularly Japanese in aesthetic and nature, that is not just a medium, or a genre, or a product but an umbrella which, as its center, contains the primary television animated program but also includes film, advertisements, toys, and other media that can be characterized as stylistically “anime” (Condry, 2013; Denison, 2015; Napier, 2005; Patrickson \& Young, 2013; Ruh, 2014). Anime is therefore not confined to a single product, but is an amorphous combination of aesthetics, production techniques, and context and touches upon many products within its sphere of cultural of influence; this influence is strongest in Japan but also has tendrils reaching to the United States and elsewhere in the world.

As a format that was produced and consumed in relation to other media forms, anime from its very outset existed as a product of transmediated production (Steinberg, 2012). According to Ruh (2013), animation and comics have "a hard time containing themselves" as they continually "push against" their boundaries, continually blurring their distinctions (p. 1). This is seen semantically as the word "cartoon" can both suggest animation and printed comics. Anime and manga scholars have noted that most anime are based upon the stories first appearing in manga (Condry, 2013; Napier, 2005). The interrelationship of anime, manga, and many other media types is widely acknowledged (LaMarre, 2009; Ruh, 2012, Ruh, 2013; Steinberg, 2012; Wong; 2006). LaMarre (2009) argues that rather than a discrete medium, anime exists as a "nodal point in a transmedial network that entails proliferating series of narrative and nonnarrative forms across media interfaces and platforms" (xiv). This media networks' prevalance in Japan has been recounted various scholars as well (Condry, 2013; Napier, 2005; Pusztai, 2015; 
Wong, 2006;). Condry (2013) reports that as much as sixty percent of animated television shows broadcasted in Japan are adapted from these manga. While in the United States, animation has traditionally been constrained to children's entertainment and superhero shows, Japanese animation is much more ingrained into the national mainstream culture (Naylor \& Helford, 2014).

\section{Anime's Cultural Influence and its Japanese Specificity}

Naylor \& Helford (2014) argue that anime provides an avenue of understanding culture as well as providing "potential for both intracultural and intercultural dialogue" to reflect on Japanese culture and the meanings associated with it (p. 312). Furthermore, Ito \& Crutcher (2014) state that "manga depicts and feeds the cultural and social consciousness" of Japan (p. 46). Anime is therefore closely, if not intrinsically, tied to Japanese culture and the meaningmaking semiology that reflects and informs Japan's cultural persona.

$\mathrm{Lu}$ (2008) conceptualized three "cultural politics" in which Japan had modernized, and continues to modernize, itself through anime. These include, first, the neutralization of particularly Japanese representation in anime toward a more "international" appeal that $\mathrm{Lu}$ defines a an "international de-politization" (p. 173). She relates this to Hoskins and Mirus' (1988) cultural discount'theory as well as Iwabuchi's (2002a) “cultural odorless-ness.” This concept is recognized by anime producers, as "the possibility of having a worldwide fan base ultimately should depend on some special characteristics of anime itself' (Lu, 2008, p. 173). In other words, in order to have more of an international market, anime needs to be produced a certain way with global audiences in mind.

Second, Lu's (2008) cultural politic of "Occidentalized internationalization," which refers to a "backlash" of Orientalism. In this politic, Japanese producers placed "Western" 
looking villain characters in opposition to the Japanese heroes who overcome e them. Here, she theorizes that this is becoming less noticeable in anime intended for global consumption as to appeal more toward "Western" audiences (again, conflating the "West" with globalized modernization"). If producers wish to have more of an international market, they need not explicitly demonize "Western" looking characters.

The third "cultural politic" that informs anime's modern production is referred to by $\mathrm{Lu}$ (2008) as "self-orientalized internationalization," in which Orientalism "has been internalized, neutralized, and 'reinvented' in anime" (p. 179). Here, anime is a way through which Japan, through "Japanese-ness," can accentuate its distinctiveness as a culture in relation to other Asian cultures, as well as justifyi its deservingness of standing on the world stage as a modern nation. Each of these three cultural politics is therefore informed by prior historical ideas concerning Japan's place as a nation and a culture in the world and to various extents, these three processes inform the ways in which - through anime - Japan is perceived as a "modern" nation.

Wong (2006) examines the popularity of manga in Southeast Asian countries, arguing that manga provides a "new image of 'Asian"” through its association with "Japanese-ness" effected by Western influence, and for the Asian audience "with a similar cultural-economic experience, these images become highly identifiable and accessible" (p. 29). Here, the cultural proximity of Southeast Asian cultures and ethnicities provides a route for these cultures to identify with Japanese-Western manga as a modern conception of what Asian"is in an era of globalization.

However, for non-Asian audiences, the Japanese-ness is not necessarily the only attraction of manga and anime (Allison, 2000; Napier, 1993; Wong, 2006) but the ability for children to identify with characters, characters' goals, and themes as a way to "transport...to 
another world - a fantasy or dream world" constitutes much of manga's international success. Wong (2006) concludes that products with less Japanese-ness are more profitable than products saturated with Japanese-ness, pointing to Pokémon's global popularity as an exemplar (p. 39). “It is the 'culturally odorless' that Japanese publishers wanted to see - a 'creation of imaginary world(s) that strike fans with a mixture of familiarity as well as fantasy"” (Wong, 2006, p. 39). Per Wong, the appeal of manga and anime for Americans possibly lies in the combination of familiarity with themes from their own culture and the distinctiveness of the aesthetics of Japanese media. She further purports that other Japanese media such as dorama (Japanese soap operas), live action movies, and songs may not capture international imaginations like manga and anime can and therefore may be not be able to "penetrate the American market without severe alteration and localization" (Wong, 2006, p. 42).

Price (2001) describes anime as material that incorporates the cultural personae, taking on and reflecting the stories and themes that resonate with Japanese people. Napier (2005) concurs, adding that anime is a "useful mirror on contemporary Japanese society, offering an array of insights into the significant issues, dreams, and nightmares of the day" (p. 8).

Furthermore, Napier states, "Virtually all anime contain some Japanese references, from psychology to aesthetics to history" (p. 26). The modern multimedia of manga, anime, and video games as well as the merchandise related to them contributed heavily to the recovery of Japan's post-recession economy as successful exports and as intra-cultural cultural products (Daliot-Bul, 2009; Machiyama, 2004).

\section{Anime in the Local and the Global}

Scholars vary in their attribution to anime/manga's growth in the United States. Matsui (2009), for instance, argues that there were two particular avenues through which manga, and by 
extension anime, became popularized in the United States. First, U.S. comic book publishers' translation and distribution of "authentic" and affordable manga led to an increase in market size as fans of comic books began to become interest in Japanese manga. Second, through the management of the stigma associated with comics, cartoons, and particularly "Japanese" products, these distributors were able to acclimate their manga and anime to American sensibilities through selecting titles that were "appropriate" to American audience (e.g. stories that they thought would resonate and therefore sell well), and translating/altering them in such a way as to adhere to content standards (e.g., censoring them). By making selective choices in both presentation and alteration, these distributors were able to successfully enter the market in the United States with products that were not too "Japanese" but existed as distinctly "other" from the usual cartoons and comics with which consumers were familiar. Here, for Napier (2005), anime represents a site of resistance to Hollywood's global dominance in the entertainment industries.

Scholars have noted distribution companies' attempts to "play it safe" when adapting manga and anime in the United States, particularly when they primarily targeted the young male demographic, as this was the demographic that primarily watched cartoons and read comics. (Adelia \& Subiyanto, 2012; Matsui, 2009). Otmazgin (2014) concludes that anime's successful entry in American markets was due to savvy entrepreneurship in identifying niche anime fandom that had been growing since the 1970s and targeting these fans with carefully localized products that balanced anime's aesthetics with Western tastes and preferences. Noh (2016) suggests that "anime's remarkable ability to be localized and forcefully re-nationalized within a myriad of communities... has led to its massive rise in popularity" (p. 34). Therefore, anime exists both 
locally as a cultural product and globally as a wider phenomenon (Condry, 2013; Denison, 2014; Denison, 2015; Napier, 2005).

Matsui (2009) argues that manga and anime producers seek to produce these products for domestic and international audiences alike. Denison (2014) cites Mahha Go Go Go (henceforth referred to its English name, "Speed Racer") as one of the first pioneers of anime's transnational successes as a product of "wholesale cultural reinterpretation and origin erasure" (Denison, 2014, p. 270). Because of this “erasure," Speed Racer was able to find success in America as a series which its creators based on a "love of American culture," particularly that of car racing (p. 272). However, Denison (2014) further argues that 2008's Speed Racer movie failed at the box office due to the directors' explicit attempts to incorporate anime aesthetics into a live-action film starring Western actors. In this case, attempts to be "authentic" to anime led to poor reception by critics who found it to be "too Japanese" and "childish." This recognition of Speed Racer's "Japanese-ness," indicates a particular type of "Japanese-ness" within anime's aesthetics. Nye (1990) referred to the Japanese production of such multi-media as an attempt at producing and distributing "soft power" - distinguished from traditional structures of power that influences the minds of international enthusiasts to form a favorable opinion about Japan and Japanese culture. Daliot-Bul (2009) argues that this "soft power" operates as a useful lens through which to view Japan's postmodern production of culture in the face of globalization. Scholars have noted the significance, success, and resonance of the stories and themes published by the most popular anime production company in Japan, Studio Ghibli, as well as its creator, Miyazaki Hayao (Boyd \& Nishimura, 2004; Darling-Wolf, 2016; Denison, 2015; Hagiwara, 2006; Napier, 2005b; Wu, 2016). As the most famous anime director in, and from, Japan, Miyazaki has created films, such as the Academy Award-winning Spirited Away, to which the 
Japanese animation industry owes much of its international popularity (Denison, 2015; Napier, 2005b; McKevitt, 2010). Denison (2015) goes as far to say that Miyazaki's films, particularly that of Spirited Away, are "canonical film text[s]" in the analyses of anime and its global popularity (p. 11).

Anime has significant cultural importance to Japan and Japanese culture. Rooted in historical caricatures and co-dependent with the comic book industry, it is an emblematic representation of Japan's modernization in the $20^{\text {th }}$ century. Programs such as Pokémon carry with them traces of cultural specificity based on the production, marketing, regulation, and distribution choices that creators make in order to both literally and figuratively sell these programs to multiple different audiences. Largely produced within the Japanese cultural context, Pokémon has gained enormous popularity both domestically as a recognizable cultural anime and internationally as a cartoon. This project seeks to determine whether there is any ambiguity distinguishing Pokémon across the blurry boundaries of a "Japanese anime" and a "cartoon" that exists merely as animation without definite cultural baggage.

\section{Pokémon}

Pokémon exists as a rare example of a Japanese anime that continues to maintain popularity through its domestic and international broadcast which largely retains the same narrative and characters it has established at its conception. Focusing on one continually broadcast text such as Pokémon allows us to examine more simply how the cultural odor of a program is managed over an extended period of time without muddying the waters with mediating factors. Furthermore, its consistent popularity both as a transmedia franchise as well as an anime alone provides an interesting example of how certain programs may find success outside of their originating culture through the management of this "odor." 


\section{History of Pokémon}

"Pokémon" - referring to both the multimedia franchise as well as the fantastical creatures comprising its narrative - is derived as an Anglicized portmanteau from its original Japanese title "Pocket Monsters" (Patten, 2004). The Pokémon franchise first began as a video game in Japan in 1996, then was adapted into a manga in the summer of that year, which after popular acclaim led to the release of a trading card game and the airing of the anime in spring 1997 in Japan and then a feature theatrical film in 1998 (Bainbridge, 2014a; Iwabuchi, 2004;

O'Hagan, 2006). In September of 1998, the North American release of the first generation of the Pokémon games (Pokémon Red Version \& Pokémon Blue Version) coincided with the first broadcast of the anime in the United States (Bainbridge, 2014b; Nintendo Press Release, 1998; Iwabuchi, 2004). Iwabuchi (2004) states that the marketing of the franchise in countries outside of Japan consisted of a subtle "packaged amalgamation of cartoons, comics, trading cards, feature films, character merchandise, and Game Boy games" that coalesced in a transmedia enterprise that reinforced each other's reception in these countries (p. 64). Rather than a staggered release of each medium, The Pokémon Company (TPC) and Nintendo released the anime, the trading card game, and the first video games along with character merchandise within several months of each other in 1998. Iwabuchi (2004) notes that Nintendo of America (NOA) was hesitant in marketing Pokémon in the United States as they were not confident that the game would appeal to children.

Because of this hesitance, NOA "facilitated the creation of a global Pokémon supersystem" as they thought that presenting the "Pokémon Game Boy cartridges at the same time as the television show, comics, trading cards, films, and character merchandise" would better appeal the franchise to children in markets around the world (p. 66). After its first year released 
internationally, the franchise produced almost the equivalent of the entire United States' video games industries' profits at \$5 billion (Buckingham \& Sefton-Green, 2004, p. 13). Patten (2004) notes Pokémon: The First Movie's popular reception within the US in 1998, acknowledging its $\$ 50$ million earnings in the first five days of its release.

According to Tobin (2004), “At Pokémon's height of popularity, Nintendo executives were optimistic that they had a product, like Barbie and Legos, that would sell forever, and that, like Mickey Mouse and Donald Duck, would become enduring icons worldwide (p. 3)." Although the franchise is not as popular as it was at its peak, it still maintains consistently high sales. As of June, 2018, the Pokémon franchise has earned an estimated $\$ 59.1$ billion worldwide since its creation in 1996, making it the highest-grossing franchise ever (Peters, 2018).

Iwabuchi (2004) purports that the exceptional success of Pokémon is due to the localization strategies employed by the co-operation between producers and distributors of the Japanese and American media industries. He further argues that Pokémon's success exemplifies the transnational acceptance of Japanese video games and anime and can help triangulate "emerging trends in the global circulation of characters, culture, and products" (p. 63). Tsunekazu Ishihara, President and CEO of The Pokémon Company (TPC), (quoted in Kelts, 2007) states that when they conducted market research into American demographics to localize the franchise, TPC “decided to introduce Japanese-designed characters without any modifications, which in fact captivated American children" (p. 93). What "Japanese-designed characters" means here is ambiguous, though it can be comfortably taken literally that Japanese character designers created the characters without outside input. As noted above, however, the phrase "Japanese-designed" characters does not necessarily imply "Japanese-looking" characters 
insofar as anime's cultural odorless aesthetic is concerned. In this case, market research found that American children enjoyed the "anime style" rather than recognizably "Japanese" aesthetics.

As Pokémon encapsulates anime's growth outside of Japan (McKevitt, 2010), Tobin (2004b) states that Pokémon is Japan's "most successful entry...in the business of globally marketing a global product" and it that "is/was not just any globally circulating children's product - it is a product from Japan," (Tobin, 2004b, p. 257). The popularity of Pokémon games and merchandise suggests that the success of the franchise stretches beyond its anime. Drazen (2003) argues that the anime was partially successful due to its ability to appeal to both boys and girls. Bainbridge (2014a) notes that the kawaii (cute) Pokémon appealed to girls while tsuyoi (strong) Pokémon appealed to boys. Iwabuchi (2004) notes that Pokémon appeals to gendered cultural notions of "cuteness" and "coolness," permitting people to identify with favored characters according to personal tastes. He argues that these notions of "cute" and "cool" are not "fixed at the sights of production of texts and characters, but at the sites of their consumption," meaning that Japanese "cute" characters can be "cool" to Americans (p. 71). Here, alternate interpretations of the franchise are informed by cultural norms at the modes of consumption.

Per Iwabuchi (2004), "The translation of Japanese cartoons and feature films generally is under the control of Americans. The American film producers...made significant changes to the TV series and the films" (p. 69). Many scholars agree that the "aggressive localization" of Pokémon led to its unprecedented success abroad (Iwabuchi, 2004; Katsuno \& Maret, 2004; Kubo, 2000;). Furthermore, Bainbridge (2014b) argues that Pokémon, and its localization, acted as an "on-switch" for more anime to be distributed internationally. Sapach (2017) further asserts that the Pokémon series is successful "due to the multiple forms of media that are used to weave together the stories of the various creatures" (p. 59). 


\section{Pokémon as Transmedia}

Pokémon's multidimensionality through various media and products keeps the franchise relevant and marketable to both old and new audiences (Tobin, 2004, p. 10). As "one of the bestknown examples of transmedia storytelling youth media today," Pokémon is consistently releasing new products in each of its various media (anime, videogames, trading cards, etc., etc.) (Bainbridge, 2014b). Condry (2011) argues that the confluence of multiple media under an overarching narrative umbrella resulted in the "explosion of interest" in the Pokémon franchise and the characters therein in the late 1990s and early 2000s (p. 72).

As a franchise that initially began as a videogame, Pokémon's "world" has been established on the foundation of the logics found within its videogame series. Ferreira \& Fernandez (2014) hypothesize that the prevalence of certain "game universes" in pop culture is due to audiences who immerse themselves and inhabit these worlds. They argue that "it is necessary to set strategies that meet their expectations and that allow them to somehow interact with the franchise, to have a closer relationship with the storyworld [sic]" in order to build a produce and distribute a successful transmedial story. (p. 9). Pokémon, then, established a "storyworld" founded upon the immersive potential of the characters, setting, and stories within these games and then applied these logics to its other media to retain its immersive features thereby providing an easy avenue of transposition between these media for the audience.

O'Hagan (2006) argues that when examining anime, manga, and video games, "there is a certain insight to be gained by observing them side by side as versatile media content" (p. 243). O'Hagan points to these media's close commercial relationship as justification to their joint consideration. As Pokémon premiered simultaneously in the United States as videogames and anime in 1998, the distinction between each medium as separate is difficult to explicate. 
However, as the video game and anime experienced differing level of localizations, the anime provides a broader opportunity for examination as it potentially contains multiple instances of visual representations of cultural specificity that the technologically-limited Gameboy game could not adequately portray.

\section{Pokémon as a Social Phenomenon}

Much like other franchises, the Pokémon franchise's media attempt to foster fan investment toward the "world" that they co-create. Scholars have noted that this occurs through several ways. For instance, Bainbridge (2014a) purports that the main character, Ash (Satoshi in Japan), "loosely modeled on the [protagonist] character Red from the games" is a stand-in for the consumer of the Pokémon franchise (p. 403). Per Buckingham \& Sefton-Green (2004), "Ash and his friends (and by extension the players of the game) have to nurture and 'train' the Pokémon they capture in order to succeed." (p. 21). Here, players are encouraged to identify with the video game protagonist persona, but also with anime-character "Ash" as a method of immersion into the Pokémon world. Furthermore, Sapach (2017) argues that the variety of Pokémon as well as their unique "cool" or "cute" aesthetics enable children to identify favorite creatures. In both the anime and the videogame, then, the audience is invited to immerse themselves within the narrative through identification with the protagonist who goes on an adventure to collect and befriend as many Pokémon as possible. As avatars for the audience, both Ash and Red fulfill the fantasies of acquisition, expertise, and social fulfillment.

Buckingham \& Sefton-Green (2003) state that the Pokémon franchise is "something you do, not just something you watch or 'consume"” (p. 12). Per Patrickson \& Young (2013) "The core text in this instance was not, in fact, an anime, or manga series, but a Nintendo Gameboy game" (p. 9). Here, the video game was the primary text which reiterated across multiple other 
media and merchandise. Children could follow along with the anime by playing the game, collecting the cards and figures, and wearing the characters on their clothing.

Collection, acquisition, and trade have been examined by scholars as activities that promotes a positive self-image (McIntosh \& Schmeichel, 2004) and as a way of expressing "connoisseurship" or expertise about a hobby (Straw, 1997). Straw further notes that "a familiarity with the symbolic universe of science-fiction is a long-term necessity for a subcultural career within fandom" (p. 9). Pokémon exists partially in this genre as it contains some common elements of science-fiction stories including, but not limited to the aliens, genetic cloning, and the miniaturization and digitization of creatures for storage within computers. Information about a fandom - a metaphysical "object" - must be collected in order to maintain an identity within the given narrative universe. Furthermore, Straw (1997) argues that "to collect the obscure is to refuse the mainstream." Insofar as the Pokémon franchise is concerned, the acquisition of extra-cultural knowledge about the Japanese franchise presents a form of resistance toward the "usual" forms of cartoons and videogames with which American culture was familiar (p. 11). Grossberg (1984) conceptualizes "excorporation" - in relation to rock and roll music - as the processes 'operating at and reproducing the boundary between youth culture and the dominant culture' (p. 231). Applied to the acquisition of digital creatures, physical trading cards, and expertise about a narrative world, fans of the Pokémon franchise produce an alternate "dominant culture" through the consumption and reproduction of an "obscure" youth culture that was distributed and localized from Japan. Here, the Pokémon franchise began as a niche foreign product targeted primarily toward children but quickly grew to an international phenomenon that people of all ages could enjoy. In this way, Pokémon became a commonly accepted part of U.S. culture, though it is still perceived to be "geeky" and for children. As Straw 
(1997) argues, "To collect is to valorize the obscure," and when children continually acquire each of these parts and parcels of the Pokémon franchise, they reproduce a cultural fascination with the exotic "Other" of Japanese cultural products (p. 12). Per Baudrillard (1994), "For the child, collecting represents the most rudimentary way to exercise control over the outer world: by layering things out, grouping them, handling them" (p. 9). The collection of data, goods, and information is a tempting way for children to acquire and exercise power within their lives in relation to their social worlds.

Sapach (2017) argues that videogame creature collection promotes enhanced immersion within game worlds and facilitates investment with the franchise. The collection of unique "cute" or "cool" creatures that are "useful" within a game that are also able to be categorized and classified in comparison to other creatures develops a form of expertise for the player, giving them insider insight into how the world functions. Jenkins (2006) argues that this expertise of knowing something their friends do not allows them to share information, further promoting investment in the franchise as they feel good about feeling knowledgeable about something. There is no one text where one can go to get the information about these various species; rather, the child assembles what they know about the Pokémon from various media with the result that each child knows something his or her friends do not and thus has a chance to share this expertise with others. (p. 132).

Here, the Pokémon's producers intentionally built investment into the franchise through the mechanics of acquisition of, and expertise in, the Pokémon world.

Bainbridge (2014a) examines Pokémon's relationship with environmentalism and Japan's relationship with the natural world. He notes the insect collecting hobby of Taji - the creator of Pokémon -as instrumental in developing the stories and themes of the Pokémon franchise's 
world. Identifying the "insect aesthetic" as a part of the "heart of Japanese culture," and as influential on many anime and manga artists such as Hayao Miyazaki and Osamu Tezuka, Bainbridge connects this aesthetic as an inherent aspect of "Japanese-ness" in the creation of cultural products (p. 402). Drazen (2003) notes the Japanese hobby of insect hunting, collecting, and battling extends hundreds of years in the rural countryside of Japan and connects this to the Japanese virtual pets of Tamagotchi (from tamago, meaning egg) that in turn, influenced Satoshi Tajiri to create Pokémon. The hunt for and acquisition of insects as well as the bartering of information and skills related to this hobby are perceptibly apparent in Pokémon's transmedia as these aspects of collecting, categorizing, and trading are inherently related not only to the video game's story world, but also to knowledge of the trading card game and meta-knowledge of the franchise in general. Part of Pokémon's appeal for children, then, is not only as an entertainment product filled with cute and cool characters, but its potential to give them agency as an "instructor" who can tell others what they know about the series and its characters (Bromley, 2004). Allison (2006) notes that travel and adventure - through the "hunt" for Pokémon and information related to the creatures - is the "organizing trope" that promotes investment in growth and acquisition within the franchise with the end goal of becoming a "Pokémon Master" who has collected all of the Pokémon creatures within the video games, and implicitly, has watched as much of the anime as possible (p. 196).

Allison (2006) notes Tajiri's hobby as emblematic of "interactions with both nature (exploration, adventure, observation, gathering) and society (exchanges and information-sharing with other kids)" and relates it to Pokémon's transmedia narrative wherein these interactions are representated (p. 201). Bainbridge (2014a) further purports a "story engine" that encourages consumers to identify with main characters of each medium and to "travel" with them on their 
journeys to collect, befriend, and experience adventures with a wide variety of creatures. He argues that while western franchises have encouraged the capitalistic mode of collection, "Pokémon was one of the first franchises to make acquisition a central part of its narrative; those who acquire a full set of Pokémon also acquire the title of Master Pokémon Trainer" (p. 404). Allison (2006) purports "Pokémon capitalism" wherein the Pokémon "double as gifts and companions" as both "things" that can be achieved and traded and friends that consumers can develop a familial attachment toward (p. 197).

The social aspect of Pokémon was further structurally sanctioned and extended in 2016 with the release of Pokémon $G O$, an augmented reality game that involved physical exercise to find and catch Pokémon as well as compete with other player factions for simulated control over real-world territories (Loveday \& Burgess, 2017; Tang, 2018; Zsila et al., 2018). As the most popular mobile game in the United States (Makuch, 2016), one that was downloaded over 100 million times in the first weekend of its release (Perez, 2016), Pokémon GO clearly indicates the Pokémon franchise's continued success 20 years after its inception. Additionally, in November of 2018, Pokémon games entitled Pokémon Let's Go Pikachu! and Pokémon Let's Go Eevee!' will be released on the Nintendo Switch. Young audiences who are relatively unfamiliar with the franchise may therefore be introduced to the franchise through re-made iterations of the first generation of the Pokémon video games on a modern platform that allows players to play games on-the-go as a mobile device as well on the television as a traditional videogame console game. Furthermore, the Pokémon videogame franchise has been co-opted and remixed by fans online as a hyper-social experiment (known colloquially as "Twitch Plays Pokémon") wherein upwards of 60,000 people cooperate to play the same game file through simultaneous rapid input suggestions to attempt the beat the game on a videogame streaming website (Ramirez, 
Saucerman, \& Dietmeier, 2014). In this way, individuals have continually found new ways to reengage with the franchise and with other fans of the series.

Bainbridge (2014a) acknowledges a reading of the Pokémon films that purports a "symbiosis" between its human and Pokémon characters. This symbiosis encourages further attachment to the collection of Pokémon and Pokémon-related merchandise consumers acquire during the course of their investment with the franchise. Per Baudrillard (1994), "Any object may be said to float midway between a practical specification or function.... and its absorption within a collection or set" (p. 14). In the digital realm, however, Allison (2006) argues objects can be practical, decorative, and indicative of an individual's expertise. Bainbridge (2014a) notes that this capitalistic theme is furthered by Pokémon's mode of acquisition: "Pokémon are 'got' in a spherical pokéball modelled after the Japanes [sic] gashapon balls that can be bought in machines, usually containing some small toy or mass-produced 'collectible"' (Bainbridge, 2014, p. 404). Here, the commodity-Pokémon are tied to Japanese culture through the articulation of gashapon represented within the franchise.

\section{Pokémon as Japanese}

Bainbridge (2014b) further argues that "Pokémon are active things that encourage some sort of investment on the part of the audience, not just time and money, but activities around collecting, battling, evolving and learning aspects of the Pokémon and their world.” (p. 4). Here, Pokémon permits its audience to improve their own social status through the proxy of digital characters and their evolution as well as within the physical world through the increase in expertise and social capital that comes with acquired knowledge and proficiency when playing, watching, and collecting the various media associated with the franchise. Bainbridge (2014b) argues that this performative function invites "consumers to interact and engage with other 
elements of Japanese popular culture too" (p. 5). According to him, Pokémon embodies matrices of knowledges, combining "Japanese mythology, pure imagination and occasional real-world locations)" into a hybridized world with hybridized characters (p. 5). Furthermore, as many Pokémon are based on real-world animals, they become "familiar yet strange" or uncanny in their proximity to the audience's own understanding of the real-world. This carries with it the amalgamation of cultural hybridization as well due to anime's characteristic "odorless" ethnicity.

Iwabuchi (2004a) asserts that it is difficult to ascertain Pokémon's "Japanese-ness" as a globalized product constructed, at least in part, with global audiences in mind (p. 61). However, Pokémon's connection with Japanese culture has been noted by several authors. Katsuno and Maret (2004), for example, conclude that a reason for the franchise's success is due to its ability to be localized into various contexts through selective editing of cultural themes and imagery. They assert that as Pokémon is "embedded" in the cultural medium of anime, it preserves "a certain Japanese aesthetic and cultural odor" (p. 104). Drazen (2003) relates the Japanese notion of "the gentle, compassionate spirit known as yasashisa" as being present within the anime alongside teamwork, and persistence in the face of adversity (p. 12). Several authors have connected Pokémon creatures to the Japanese yokai folklore (Allison, 2006; Bainbridge, 2014b; Foster, 2008). Bainbridge (2014b) notes that "Pokémon are monsters in the yokai tradition (Japanese folkloric monsters and supernatural beings but more often used to describe any supernatural or unaccountable phenomena)" (p. 8). He points to the characters of "Ninetales" - a nine-tailed fox creature - as exemplary of this yokai connection. Here, he notes that Ninetales is directly based on the myth of the Japanese kyūbi no kitsune (nine-tailed fox). Bainbridge further notes a long tradition of the "kawaii culture" of Japan since the 1970s utilizing yokai folkloric inspiration in its entertainment apparatuses (p. 8). Allison (2006) argues: "Folded into a tale 
about imaginary beings ... is an ideological one about Japan's place in the world, tallied on the basis of a science devoted to playthings: a commentary on Japan's rise to global prominence as producer of (“evolved”) kids' goods" (p. 208). In this case, yokai are ideologically tied into Japan's cultural "face" as means of producing transmedia entertainment inspired by its traditional folklore and customs. Bainbridge (2014a) further connects this symbiosis to the natural world of the Shinto religion - inherently advancing the connection of a subtle Japaneseness within the franchise.

Sørensen (2008) notes that many of Japan's most popular anime contains elements of Shintoist folklore and native animism. He points to the works of Miyazaki that often contain representations of kami (divine, natural forces that are equivocated as "gods"), and yokai (demons, ghosts, supernatural entities, and other cryptozoological folkloric creatures). Sørensen correlates Shintoism and its related concepts to be synonymous with Japanese-ness As a major indigenous religion that has informed much of Japanese culture and history. Sørensen further notes physical representations of Shintoism in objects such as torii shrines and gohei purification rods in Miyazaki's film Tonari no Totoro (My Neighbor Totoro) which are objects deeply embedded in the Shintoist tradition. While a domestic Japanese audience would recognize - and connect with - these symbols, these objects may not culturally resonate with international audiences, potentially leading to an interpretation of the film's setting as "strange," or "exotic" in nature. Sørensen (2008) notes that, while there are "layers of meaning" of the film that are "not readily accessible to viewers who are uninformed on the Japanese background, there are other layers that lend themselves to universal fascination and meaning construal without hindrance" (p. 192). He notes, for example, feelings of nostalgia, childlike-wonder, family and the home, and 
adventure as universally recognized and appreciated emotions that continue to resonate amongst people around the world.

From its connection to yokai folklore and Shinto tradition, Pokémon contains subtle elements that are not easily extricated or localized for non-Japanese audiences. While its domestic audience may appreciate these references, and identify with their cultural specificity, international consumers may find them alien. Alternatively, they may equate these "quirky" elements as merely fantastic in nature and without cultural specificity if they do not have the prerequisite knowledge concerning their association with Japanese culture. For its primarily preadolescent audience, this lack of knowledge potentially leads to widely differing readings of Pokémon's cultural roots between its audiences in the United States and Japan.

Per Patrickson \& Young (2013), Pokémon represents Japan's participatory consumer culture as a "flagship" franchise that introduced children around the world to anime - and consequently the media mix wherein multiple media constitute a franchise's ecosystem. Bainbridge (2014b) argues that a close "relationship with a mass-produced imaginary is what constitutes Pokémon's social network, connecting both Pokémon's creators and its audience [...] to the national imagination of Japan itself" (emphasis in the original) (p. 3). Every aspect of the franchise, then, acts as an entry point to a social network that extends around the world and stems from the creative imagination of Japan.

However, some scholars have noted Pokémon's producers' tendency to downplay the obviously "Japanese" aspects of the franchise. Iwabuchi (2004a) notes that the decision to mask Pokémon's "Japanese-ness" was a mutual conclusion reached by its Japanese producers and American distributors. These structural forces attempted to negate cultural specificity for the franchise, bringing a mukokuseki (stateless) nature to the Pokémon "world." Iwabuchi (2004) 
translates and cites Kubo Masakazu's (2000) explanation that the "setting of the adventure explored by Satoshi and Pikachu looks mukokuseki and religion-free. It appeared easy to produce international versions by erasing Japanese language signs as much as possible” (Iwabuchi, 2004a, p. 68). As this setting was conceptualized relatively free from signifiers of "Japaneseness," it allowed producers to easily translate and localize the franchise for global audiences. Furthermore, Iwabuchi (2004a) argues that "images and commodities tend to lose their cultural odor as their original meanings and purposes are recreated by processes of local appropriation and negotiation" (p. 73). This suggests that the embedded "Japanese-ness" of the Pokémon franchise was lost along the way as it was distributed internationally.

Bainbridge (2014a) acknowledges an "abstracted strangeness" of the Pokémon world in which consumers relate their real world to that of the fantasy world where Pokémon exists (p. 408). Allison (2000) found that children from both the United States and Japan enjoy the stories that "are the ones in which they can see or feel something of themselves - by identifying, for example, with a lead character" and contains the possibility of "transport[ing] them to another world - a fantasy or dream world" (p. 84-85). Here, the "Japanese" cultural odor of the product takes a backseat to the potential for identification and immersion within the franchise's world. If children can find something to grab on to - and relate to something familiar in franchises - then it opens up an avenue for exploration into another "world" that is different than their own.

Furthermore, Condry (2009) argues that as anime is connected to larger cultural contexts, "the world-settings of anime and contemporary worlds in which we live are necessarily connected, through language, imagery, symbolism, to larger cultural forums" (p. 27). Pokémon therefore, through its products, connects people to the Japanese cultural forum. Kelts (2007) refers to the fascination with Pokémon as a "third wave of Japanophilia" that accentuates the 
exoticness of Japan's consumer culture. Bainbridge (2014b) argues that Pikachu and other Pokémon have "become iconic totems of Japanese culture just as sumo, sushi, bushido samurai and ikebana [flower arrangement] have been before them" as emblematic of the twenty-first century Japanese entertainment and consumption apparatuses (p. 6). Kelts (2007) refers to the Pokémon franchises as a "Rosetta stone for the Japanese anime industry: a critical translation device that unlocked for Americans and Europeans an entirely new language of entertainment" (p. 89-90). As children had been watching cartoons and playing with trading cards decades beforehand, Kelts argues that Pokémon slid into American culture on the backs of these culturally-acceptable past-times, and the anime was the "Japanizer" that transformed these hobbies into a cross-cultural foray. Kelts (2007) argues that Pokémon brought Japan to the United States in the following ways:

First, it familiarized kids with the aesthetic form of Japanese anime... [it introduced] the week-toweek plot development of new Pokémon characters - a process that was perfectly synchronized with the toy merchandising apparatus...[and] giving Americans a sense of anime's undying saga - a concept that makes the perpetual marketing of toys inevitable (p. $90-91)$.

Here, the capitalistic elements of acquisition were conflated with a sense of discovery to keep children invested in the franchise as a "cartoon" with a unique aesthetic and an eternal story that due to the endless opportunity for merchandising. This is exemplified by the fact that although Pokémon began with 151 Pokémon under its umbrella, there now exists almost 900 creatures. 


\section{Conclusion}

Rooted in the processes of globalization and localization and influenced by orientalist perceptions in its export, anime has taken an unusual path to global saturation. Since anime is a product ingrained in and with Japanese cultural tradition, its popularity around the world seems odd at first glance. However, the spread of anime - and consequently Pokémon - from Japan to the rest of the world did not occur from out of thin air, but has had a long and complex history of Japanese producers and foreign distributors finding ways to negotiate the medium's entrance into new markets. In his book Japanameria: How Japanese Pop Culture has Invaded the U.S., Roland Kelts (2006) notes that Frederik Schodt, one such American distributor felt the need to essentially re-make one of the first anime series that gained widespread popularity in America (Battle of the Planets) from the ground up. Schodt recalls, "We had the cartoons themselves and the Japanese scripts and we totally redid the whole series. We did new music, new scenes - we even invented a new character that looked like R2-D2" (Kelts, 2007, p. 13 - 14).

Here, Schodt recalls being influenced by Star Wars' success in United States and therefore thought Battle of the Planets' high-tech, sci-fi atmosphere would do well in the United States because of George Lucas' smash-hit. Therefore, the beginnings of anime's journey to the west were partially influenced by western entertainment. Because this series was similar enough to western tastes, it therefore held the potential to be further edited to align even more closely with American audiences' fascination with science fiction adventure stories. This was not the first time that anime had been edited for consumption by audiences in the United States (the shows Astro Boy and Speed Racer having been introduced years before to local syndication networks), but it marks itself as an example where American distributors identified generic 
market preferences and imported a Japanese product that could easily be tailored according to these preferences.

Since then, many other anime programs have come and gone on American television channels after having received similar treatment by its distributors. However, one anime - the media phenomenon Pokémon - continues to be produced, translated, and broadcast today on American television. This project explores the reasons for its continued success, particularly the methods through which its producers and distributors managed to balance its Japanese "cultural odor" so that audiences in the United States would be more amenable to its narrative content. By examining how these producers and distributors managed, and continue to manage, its cultural specificity for foreign audiences, this project discovers whether audiences can "see through" this management, whether the remaining Japanese cultural elements can "teach" new audiences about Japanese culture, and whether these techniques could be applied to other cultural products so as to facilitate intercultural awareness in the age of rapidly expanding processes of globalization. 


\section{CHAPTER III: METHODS}

\section{Background of Anime's Broadcast in the United States}

Iwabuchi (2002c) identifies three phases of anime's entry into the United States. The first, beginning in the 1960s, included the broadcast of dubbed anime such as Astro Boy dubbed in English in locally syndicated markets. The second phase in the 1980s began the active localization of anime for American tastes as far as rewriting stories, changing music, and censoring "unsuitable" content is concerned. The third, most recent phase began what Iwabuchi states "Experimental American-Japanese collaborations in anime productions" (p. 61). While these phases are useful metrics to quantify the "periods" in anime localization in the U.S., it simplifies the process to the point where each phase's influence upon each other is ignored. For instance, without sustained niche fandoms who circulated VHS and Betamax tapes of the anime of the 1970s at comic conventions (Anime News Network, 2018; Ladd \& Deneroff, 2009), the second phase may never have come about. Additionally, without this second phase's attention toward catering content to a U.S. audience's tastes, the collaboration of TPC with 4Kids Entertainment may not have been achieved either.

In 1963, Fred Ladd, then an executive of distribution for NBC, took on the task of adapting Astro Boy to U.S. markets for distribution for syndication in independent television stations. He saw potential in the titular robotic Astro Boy as a Pinocchio-like character that could sell in the United States. This similarity to the puppet-boy therefore led to the introduction of anime to the U.S. in the early 1960s (Ladd \& Deneroff, 2009).

In 1977, Fred Patten and other writers who were fans of anime created the Cartoon/Fantasy Organization (C/FO) that, as Ladd and Deneroff (2009) state, may have been "the first organized fan club for anime in the United States" (p. 163). Furthermore, they 
emphasize that the anime community in Japan took note of the burgeoning fandom in the U.S. and note that prolific anime and manga artists such as Osamu Tezuka began to make speaking appearances at conferences the C/FO organized across the U.S.

The international spread of anime therefore began with producers who identified cheap foreign animation they could air in local markets to pad out programming for children that then created fans who circulated these programs via bootleg VHS and Betamax tapes (Anime News Network, 2018; Ladd \& Deneroff, 2009). Therefore, the beginnings of anime's spread to the U.S. traced a route of globalization that exemplified the push-and-pull of media production. Producers "pushed" products to audiences and consumers who liked the anime that were introduced "pulled" further anime into the U.S. based on their demand. This route toward glocalization was mirrored in Pokémon's global rise to prominence. Initially created as a videogame in Japan, its domestic success led to further successful tie-ins including the anime series. However, unlike previous anime series, the Pokémon franchise (e.g. anime, games, trading cards) was mutually exported other countries as a whole transmedia ecosystem (Bainbridge, 2014b; Nintendo Press Release, 1998; Iwabuchi, 2004).

\section{Background of Pokemon's Broadcast}

First aired in Japan in 1997 and in the United States in 1998, the Pokémon anime continues to be broadcast around the world to this day, over twenty years later. The show has become a staple of children's television programming in Japan having aired over one thousand episodes in Japan and a similar number internationally - one caveat being that some episodes were banned in particular countries. Furthermore, twenty-one movies have stemmed from the anime's popularity with the most recent being Pocket Monsters the Movie: Everyone's Story, released in Japanese theaters in July of 2018 and slated for limited theatrical release 
internationally in November of 2018. The continued existence of the television show as well as the consistent film releases indicate Pokémon's lasting success as a media franchise.

In line with current conceptions of globalization and localization as series of processes constitutive of bi-directional connections between nations, cultures, corporations, and individuals (Crane, 2002; Steger, 2009), the history of Pokémon's production and distribution by various companies has not been a case of simply exporting a product from a central production point, but is formed by complex transnational flows. This complexity is exemplified by Pokémon's localization to countries outside of Japan. Iwabuchi (2002) notes Pokémon's "Americanisation of Japanisation" where he accentuates "the re-made-in-the-US version of Pokémon that has been exported to other parts of the world" (p. 458). The US distributors (4Kids Entertainment), therefore, were the gatekeepers toward the reception of Japanese cultural "odor" in these other countries.

Originally, 4Kids Entertainment localized the anime created by The Pokémon Company. From 1998 to 2006, 4Kids controlled the license to distribute the anime in countries outside of Japan. Here, 4Kids dubbed and edited the anime from its original Japanese version into English and subsequently sent it to other distribution companies in other countries to receive second-odor localization there as well. The licensing agreement between The Pokémon Company (TPC) and 4Kids expired in 2005, however, where The Pokémon Company International (a subsidiary of The Pokémon Company henceforth referred to as TPCi) then decided to bring the anime's dubbing in house where it currently is responsible for licensing the anime in countries outside of Asia (TPC itself manages the licensure for Japan and other Asian countries) (4Kids Entertainment, Inc., 1999; BusinessWire, 2005; Pokémon Company International, Inc., 2018). Furthermore, the rights to air Pokémon in the US have changed hands several times over the 
anime's history. Initially syndicated, the WB received exclusive rights to air it on its Kids WB programming block in 1999 (Anime News Network, 1999). It later aired on Cartoon Network and is currently is broadcasted in the US on Disney XD (Anime News Network, 2016).

This history suggests that the Pokémon anime's route to global saturation was not as straightforward as it seemed. As the "American" version of the anime was the one that was sent to other countries, it may be argued that they received even further "de-odorized" final products due to their own respective edits. Furthermore, the turbulence present in its distribution indicates that variation in the flows of Pokémon to other countries may have impacted the reception, and likely the representation, of Japanese culture in these cultures over the anime's broadcast history. Therefore, these factors of production and distribution by 4Kids Entertainment, TPC, and TPCi, likely affected how Japanese culture was represented in the Pokémon anime.

In this project, I conducted a textual analysis that examined Seasons One and Twenty of the Pokémon anime for evidence of cultural odor in its representation of particularly Japanese symbols. In doing so, I synthesized several themes concerning the management of cultural odor in the anime. For examples, the balance that TPC and 4Kids Entertainment struck in the first season of the anime, for example, gave the landscape and setting of the first season an "everywhere but nowhere" aesthetic. The appeal of this aesthetic presented an opportunity for the show to be read in different ways by domestic and international audiences.

\section{What Are Pokémon?}

"Pocket Monsters" - often referred to as the portmanteau "Pokémon" are creatures that vary incredibly according to their appearance, disposition, and abilities. These Pokémon are categorized by taxonomical "Type" that align with naturalistic elements (e.g., "Fire-Type," “Water-Type," and "Electric-Type” Pokémon) and their respective biological characteristics (e.g. 
"Bug-Type," "Flying-Type," and "Steel-Type" Pokémon). Pokémon have additional typestrengths and weaknesses that are strategically deployed by trainers to win battles. Furthermore, Pokémons' Types are usually dependent on their native habitat with their personalities and temperaments correlated to their Type. For instance, the Bug-Type hornet-Pokémon Beedrill live in swarms in the forest and are quick to anger. Furthermore, many of the Pokémon in the anime are complex characters with likes, dislikes, and emotions. The titular creatures are often the focus of each episode with many of the episode's particular problems caused, solved, or otherwise influenced by them. The multitude of Pokémon with different Types, habitats, and personalities give the anime a rich, complex, world for viewers to explore alongside Ash.

There exist distinctions between wild Pokémon as potentially dangerous creatures capable of serious injury and "domesticated" - or captured - Pokémon that are friendlier in nature. However, Pokémons' dispositions are not that dichotomous as many featured Pokémon run the gamut of dispositional characteristics including being portrayed, for example, as capricious, shy, obnoxious, gluttonous, or arrogant. Furthermore, the natures of these Pokémon are often key to the stories of the episode. As a key aspect of the overarching premise of the series, human characters' various interactions with Pokémon play the primary role in the narrative of each episode.

With different frames of reference with regards to cultural production and consumption, the individuals who receive messages interpret them from differing perspectives, influencing them to focus on some aspects and disregard others. This is significant when considered alongside the circuit of culture model, wherein cultural meaning manifests itself through the articulation of the production, consumption 
As this project sought to discover how the representation of Japanese culture was managed over the anime's broadcast history, its focus lies at the circuit of culture's site where representation is articulated in relation the node of production. In doing so, I implicate Pokémon's consumption of the represented identities as well as the identity of the anime as a Japanese product. What follows is a brief description of the Pokémon anime and its aesthetic qualities preceding a summary of the methods I used to analyze the anime and its cultural specificity from its initially broadcasted English episodes in 1998 to its most recent completed season in 2018.

\section{Description of the First Season's Setting}

The first season of Pokémon is set in the fictional province of Kanto, an idyllic and natural country interspersed with various locales including sprawling cities, rural towns, secret nature reserves, and an assortment of other areas based loosely on locations found within the videogame series. The story begins in rural Pallet Town, the hometown of the main character ten-year-old Ash Ketchum - as he sets out on his journey to become a Pokémon Master, one who has caught, collected, and befriended all known "Pokémon" - strange creatures who live natively in the wilderness and vary incredibly in shape, size, appearance, and ability.

During his journey, Ash travels alongside several companions and pas they explore Kanto in a semi-serialized episodic format where each episode operates as a stand-alone adventure in which Ash and the others solve a mystery, assist other characters, thwart the evil Team Rocket, or otherwise overcome a particular "problem" in the episode. However, the first season of the series is informed by Ash's overarching goals to become a Pokémon Master by capturing Pokémon and becoming the Indigo Pokémon League champion by collecting all eight gym badges. These badges are obtained by defeating Pokémon "Gym Leaders" in "Pokémon 
Battles" wherein Pokémon are pitted against each other in an altercation to drive the opposing team's Pokémon into unconsciousness or otherwise into a situation wherein the team is unable to continue to battle. Furthermore, the defeat of these Gym Leaders serve as stepping stones to the Pokémon League as any trainer who wishes to challenge the League must collect all eight badges. Pokémon battles are one of the main identifiers of a Pokémon Trainer's capability and expertise (alongside competency in taking care of Pokémon among other things), Ash journeys not only to befriend Pokémon, but also to strengthen them through battle to become the Pokémon League champion. In each episode, Ash learns some sort of lesson in capturing, battling, or befriending Pokémon by overcoming the episodes' problems which contribute to his progress as a trainer attempting to become both a Pokémon Master and Pokémon League champion.

Over the course of the first season, Ash travels with his companions through towns, forests, mountains, and other locales, as they befriend Pokémon, battle trainers, and overcome problems as Ash collects gym badges to challenge the Pokémon League. Furthermore, Ash befriends the people who he helps along his journey - developing bonds with recurring characters and finding himself in comical situations in his attempts to solve their problems. While the overarching narrative remains semi-present in each episode, these episodes can, for the most part, be understood as stand-alone stories. Furthermore, only a passing familiarity with the show's characters and premise is necessary to understand the theme of the episode.

\section{First Season Character Summary}

While each episode of the series contains ancillary characters that serve primarily as catalysts for the narrative of the episode, there remains a primary cast of characters through which the audience follows the overarching story of the series. These characters consist of the protagonists - Ash, Pikachu, Misty, and Brock - whom the audience is encouraged to support 
and identify with and the antagonists - Team Rocket - who regularly appear in episodes as troublemakers. What follows is a brief summary of the main characters and their "position" within the story of the anime.

Ash Ketchum is a ten-year-old boy who dreams of becoming a Pokémon Master. In order to do this, he must capture all known Pokémon, collect all eight gym badges necessary to enter the Pokémon League Tournament, and defeat other challengers to become he Pokémon League champion. As a stubborn pre-adolescent, Ash is hot-headed in his approach to problem-solving which often gets him and his companions into trouble. Nevertheless, he is eager to make friends and to care for his Pokémon. Furthermore, he is enthusiastic when helping others with their problems - eager to prove his capability as Pokémon trainer and future-Pokémon Master.

Pikachu is Ash's first Pokémon, first traveling companion, and best friend. Furthermore, the mouse-like Pokémon is the mascot for the Pokémon anime as well as the Pokémon franchise as a whole. Alongside Ash, Pikachu is the only character to have appeared in every episode of the mainline Pokémon series thus far. Spritely and cute in nature, Pikachu is only able to "speak" by saying his own name, with Ash and his companions providing translated exposition for the viewer to understand his intentions.

Ash travels with Misty who is an eleven-year old Pokémon trainer specializing in WaterType Pokémon. Although she is temperamental, she is often a foil to Ash as a voice of reason with respect to his stubbornness. Although Misty is "tomboyish" in appearance and in temperament, she nevertheless appreciates cute things - particularly cute Pokémon.

Brock is the most "responsible" member of the first season's main characters. The oldest of the group at fifteen, he is the group's level-headed companion who dispenses useful advice concerning Pokémon strategy from his experience as a Gym Leader. Brock does, however, 
display traits of a hormonal teenager - providing recurring gags by flirting with every attractive woman that the group encounters.

Team Rocket are the primary recurring antagonists of the first season. Comprised of Jessy, James, and the Pokémon Meowth, their mission is to steal Pikachu away from Ash as they note that it is a particularly powerful and rare Pokémon. They receive this mission from the mysterious leader of Team Rocket as the Team's goal is to steal rare Pokémon from trainers around the world and profit by capitalizing off their rarity through a variety of purposes. Additionally, Team Rocket is often the cause of many of the episode's stories while Ash and company seek to resolve the situation and free the local people and Pokémon from Team Rocket's scheming. In the twentieth season, Team Rocket follows Ash to Alola in order to steal rare Pokémon for their mysterious leader.

\section{Description of the Twentieth Season's Setting}

In this season, Ash and Pikachu embark on another journey in an exotic region replete with new Pokémon, new friends, and new enemies to continue on his quest to become a Pokémon Master. In this region, Alola, Ash journeys through an archipelago comprised of four islands characterized by regional particularities including volcanos, beach resorts, dank forests, mountainous trails, and meadows filled with flowers. The central tropical atmosphere of Alola is contrasted to Kanto's expansive range of locations that vary extensively in nature and setting. Furthermore, Alola is populated by new Pokémon for Ash to discover, befriend, and catch on his journey. Several of these new Pokémon are regional versions of Kanto’s Pokémon, some of whom are explicitly stated to have migrated from Kanto and evolved in alternative ways to better suit the tropical climate. 
Originally arriving in Alola as a vacation from his quest, Ash decides to stay at the Pokémon School on Melemele Island and take the Island Challenge - this region's version of the Pokémon League - where he must challenge each island's "Kahuna" - or leader - to Pokémon challenges that include tests of bravery, intellectual contests, and - of course - Pokémon battle. At the Pokémon School, Ash studies to learn more about Pokémon and how to become a better Pokémon trainer while venturing off to the other islands episodically to get "hands on" experience as a trainer.

\section{Twentieth Season Character Summary}

In the twentieth season, Ash and Pikachu remain the main characters. However, Brock and Misty are absent for reasons left unsaid. Rather, a host of new characters join him on his Pokémon journey. These include Professor Kukui, Ash's instructor at the Pokémon School as well as several of his classmates; Lana, Lillie, Sophocles, Mallow, and Kiawe.

Lana is a short, blue-haired girl who likes fishing on the ocean and Water-Type Pokémon. Lillie is a pale, blonde girl who is, at first, deathly afraid of touching Pokémon. Mallow is a Grass-Type enthusiast who enjoys foraging in the nearby jungle for ingredients for new recipes and is daughter of the owner of the local café on Melemele Island. Sophocles is a technological genius with a knack of inventing gadgets and an affinity for Electric-Type

Pokémon and Kiawe is a tall, dark-skinned boy with a quick temper and penchant for partnering with Fire-Type Pokémon. As main characters, each of these characters are consistently present within season twenty of the anime

\section{Episode Analysis}

In this project, I analyzed episodes from two primary seasons of the Pokémon anime to determine if the producers and distributors of the series chose to use different approaches in 
maintaining, reducing, or increasing the "cultural odor" of the series. I chose the first season aired in the United States in 1998 and the most recent season aired in 2017/2018 as primary texts as comparative to see whether anything has changed in the twenty years since the series' original broadcast. As research has indicated that the aesthetic components of products and media contain within them cultural specificity - or "cultural odor" - that is either intentionally or unintentionally embedded within these products, I examined Pokémon to determine how cultural odor was initially managed during the height of its popularity as well as how it is managed currently.

\section{Japanese Content}

As a program developed within Japan. I assumed that there would be at least some underlying Japanese particularities associated with the aesthetics of the program. I took note on the visual, aural, and linguistic qualities of the episodes - particularly anything that I perceived as being associated with Japan or Japanese people or associated with perceptions of Japan or Japanese people. For example, references to Japanese cultural products such as food, games, traditional attire, and specific cultural practices were noted and considered constitutive of its cultural odor. Furthermore, I also noted instances where the show made reference to Japanese history, movies, television, or other assorted culture-specific media and knowledges to determine how Japanese producers of the show introduced cultural specificity to the show. As an avid fan of Japanese media, I recognize and understand many intertextual references and historical allusions to other Japanese stories, media, celebrities, and other assorted cultural products.

As I am familiar with both the Japanese and English versions of the first season, and was able to access both versions of the twentieth season, I watched the selected seasons in both languages, comparing the versions to each other whenever I suspected there were alterations 
made. Furthermore, names of characters were cross-referenced across episode translations between the Japanese and English versions for the purpose of determining whether differences in nominal attributes of human characters, locations, and Pokémon were present across the twenty years of the program's broadcast. As the language was translated for release of the show within the United States, I hypothesized that specific characters' names, as well as the names of Pokémon, cities, towns, and objects would be altered by distributors to better appeal to English speaking nomenclature conventions. Additionally, I examined whether this alteration continued over the course of the show's broadcast history with the maintained popularity of the franchise and the anime itself.

Implications for this study may suggest several things. If the amount of residual cultural "odor" has been reduced from season one to season twenty, it may suggest producers' and editors" intentions to continually "scrub" the anime from a particular culture in order to theoretically enhance its international appeal. If, however, the cultural "odor" is maintained as is or even increased, it may imply that the inherent "Japanese-ness" of the anime was recognized by producers as a vehicle that enabled Pokémon to become popular worldwide. In any case, the exposure to representations of Japanese culture are managed by both the producers and editors of the anime. Any of these ways could possibly influence viewers to perceive Japanese culture a certain way.

\section{Selection of Episodes}

To determine whether the management of its "cultural odor" has changed over the course of its English broadcast, I began my textual analysis with the first season of Pokémon as well as its most recent season. I began with watching ten episodes from each season as an exploratory analysis for patterns in "cultural odor" management. Here, I employed textual analysis in 
examining the first five episodes and the last five episodes of each season. I analyzed these texts in order to determine whether patterns existed in the management of Japanese-ness within each season. After this initial pattern analysis, I further examined three other episodes from each season to explore whether the patterns found were present in other episodes of the season as well. A complete list of episodes analyzed can be found in the appendix to this thesis.

\section{Conclusion}

This chapter has foregrounded the context of Pokémon, its character and settings in seasons one and twenty, and the methods used to analyze the episodes in each of these seasons with respect toward the management of cultural "odor." In the next chapter, I analyze the selected episodes through the lenses of cultural "odor" and orientalism that were theoretically established in chapter two, focusing on whether, and how, images of Japanese culture were represented in Seasons One and Twenty. Additionally, images of English and Japanese diegetic text (linguistic text found "in world") are noted. 


\section{CHAPTER IV: ANALYSIS}

\section{Background of Season One}

The geographic world of Pokémon consists of various terrestrial "regions" that serve as the physical settings of the anime across its twenty-year history. Rather than "countries," the anime producers instead employ "regional" terminology in order to dissociate the show from real-world ethnic and national distinctions. Each of these regions has different locales, climates, and other particularities that set them apart from each other. In the series, the mysterious animistic Pokémon, the rural mountainsides, the forests and towns, as well as the expansive cities combine to place the series within the context of a quasi-magical, idyllic land. The first season of Pokémon takes place in a region in an unspecified time period that combines advanced technology considered to be "futuristic" in 1998 as well as traditional, rural, and "natural" aesthetics.

Ash's journey begins in Pallet Town on the day he is to set out upon his adventure. The first episode begins with Ash's mother forcing him to go to bed to get a good night's sleep for the first day of his journey. Ash nevertheless wakes up late and misses the chance to choose a preferred "starter" Pokémon (i.e., Pokémon freely given to beginning trainers by Professor Oak to start their journey, as is the tradition for children embarking on their Pokémon quest in Pallet Town). The concept of "starter Pokémon" directly stems from the videogame's mechanics that give the player a free Pokémon with which to start the game's story. In both the Pokémon games and the anime, people use Pokémon to battle other Pokémon for the purpose of capturing and collecting them. In order to capture Pokémon, trainers must exhaust the wild Pokémon through battle to prevent its escape. After capture, trainers train these Pokémon to become stronger so as to defeat stronger Pokémon for further capture. Similarly, trainers also train Pokémon in order to 
defeat other trainers in battle to resolve conflicts, win prize money, or to have fun. In the videogames, players catch Pokémon to add to their collections and do battle with non-playablecharacters in order to become stronger so they can eventually defeat the Elite Four - the "bosses" of the game. Likewise, in the first season of the anime, Ash collects and trains Pokémon to enter the Pokémon League - a tournament equivalent of the game's Elite Four. This is but one instance where the anime and the videogames share common characteristics. While the scope of examining this commonality extends beyond that of this project, it is worth mentioning as a method of clarifying the texts' transmedia codependence.

Rather than receiving the "starter Pokémon" he wants, Ash instead receives the obstinate Pikachu (an Electric-Type mouse Pokémon and mascot for the Pokémon series) as a companion. As Pokémon tend to use abilities dependent on their Type, the quick-to-temper Pikachu often uses lightning techniques both in battle and to shock the people and Pokémon that anger it. At first stubborn and reluctant to travel with Ash - shocking the ten-year-old with its electric ability when it is particularly frustrated - Pikachu warms up to Ash after he saves its life from a flock of enraged Spearow (bird Pokémon).

As Ash embarks on his journey, he travels through various towns, cities, and villages in his quest to become a Pokémon Master. Along the way, he meets, and makes friends with, a variety of people and Pokémon that he helps as he solves (and sometimes causes) problems in each episode. On this journey, Ash and his new-found friends explore and learn more about Pokémon and the world they inhabit.

\section{The Management of Cultural "Odor"}

Essentially, the task of the producers and editors of the Pokémon anime was tailoring the first season to as broad of a base as possible while retaining cultural specificity to keep it 
relevant to the Japanese market. To do this, they had to balance several "types" of audience in mind. These theorized audiences emerged through the textual analysis of the patterns of cultural odor management that The Pokémon Company, The Pokémon Company International, and 4Kids Entertainment engaged with to appeal to as broad of a base as possible. The first, which the initial producers of the anime held in primary regard, was the Japanese audience who was familiar with all of the cultural images and their specificity present within the anime. This audience could clearly see - and therefore appreciate - that Pokémon was a Japanese product and therefore, they expected a specifically Japanese presence in "their" product.

Another audience "type" with which editors were concerned was that of non-Japanese anime fans who could recognize Pokémon as a Japanese anime, but also needed some translation and clarification as to the exposition of the episodes. While this audience liked anime, and were likely familiar with Japanese cultural symbolism, they nevertheless needed the anime translated so that they could understand the plot of each episode. Here, the attraction of Pokémon was its status as an anime and therefore editors needed to keep some aspects of Japanese-ness so that this audience would "buy into" the Pokémon world.

A third audience with which editors were concerned was that of younger non-Japanese audiences who liked cartoons but were unfamiliar with Japan and anime. To appeal to this group, editors needed to familiarize this audience through the use of English translations that simplified concepts and names so that they could understand the Pokémon world without becoming confused by foreign names, ideas, and cultural knowledge. In order to get this audience invested in the transmedia Pokémon franchise, editors needed to adapt and translate the Japanese-ness of the original product so that children could understand who the characters are, where the Pokémon world existed, and how the world operated. To do this, editors needed to translate, edit, 
and simplify a lot of things to achieve this goal. If any Japanese-ness could potentially "interfere" with a child's interpretation of the world, it needed to be translated or removed entirely so that this child would remain invested as an "expert" of the world. If children could not understand the plot, characters, or the action taking place, it is a reasonable assumption that they would tune-out and find something else that they could understand.

The challenge for producers and editors for this first season, then, was to make the anime globally marketable as a product that could appeal to each of these audiences simultaneously. For foreign audiences, they needed to appeal to children's ability to comprehend foreign products and foreign information, yet retain enough of the Japanese-ness to appeal to foreign anime fans. To do this, editors left in much of the Japanese-specific visual symbols indicative of Japanese cultural specificity, yet translated or outright removed much of the Japanese linguistic text present in episodes. By doing this, they were able to retain elements of "subtle" Japaneseness that anime fans familiar with some of these symbols could recognize but, because of the edits made to the episodes, children unfamiliar with Japanese culture could also comprehend. Therefore, in the creation and distribution of the first season of Pokémon, producers and editors had to carefully manage the Japanese cultural "odor" present in episodes in order to appeal to each of these audiences.

\section{Analysis of Episodes}

In this chapter, I identify instances where the Japanese-ness of Pokémon is represented as well as instances where this Japanese-ness has been scrubbed, or attempted to have been scrubbed, in order to strike that balance between a distinct cultural product and a marketable commodity that could appeal to people of other cultures as well. Having previously seen the Japanese versions of the episodes, I focused primarily on the US versions for my analysis of the 
management of Japanese "odor" in this program. How producers and editors managed the show's cultural "odor" in order to appeal to domestic Japanese audiences and to make it marketable to international audiences is reflected in the editing choices they made.

In the first episode of Pokémon's first season ("Pokémon - I Choose You!”), many themes concerning the management of Japanese cultural "odor" are presented that consistently reoccur throughout the first season. The Pokémon world's ambiguity as an "everywhere but nowhere" place is exemplified by this episode. Architecture and other assorted objects specific to Japanese culture are observable, for instance. However, there is no explicit connection between the inherent Japanese-ness of these objects and real-world Japanese culture. Instead, these objects are present as a part of the "Pokémon world" - a place intentionally displaced from any real-world culture.

Japanese diegetic text (linguistic text that is understood by viewers to be part of the Pokémon "world" and therefore visible to the anime characters themselves, as opposed to text such as subtitle translations that can be seen by the audience but is not visible to the characters) is also present within this episode as well. Furthermore, there are also instances where diegetic text is obviously edited and replaced by English text. Each of these, along with culture-specific references to folklore, the geographical landscape of the show, and the aesthetics of the anime itself, perform in conjunction to indicate a particular cultural "odor" of the show. However, editors of the show who retailored the program for English-speaking audiences attempted, in semi-consistent patterns of alteration, to reduce this odor via the removal of the diegetic text that directly informed the "Japanese-ness" of Pokémon for a Japanese audience. While translating the show, editors modified the show so that even minute instances of the Japanese language were painted over. What follows is an examination of these patterns of inclusion and exclusion of 
Japanese-ness. While editors attempted to scrub Pokémon of its cultural "odor," it nevertheless retained aspects of Japanese-ness. The balance struck between its cultural odorless-ness and its distinction as a Japanese anime program marked its unique accomplishment as a cultural commodity that found its way to worldwide dominance as a global phenomenon.

\section{Landscape}

The first season of Pokémon takes place in a region known as Kanto. "Kanto" refers directly to the Kantō region of Japan - the area on the main island of Honshu which houses Tokyo. Furthermore, the geography of both this region and the anime's Kanto are similar in size and shape. Particularly, the Chiba peninsula resembles that of (the Pokémon world) Kanto's Fuchsia City. The direct correlation of real-world Japanese locations to the fictionalized Pokémon world can be read in different ways by different audiences. Japanese children who were aware of the Kantō region in their own, real-world experience were able to connect the real-world Kantō to the fictionalized Kanto in the anime - grounding Pokémon in a familiar Japanese experience. However, English-speaking audiences - particularly children who were not cognizant of Japan's prefectural makeup - did not have this information available and therefore could not accomplish the same "grounding" as Japanese children could. So - to the Englishspeaking audience - Kanto (pronounced CAN-toe in the English version rather than the Japanese

pronunciation, KAHN-tohh) was perceived as a strange land divorced from Japanese relation and unfixed from real-world specificity.

However, in none of the episodes analyzed is the Kanto region directly shown. Rather, players of the videogame can access a Town Map item that allows them to view the region from above as a map that aligns with the real world Kantō - privileging the experience of the transmedia consumer. Nevertheless, English-speaking audiences with access to this Town Map 
may still not immediately recognize the similarity between the real world Kantō and its fictional counterpart. The Japanese viewers would have already been familiar with the regional specificity to Japan by name alone. Although it cannot be assumed that every player of the videogame watched the anime or vice versa, it is likely that Japanese viewers would feel more "connected" with the media franchise due to the regional specificity than U.S. audiences while these U.S. audiences would perceive this "CAN-toe" region as a strange, unfamiliar world inhabited by magical beasts rather than a Japanese regional simulacrum.

Kanto is comprised of a variety of locales - most ubiquitously the forests, mountains, and rural towns through which Ash journeys on an episodic basis. In most episodes, the forested mountains background Ash's adventures. These forested landscapes resemble the mountainous landscapes of rural Japan. As many of Japan's prefectures are located within the valleys between mountain ranges, these ranges are an omnipresent landscape for people living in this region. Satoshi Tajiri - the creator of Pokémon - grew up in rural Machida, Tokyo during a time when this location was still rural and surrounded by dense forests (The Ultimate Game Freak, 1999). According to Tajiri, he took inspiration for Pokémon from his hobby of catching bugs in these mountains and forests during his childhood - establishing Kanto's woodlands as a subtle Japanese backdrop to the first season as a whole. As even many of the most rural American children would be unfamiliar with the abundant forests and looming mountain ranges of Japan's topography, these landscapes could be interpreted as exotic and "adventurous" in relation to their own experiences.

Episodes One through Five of Season 1 all take place against the backdrop of these aforementioned forest mountains. Both Pallet Town and Viridian City lie in idyllic valleys nestled within mountain ranges. Viridian City's design resembles that of a rural Japanese town, 
while Pallet Town can hardly be considered a town at all, resembling a small village interspersed with wide fields and occasional trees. Pewter City, while equally rural and also backgrounded by a mountain range, is more expansive and city-like than both Pallet Town and Viridian City with taller buildings and a more sprawling town layout. These locales, then, closely resemble the mountains and valleys of rural Japan. This "rurality" is further represented throughout the season as only Episode Fifty-Two (“The Breeding Center's Secret") takes place within an actual (unspecified) city. This unspecified city is of ambiguous origin. The skyscrapers, alleyways, and cosmopolitan restaurants could be read as Tokyo, New York, or any other city with similarly urbanistic landscapes. Other episodes such as Episode Nineteen ("The Ghost of Maiden's Peak") and Episode Thirty-One ("The Ninja-Poké Showdown") take place in a rural coastal town and a meadow, respectively, each of these being similarly Japanese in referential nature to the aforementioned townscapes. Furthermore, Episode Twenty-Five, ("Primeape Goes Bananas") takes place on an ambiguous prairie.

There is therefore a consistent pattern to Kanto as a land existing primarily rurally in a "naturalistic" setting interspersed with cities and other "natural" locales. The emphasis on Ash exploring rural, mountain landscapes covered in forests not only facilitates a sense of naturalistic adventure, but closely matches the landscape of rural Japan. Aside from select sprawling metropolises such as Tokyo and Osaka, the majority of towns in Japan are located within mountain valleys and surrounded by forests. As such, these landscapes would be read as Japanese by Japanese people, but merely recognized as mountainous and forested by those unfamiliar with Japanese topography. Therefore, editors did not need to edit this Japanese-ness out of the show as it is not obviously related to the "Japanese experience." The Japanese landscape - because of its ambiguously cultural properties - went unaltered because non- 
Japanese viewers would not recognize it as Japanese. Rather, depending on the audience, the Japanese forested mountains are paradoxically both a signifier of Japanese culture and a culturally odorless landscape. This paradoxical attribute permits a non-Japanese audience to read these forest mountain ranges as natural, adventurous settings to be explored rather than a Japanese audience's familiar "backyard."

\section{Japanese-ness in Clothing, Architecture, and Food}

Within the Pokémon world, there exists clothing, food, and architecture of particularly Japanese specificity. In this fantastic, other-worldly setting, Japanese culture is represented in both the original Japanese version and in the US version of the anime through symbols emblematic of this culture. Furthermore, these objects are consistently represented throughout Season 1 of the anime. The consistency of each type of object varies in frequency and degree, but none of these are pointed out in diegesis as "Japanese" since the world of Pokémon and Kanto are set within a separate, yet similar world of their own - independent from familiar nation-states and cultures. The following section traces the pattern of occurrences of these Japanese objects as well as instances where Japanese cultural objects invite a "Japanese" reading of the program by the anime's domestic audience. Furthermore, this same "Japanese-ness" undergirds the "everywhere but nowhere" aspects of the Pokémon world, inviting international audiences to receive subtle representations of Japanese culture in conjunction with the fantastic representations of Pokémon. This conjunction conflates Japanese culture with a "Pokémon culture" thereby offering an avenue for learning aspects of Japanese culture through the learning of Pokémon culture.

Clothing. In the first season, most of the characters wear clothes of Western origin (e.g. Ash's blue jeans, Misty's short-shorts and suspenders). However, there are frequent occurrences 
where Japanese traditional clothing is represented. Beginning in the first episode, brief and subtle examples of Japanese-specific cultural clothing are shown. For instance, in the first episode ("I Choose You, Pokémon!"), men in a crowd are wearing hachimaki headbands, indicating the Japanese nationality of the wearers. As hachimaki are common clothing items in Japan that signify hard work and perseverance and are traditionally worn by manual laborers, students, and sports fans, the crowd members wearing these reflect the atmosphere of the scene where they cheer on Ash as he departs on his Pokémon journey and encourage him to do his best (or ganbaru which in of itself is a Japanese-specific idea of perseverance in all that one pursues). Hachimaki are also represented in Episode Twelve_when the "Squirtle Squad" - a gang of troublemaking Squirtle - wear hachimaki while they play pranks and bother citizens of a local town. They also carry a flag with the Japanese character "ze" representing Squirtle's Japanese name "Zenigame" in the Japanese version of the episode. The "ze," however, was scrubbed from the edited English version. Furthermore, at the end of the episode when the Squirtle Squad are reformed as town saviors with the help of Ash, they receive happi jackets along with a matoi fire fighter standard to indicate the squad's new role as the town's fire brigade. Furthermore, the Japanese Rising Sun Flag is represented in the background behind the Squirtle. In these cases, Japanese clothing is closely connected to Japanese philosophy and culture.

This connection of clothing to cultural specificity is represented again in Episode FortyEight (“Bulbasaur’s Mysterious Garden”), where a tribe of Bulbasaur (Grass-Type Pokémon) hold a festival to advance into Ivysaur - their next evolutionary form. Evolution, in terms of the Pokémon world, refers to the phenomenon where Pokémon change form and gain new abilities as a result of battling other Pokémon and becoming stronger. In this episode, Team Rocket wear Japanese festival attire. In these scenes, Jessie and James wear traditional Japanese happi jackets 
- attire that is traditionally worn at Japanese festivals. As this episode takes place during a festival in which the Pokémon Venusaur facilitates the evolution of a congregation of Bulbasaur into Ivysaur - their next level of advancement - the clothing would seem appropriate to a Japanese audience. To an English-speaking audience unfamiliar with Japanese festival (matsuri) tradition and custom, Team Rocket's outfits are unfamiliar, exotic, and non-specific to any particular culture. Furthermore, there is a shot of Team Rocket with a matoi-or standard that was used by fire fighters in feudal Japan to signal that houses nearby were on fire but are now used in festival ceremonies - and a kama - a hand-held sickle used to cut grass and harvest crops. In this shot, while the objective iconography remains unedited, the diegetic hiragana "ro" is changed to an " $\mathrm{R}$ " in the global version of the episode. As "ro" presumably signifies "Team RO-cket," the " $\mathrm{R}$ " is appropriate. Nevertheless, the "odor" of Japanese matsuri remains "floating" within the scene, unbound by the lack of familiarity English-speaking audiences presumably have toward Japanese customs. While the Japanese audience would be familiar with the clothes and their significance in relation to the episode, an English-speaking audience may read their attire more as a "costume" or "disguise" rather than a cultural object that closely relates to Japanese tradition.

This "costuming" of culture appears elsewhere in the first season. Examples of matsuri's association with particular types of Japanese clothing occur elsewhere in the first season as well. In Episode Nineteen during a summer festival, Ash and Misty wear yukata - summer kimono traditionally associated with summer matsuri - at the end of the episode. Throughout the episodes, visual representations of artifacts related to Japanese culture are also presented. Street food vendors serving Japanese food such as takoyaki and yakisoba as well as game stalls line the streets of the small, rural town in which the episode takes place. Furthermore, a large structure 
holding taiko drums and lanterns hosts a procession of people in yukata performing music and dances for festival goers.

In the fourth episode ("Challenge of the Samurai"), a character aptly named "Samurai" challenges Ash to a Bug-Type Pokémon duel within the mountain forest in which the episode takes place. Samurai is a bug-catcher trainer who wears - as his name suggests - a samurai helmet and armor. The purpose of this armor is never clarified but is presumed to protect him from the venom of the bug Pokémon of the forest who are portrayed as quick to antagonize and fight against anything that encroaches upon their territory. Samurai speaks very formally and politely but tersely, indicating his no-nonsense approach to Pokémon battling. Furthermore, he speaks frequently of honor as a Pokémon trainer and trainers' duties toward their Pokémon both as comrades and as masters. The voice work as well as the translation of the Japanese script for Samurai indicates that the script editors and English voice actor knew the Japanese origin of Pokémon and adapted the English script and voice to "fit" with that Japanese tone. So an English-speaking audience received an animated representation of a boy in a samurai outfit speaking more formally than they are accustomed to with Ash their guide through the land of Pokémon in the anime. The presence of a character and a willingness to adhere to that character's original conception by the Japanese producers shows that, at least initially, the editors and distributors of the American version of Pokémon were amenable to representations of Japanese culture within this version as long as it fit into stereotypical ideas concerning Japan.

Samurai's garb is not the only instance of stereotypically Japanese historic professions being present in the anime. In Episode Thirty-Two (“The Ninja-Poké Showdown!”), the gym leader Koga and his apprentice Aya wear clothing associated with Japanese ninja. This episode is unique in that Aya directly says that she is a "ninja," directly connecting the Pokémon world to 
that of (a stereotypical) Japanese culture. This, along with the fact that the episode takes place in a Japanese-style house inhabited by these two ninja, correlates the architectural surroundings with the "Japanese-ness" of ninja thereby infusing the episode with a strong cultural "odor" of Japan. In these episodes, the stereotypical representation of ninja and samurai contribute to both a shallow understanding of Japan and, potentially, to a more thorough understanding of less "obviously" Japanese images in the show as Japanese due to the connections made through symbolic associations.

The inclusion of the ninja in this episode is likely a product of producers' intentions to sell Pokémon worldwide. As arguably the most recognizable Japanese profession, the representation of ninja presents an opportunity for producers to tap into foreign audiences' schema regarding Japanese culture as an avenue through which they can connect these audiences to Japanese culture in a familiar way. As such, the stereotypical image of the ninja becomes a tool used by producers to sell the Japanese-ness of Pokémon to an international audience without at the same time introducing them to cultural markers that would be "too Japanese" for their tastes.

Another example of Japanese traditional dress being "costumed" by editors is in Episode Fifty-One ("The Ultimate Test"). In the episode, Ash and Team Rocket decide to take a test designed as a shortcut to allow trainers into the Pokémon League Tournament. Ash does this in order to fulfill his dream of becoming a Pokémon Master while Team Rocket does so in order to steal rare and powerful Pokémon from trainers. In a scene where Jessie extolls her various talents, she lists various professions at which she excels, including hostess, florist, costume designer, wine-expert, beautician, and style consultant. This list is accompanied by a series of visual representations of Jessie performing these roles. However, there exists a gap between 
Jessie's verbal statement and the actual images represented. For instance, "hostess" is represented by an image of a tea-house owner, a "florist" - an ikebana flower arranger and a "costume designer," - kimono fitter. These Japanese professions are intentionally misrepresented as professions that English speakers could more easily recognize, thereby diminishing the cultural specificity of the objects represented. As US viewers would not necessarily understand what an ikebana flower arranger is, or why it is a profession culturally significant to Japanese people, editors therefore translated it to something that these audiences would understand - a flower seller. The most egregious example of deodorizing these traditional Japanese professions is that of the "costume designer." As kimono necessitate a second person to help women dress in these outfits, kimono shops offer services to help women dress. However, the representation of this service as a "costume designer" directly Orientalizes Japanese tradition and culture and reduces it to a "costume" rather than presenting kimono and kimono sellers' status as distinctly Japanese and steeped in history and tradition. In contrast to the connections made through associative symbols above, the "costume designer" translation offers no connection to a Japanese understanding of the "costume." Rather, the meaning of the kimono is left "floating" as a "costume." But a costume of what? If this piece of clothing is a "costume," why is Jessie wearing this "costume" in the other shots of a "hostess" and "flower arranger?" If a kimono were to be encountered in a future episode or in other representations on television, or even in real life, would the word "costume" be associated with the garment? These questions remain ambiguous due to the lack of association made with "costume designer" as a referent.

Furthermore, in this scene, Jessie wears the outfits associated with each profession. When she mentions "wine-expert," "beautician," and "style consultant," she wears a sommelier outfit, a blazer with a skirt, and a pantsuit respectively - all typical "Western" outfits. However, when she 
mentions her other three talents: "hostess / tea-maker," "florist / flower arranger," and "costume designer / kimono fitter," she is also dressed accordingly, but these three outfits are more closely related to Japanese culture as Jessie wears kimono in all three of these shots. Here, while the visual Japanese specificity is retained, the expositional aspects are diminished for an Englishspeaking audience's familiarity.

These examples of "deodorization" indicate that the reception of culture has just as much to do with the way culture is presented verbally as it is visually. Although the visual symbols of Jessie wearing kimono in a variety of different professions persist, the way that these professions are presented verbally to English-speaking audiences is significantly changed. For anyone not previously familiar with Japanese culture, these translated professions, such as "costume designer" would instead be fallaciously attached to the visual Japanese symbols of kimono, ikebana, and the like. Meaning, a "costume designer" in the Pokémon world, for instance, would make and wear kimono. To a US audience, this essentially erases the specificity of these professions to Japanese culture; instead, they become Pokémon versions of familiar professions.

In addition to this Orientalist "costumification," there is also a subtler example of Japanese fashion being extant as a disguise within the episode. James' disguise in this episode is that of a Japanese high school student - complete with high school gakuran uniform. A gakuran uniform, here, refers to a long-sleeved black jacket with gold buttons clasped to the top and black trousers. James also wears a pair of thick, round glasses stereotypical for Japanese "nerds." While not as apparent in its significance to Japanese culture, this "disguise" represents Japanese male high-schoolers' attire and, indirectly, their experience taking college entrance exams - a Japanese cultural keystone where students test into specific universities through standardized tests which are similar to the SAT or ACT. As these tests occur in middle school for high school 
as well as in high schools for universities, these entrance exams, due to their profession-defining properties, are pushed upon students by their parents as well as Japanese culture writ large. Therefore, a Japanese speaking audience would understand, and be closely familiar with, the uniform within the test context as attire consistent with students' experiences and expectations for their schooling. An English-reading audience, on the other hand, would merely perceive this attire to be yet another Team Rocket disguise.

In Episode Nineteen (“The Ghost of Maiden's Peak"), several characters wear traditional Japanese matsuri festival clothing including James, Ash, and Misty with several other shots of background characters wearing similar clothing and doing traditional dances celebrating (the implied) summer Obon festival. Misty, however, carries a Japanese hand-fan that has had its diegetic text removed for the English version. So, while much of the visual "Japanese-ness" remains in the episode, some of the diegetic text indicating its origin has been removed - though not all, as will be discussed in the proceeding sections.

The presence of Japanese clothing in the anime suggests that editors allowed traces of Japanese "odor" to be present in the show. The balance struck between the presentation of clothing objects representing Japanese cultural "odor" and "de-odorized" symbols non-indicative of any particular culture suggests that editors carefully balanced this "odor" in order to appeal to several audiences. As Japanese linguistic text was too specifically Japanese, editors removed much of it in order to "de-odorize" the anime. And while these editors translated most linguistic Japanese text directly, they left visual representations of Japanese culture unaltered, permitting the episodes to retain some subtle cultural "odor." Furthermore, this unaltered "odor" could be read differently by several different audiences: a Japanese audience who is familiar with these objects and could therefore "ground" the Pokémon world as Japanese in nature, non-Japanese 
anime fans who recognize its "odor" and could similarly appreciate the show's status as Japanese, and a non-Japanese audience unfamiliar with Japanese linguistic and visual symbols. Editors assumed that this latter audience would recognize the Japanese-ness of the linguistic symbols but would not recognize the "odor" present in the visual symbols. Therefore, they "deodorized" much of the linguistically Japanese symbols on screen in order to prevent the show from being "too Japanese" for US audiences.

These producers likely thought that certain elements of Japanese "exoticness" could help make the series profitable around the world. As anime is inherently associated with Japan and Japanese culture, certain aesthetic expectations are tied into its reception it as a television product. In other words, both a Japanese audience as well as a non-Japanese anime-loving audience would expect Pokémon - as an anime - to look a certain way. If these expectations are not met, then by producers' estimates, the show would not succeed among either audience. Furthermore, audiences unfamiliar with Japanese culture might think these aesthetics to be "exotic" and therefore may be inclined to search for more of these novel attributes. Therefore, both producers and editors balanced the Japanese-ness of the anime by leaving in the symbolic "odor" associated with Japanese objects and traditions, but edited out specifically-Japanese linguistic text in order to prevent it from becoming "too Japanese."

Architecture. Many times, a distinctly Japanese-style architecture of buildings, towns, and decorations are represented throughout the first season. For instance, in the first episode, ("I Choose You, Pokémon!"), the gates outside the Pokémon laboratory where Ash begins his journey resemble those typically seen outside of Japanese school gates - complete with a sign indicating the building's name "Oak's Laboratory" in Japanese. Here, the Japanese text remains unedited alongside the Japanese object of the laboratory's sign, cementing it as Japanese to a 
Japanese audience. Other specifically "Japanese" architecture in the series include police koban (miniaturized neighborhood police station "boxes") in Episode Two.

Japanese home exterior and interior design patterns are represented throughout the first season as well. In the third episode, Ash visits the rock souvenir shop of a man named Flint in Pewter City in order to figure out a strategy to defeat the Pewter City gym leader, Brock. The interior of the shop is similar to that of a traditional Japanese homestead. Here, the floors and walls are made out of wood and Ash and Flint sit and kneel in the dogeza position respectively upon zabuton pillows on the floor. Furthermore, both Ash and Flint have removed their shoes, a cultural practice that while not exclusive to Japan, is ubiquitous within the country and its traditional culture. Flint additionally has made tea; he holds and sips from a yunomi (Japanese tea mug) in a traditional polite manner. In the next scene, wherein Flint shows Ash how Brock lives and takes care of his brothers and sisters, similar imagery is present indicating to a Japanese reading of the episode that this show is Japanese. Furnished with tatami flooring, zabuton pillows, a chabudai short-legged table, and shöji rice-paper doors, Brock's home is made apparent as traditionally Japanese in nature. Furthermore, Brock and his siblings are portrayed similarly to stereotypical caricatures of Japanese people with a Japanese appearance potentially amplifying the Japanese audience's resonance with the show. On the other hand, these images are divorced from Japan and the Japanese as there are no examples of diegetic Japanese text or dialogue to anchor these Japanese symbols to the culture for a global audience of the anime.

In Episode Nineteen (“The Ghost of Maiden's Peak”), during an end-of-summer festival, a town displays a painting from a shrine as a two-thousand-year-old tradition. The design of the shrine itself is typical of many Shinto shrines throughout Japan. This Maiden's Shrine is said to house the spirit of a forlorn maiden who lost her betrothed at sea two thousand years ago. As 
many shrines in Japan are said to be sanctums for local spirits, this directly relates, and refers to, the Shintoist understanding of spirits. Additionally, Episode Thirty-One of the series ("The Ninja Poké-Showdown!") takes place entirely within a ninja "trick house" with traps preventing intruders from entering and advancing too far into the house without harm. This is directly based on feudal samurai homes that were deliberately trapped to prevent invasion by rival clans. This is evidenced by the rice-paper shoji doors, weaved tatami mat floors, and other assorted Japanese decorations. These Japanese-specific architectural configurations might function in different ways for an English-speaking audience. On the one hand, for those unfamiliar with Japanese festival and customs, the architecture of Episode Nineteen's shrine and Episode Five's souvenir house might be extremely unfamiliar and alien. From a non-Japanese child's perspective, this lack of connection to a familiar schema forces the imagery in this episode to "float" as strange and unfamiliar objects in the Pokémon universe. To this audience, tatami, chabudai, and zabuton are not "Japanese" but "Pokémon-ese." These unfamiliar elements of the show, combined with the English language translated from the original Japanese version, dissociate it from the familiar realm of American cartoons and into a "floating world" of anime - specifically Pokémon aesthetics. On the other hand, as Episode Thirty-One takes place in a "ninja" house with "ninja" characters, the ninja theme of this episode may make a distinct and concrete connection between Japan and the Pokémon anime, thereby giving viewers a tool to "connect the dots" of previously received information as well as future information as to the cultural background of the show. In this case, the stereotypical aspects of Japanese representation might lead to a more thorough reading - and therefore understanding - of other, less represented, aspects of traditional Japanese cultural identity. 
Here, as US viewers of the anime are likely aware of at least a few of the most stereotypically Japanese professions (ninja, in this case and samurai in an earlier case), they are, through these representations, invited to view this show as Japanese. Unlike most other Japanese symbols present in this season (e.g. shrines, matsuri clothing, zabuton pillows) Japanese ninja have been consistently represented in American media and have therefore become common - if stereotypical - associations with Japan. Stereotypes of Japanese culture have therefore connected the unfamiliar symbols of Japanese culture for non-Japanese audience through textual proximity. And while it cannot be said that this proximity "teaches" Japanese culture nor does it necessarily influence people to learn more about Japanese culture, the conjunction of these images at least facilitates thought that Japanese culture is more than the stereotyped ninja and samurai. Potentially, however, those who have developed an interest in Pokémon, they may seek further representation of these symbols in other anime as well. Pokémon therefore presents aesthetic opportunities for people to become cognizant and appreciative of other cultures through its representation of Japanese cultural symbols.

Food. Throughout the episodes examined, there are multiple instances where Japanese food is present in scenes. For example, in the second episode of the first season, Professor Oak cooks ramen in a beaker at his laboratory. He mentions this ramen by name in the original Japanese version of the episode, yet says that it is his "pizza" in the English translation. A similar "error" is made in Episode Twenty-Five ("Primeape Goes Bananas"), where the onigiri rice balls that Brock makes for the group are referred to as "doughnuts" disregarding the fact that they look nothing like the American food. However, in Episode Fifty ("Pokémon Paparazzi"), this same food is referred to, correctly, as rice balls. In the first scene, Ash and company are eating onigiri rice balls on the side of a road while Brock cooks lunch. Both Ash and Misty clearly state that 
they enjoy the "rice balls" that Brock has made. Here, they use the English translation of onigiri to convey the compositional aspects of the food. Rather than refer to onigiri as "doughnuts" as they have done in previous episodes, they use the correct nomenclature in this episode. The reasons for this can only be presumed. Perhaps the editors and scriptwriters realized that onigiri look nothing like doughnuts and decided to re-script it as "rice balls" as it would cause less dissonance between an American audience's experience with doughnuts and the visuals on screen. Or perhaps they potentially forgot about the previous instance of onigiri in the anime. In any case, the rice balls and ramen on the screen still present an image from another culture as very few American audiences (with the exception of co-cultures such as Asian-Americans) would recognize rice balls as a common lunch food.

In addition to these examples, in Episode Five ("Showdown in Pewter City"), during a lunch scene, Misty eats her meal with a fork while Ash eats his bowl of rice with a pair of chopsticks. In this case, chopsticks serve as a symbol that grant Pokémon an Asian cultural odor with the fork indicating familiar "American" or otherwise "Western" "odor." In this scene, the duality of Pokémon as a Japanese franchise influenced by Western globalization is typified by the representation of both Western-ness and Eastern-ness in the same context. Chopsticks are consistently shown in this season's episodes as evidenced in Episode Forty-Nine ("The Case of the K-9 Caper") where Ash, Misty, and Brock eat with chopsticks and Ash and Brock have tonkatsu pork cutlets on their plates. Additionally, in a wide shot of the group along with a closeup shot of Ash's plate, Japanese food such as miso soup, tonkatsu, and rice bowls are on each person's plate. The presence of these Japanese food items lends a sense of Asian-ness to the episode. Although the English-speaking audiences may not be aware of the cultural specificity of these particular foods, the conjunction of chopsticks and rice with them may indicate that they 
are at least Asian in nature, if not specifically "Japanese." Here, chopsticks serve as a cultural "adhesive" that links the Asian-ness of chopsticks to other, hitherto unfamiliar, cultural objects.

In Episode Fifty-Two (“The Breeding Center's Secret”), on a restaurant's door is a flyer advertising an all-you-can-eat buffet to any Pokémon trainer. The Japanese version of this flyer offers all you can eat "omurice" - a Japanese dish that features white rice inside an omelet while the English version makes no mention of the dish. Furthermore, later on in the episode when they receive admittance to the buffet, Ash and Misty mention how good the "ice cream" is. The English scriptwriters of the episode may have found the image of the omurice similar enough to that of ice cream even though there is ketchup on the omelet. Furthermore, as omurice is a portmanteau of "omelet" and "rice," - two English words - the editors could have easily portrayed it as an omelet. The intention to completely dodge the Japanese-ness of the dish caused the editors to overlook the fact that omelets are dishes that are familiar to English-speaking audiences. In this attempt to overwrite the Japanese-ness of the omurice, the editors inadvertently caused dissonance between the image of the omurice and the expressed "ice cream" that Ash and Misty mention, once again causing Pokémon to seem strange and unfamiliar to a US audience.

Along with Japanese food, there are instances where familiarly "Western" food is both mentioned and shown in episodes. In Episode Fifty ("Pokémon Paparazzi”), after meeting Ash, Brock, and Misty and inadvertently ruining their lunch by surprising them with his camera, Todd - a Pokémon photographer - invites them into his (Western-style) house and cooks them pancakes. In each language version, the food that Todd makes is pancakes, indicating the globalized nature of the food; Japanese people are well aware of pancakes and other types of Western food due to the history of American occupation and the subsequent globalized flow of American commodities and culture to their country. Furthermore, the conflation of the Japanese 
onigiri alongside the English pancakes obfuscates the "true" cultural origin of the show allowing it to be read as Japanese by the Japanese and as American (or Western) by English speakers. However, while the Japanese viewers have a familiarity with pancakes as a foreign product, English-speakers may have only a passing awareness of rice balls as "Asian." Here, Pokémon "floats" as an indistinctly cultural product for those not accustomed to specifically Japanese objects.

The choices made in translating onigiri and omurice as "doughnuts" and "ice cream" respectively reflect an intentional attempt to rid these objects of their Japanese "odor." The dissonance created between the verbal dialogue mentioning these food items and their visual representation again led to a dissociation of Japanese culture from these cultural-specific foods. These images therefore became representations of "Pokémon-ese" food items. As these foods were never explicitly associated with Japanese culture due to the excision of Japanese linguistic text and other cultural signifiers, they remained "floating" as non-culturally specific objects.

\section{Japanese Cultural Knowledge}

Japanese conventional knowledge concerning behaviors, cultural objects, history, and mythology are present throughout the first season as well. As these images are not as easily "scrubbed" as the verbal dialogue, they remain extant as markers suggesting the "Japanese-ness" of the anime. Therefore, what follows is an examination of these extant symbols and how they connect to Japanese culture.

In Pokémon, the titular creatures are caught with, and confined within, pokéballs. These pokéballs are high-tech spheres that allow Pokémon to be comfortably held within a small space so as to facilitate easier transport within trainers' pockets. Pokéballs are based on the appearance and function of Japanese gashapon vending machines wherein random items such as toys, dolls, 
stickers, and other trinkets are contained within small capsules that people pay money for the chance to receive. The machines function by inserting coins and turning a handle which then dispenses a random capsule. While machines like these can be found in grocery stores across the United States, their existence in Japan is much more ubiquitous and their contents usually of higher and more collectible quality. As pokéballs are present throughout the series as well as the videogames, comic books, and other assorted merchandise, their Japanese specificity is subtly prevalent throughout the franchise.

Other forms of Japanese cultural knowledge are present as well. Throughout the season, whenever Nurse Joy - a Pokémon healer - appears, she bows before greeting the main characters. Additionally, in a scene in Episode Fifty-Two ("The Breeding Center's Secret"), a weather forecaster delivers a "pokéweather" report to the denizens of the city from a flat screen television perched upon a building. When she concludes, she delivers a short, quick bow to the camera. Similarly, in a scene where Team Rocket members "Butch" and "Cassidy" report to their leader via video conference call, they also give a deep bow to him before ending communications. While the latter instance suggests a pair of minions giving respect to their master, Nurse Joy's and the weather forecaster's bows may be interpreted differently. As English-speaking audiences would not be familiar with weather people bowing after their reports, this action would seem foreign to them by its formality. And while this would not directly be present in the English version, Japanese newscasters, weather people, and other assorted employees of service industries use a Japanese formal dialect known as keigo to indicate their status as being in the service of the public. This is accompanied by formal, polite behavior such as bowing. So, while the verbal aspects of keigo are not delivered in the English version of Pokémon, the bowing remains as a symbol of Japanese formality. Furthermore, the general act of 
bowing may be perceived as "Asian" to English-speaking audiences, allowing some of the Japanese cultural "odor" to be salient for these viewers.

Along with bowing, other Japanese behavioral customs are present throughout the first season. In Episode Five ("Showdown in Pewter City"), Flint - the owner of the rock souvenir shop - brings tea to Ash when he visits the shop to commiserate about battling the gym leader Brock. Furthermore, in Episode Forty-Nine, ("The Case of the K-9 Caper") Officer Jenny brings Ash, Pikachu, Misty, and Brock lunch and tea while they talk about training Pokémon. Serving guests tea and food in Japanese culture is a custom that is ingrained in Japanese social tradition. While English-speaking audiences may be familiar with asking guests if they'd like something to drink while they're visiting, this formality is absent from the show's dialog as both Flint and Jenny bring tea and food without prompt. Furthermore, the Japanese aesthetics within objects of these episodes - that is, Flint's Japanese interior design, the chopsticks and Japanese food on the main characters' trays - further correlate to this Japanese behavior. Furthermore, characters in Flint's shop and Brock's Japanese-style home are without shoes - further connecting Japanese behavioral custom with the images on the screen.

In Episode Three, “Ash Catches a Pokémon!" there are brief instances of Japanese social and cultural specificity. For example, Team Rocket briefly flash Japanese sensu hand fans as celebratory toward a perceived impending victory. While brief, this marks another instance where Japanese objects exist in the world of Pokémon. This scene, in conjunction with the mountain forest context of the episode in question grounds it as Japanese for a Japanese audience. However, to an American audience unfamiliar with the sociohistorical contexts related to these images, they are separate and non-indicative of a particular culture. Here, nothing was edited, hidden, or even erased, but audiences in the United States nevertheless read these 
instances differently than Pokémon's domestic Japanese audience due to the presence of engrained, socially familiar images that resonated with a Japanese identity.

Japanese matsuri festivals are commonplace in the country, with Japanese celebrating many such matsuri festivals to honor the natural world and its spirits. Japan has multiple national festivals such as the Obon festival in the summer - celebrating the spirits of Japanese people's ancestors and the Hanami, or "Cherry Blossom Viewing" festival - where locales celebrate the blooming of the country's native sakura trees. There are also innumerous local festivals sponsored by native shrines that celebrate the municipalities' traditions and cultural heritage. In this first season of Pokémon, as stated in an above section, a matsuri is held to celebrate the plant-dinosaur Pokémon Bulbasaur collectively "growing" into their next evolutionary stage. In Episode Nineteen (“The Ghost of Maiden's Peak"), Shinto ofuda (protective paper talismans) are referred to as "anti-ghost stickers" that protect from the "Maiden's Ghost" in the English version of the show. While functionally accurate in nomenclature, ofuda are distinctly cultural as they remain relevant artifacts of Shintoist belief in guarding against evil and dispelling unwanted spirits. Furthermore, the Japanese text on the ofuda is replaced by indistinct scrawl. However, in other shots, this scrawl reverts back to the original Japanese version with stars and kanji written upon it. Furthermore, the old lady who sells these "stickers" uses Japanese currency complete with one-thousand and five-thousand yen notes and five hundred yen coins. The "Maiden's Ghost's" haunting in this episode is revealed to be caused by the Ghost-Type Pokémon Gastly - a floating orb of purple, incandescent gas with a threatening face. This Gastly is unique, however, as it is capable of human speech. Its trickster personality is reminiscent of the mischiefs of particular Japanese yokai spirits who enjoy tormenting humans. Misty attempts to defeat Gastly with a Christian Crucifix. At the end of the episode, tôrō nagashi (Japanese 
lantern boats that send souls of the deceased to the afterlife) float on the surface of the ocean. This practice is common during Obon as this festival functions as both remembrance and celebration of ancestors and the deceased. While this festival is never named in the show, the imagery and traditions associated with it are clearly present. Furthermore, it is revealed that Gastly "haunts" on behalf of the true "Maiden's Ghost" as it enjoys keeping traditions and legends alive. Additionally, a structure featuring a procession of people in traditional yukata accompanies Jessie and James (dressed similarly) as they hit a taiko drum to the music.

In addition to the physical objects associated with traditional Japanese culture, references to Japanese religions and mythology are subtly present within the first season. Japan has a history of naturistic and animistic cultural traditions and values, with close connections to Shintoism, Zen Buddhism, and Confucianism. As a result, Japan and its people have cultivated a rich naturalistic mythology. Furthermore, as the country and its cultures have historically been viewed through Orientalist lenses - both by external and internal commentators - it has maintained a national-cultural identity intrinsically tied to the respect and celebration of nature. One such aspect of this identity that is continually and consistently represented in its media is the concept of "yokai" and "kami" - respectively, natural spirits and deities that inhabit Japan. Yokai and kami, as derived from the country's animist traditions, are ethereal entities that exist in a variety of forms and perform a multitude of functions. Some protect, others trick and harm. Some demand respect and offerings, while others offer gifts in exchange for tributes. This mythology of Japanese spirits constitutes a loose pantheon of deities within Japanese culture. For example, the kami Inari is the deity of foxes, rice, and sake rice wine and has shrines throughout Japan, where pilgrims make offerings to Inari in exchange for luck, fortune, and protection. 
In the Pokémon media franchise, this mythology is primarily represented through the the mysterious creatures known as Pokémon who inhabit the world. The Pokémon "Ninetales," for example, is a nine-tailed fox that closely resembles kitsune yokai which are trickster foxes that are able to shapeshift in order to play pranks on people. Another direct example is the Pokémon Exeggutor which is based on ninmenju which are trees with human faces as fruit. As a GrassType Pokémon, Exeggutor is a coconut tree with its "coconuts" comprising its multiple faces. Indirectly, Pokémon such as Voltorb (a Pokémon that resembles a pokéball), and Magnemite (a hovering steel magnet), resemble tsukumogami yokai - inanimate items that have gained sentience by being inhabited by a spirit. Pokémon, therefore, has not only been influenced by its creator's love for bug-catching as a youth, but also a cultural mythology that extends thousands of years into Japan's past.

In the first episode, the audience is introduced to the creatures known as Pokémon. Three of the first Pokémon the viewers become aware of are Charmander - a two-legged Fire-Type salamander with a flame on its tail; Bulbasaur - a quadrupedal Grass-Type Pokémon with a flower bulb on its back; and Squirtle - a Water-Type, bipedal turtle with a squirrel's tail. The elemental, and therefore natural, associations between the creatures and their respective Types are immediately made obvious to the audience. This is compounded in the English version of the series by the Pokémons' respective names: Char-mander, Bulb-asaur, and Squirt-le are all conjunctions of words related to their respective element and an animal. The animistic association of Pokémon with yokai and nature is made evident not only in these three Pokémon, but in other Pokémon throughout the series as well.

As part of the natural world, Pokémon represent the animistic spirits that are present throughout Japan. In several episodes, it becomes clear that Pokémon are powerful creatures in 
tune with the natural world. In Episode Forty-Eight ("Bulbasaur's Mysterious Garden”), the action takes place in a lush forest meadow and a "Mysterious Garden" that the Pokémon Bulbasaur flock to in order to attend a festival for evolution. Bulbasaur are Grass-Type Pokémon that resemble quadrupedal dinosaurs with a flower bulb on their backs and Ivysaur and Venusaur are subsequent evolutions that become incrementally larger with each evolution. The episode begins with Bulbasaur becoming ill and consequently taken to a nearby pokécenter by Ash and company. At the pokécenter, they notice that flowers are beginning to grow and bloom due to Bulbasaur's presence. Nurse Joy, the head nurse at the center, remarks that it is presently the time of year when Bulbasaur gather in the "Mysterious Garden" - a space reserved only for Pokémon and forbidden to humans - for their festival that signifies, and catalyzes, their ascension into their next evolutionary stage.

In this episode, the Bulbasaur, Ivysaur, and Venusaur are represented as wild and free yokai who have their own culture and traditions away from human society. Furthermore, they are neither portrayed as villainous nor heroic but simply animistic and natural - in tune with the "magic" of evolution and the ingrained tradition that goes along with it. Bulbasaur's presence at the pokécenter, for example, causes flowers to bloom and flourish - indicating its natural abilities as a yokai embedded within the natural world. Similarly, Ash's Bulbasaur uses the move "Solar Beam" to harness the power of the sun to punish Team Rocket for intruding upon the mystical territory of the "Mysterious Garden" in their attempts to kidnap all of the assembled Ivysaur and Venusar. Since Ash and company apologize to the assembled Pokémon (though nevertheless stand their ground in defense of Ash's Bulbasaur, with Ash going so far as to take an attack from Venusaur meant for Bulbasaur) they are permitted to leave peacefully. In this episode, facets of the yokai as natural, benevolent protectors as well as temperamental, punishing 
beings are explored through the guise of Pokémon creatures who stand in proxy to the Japanese mythical spirits. As Ash was both apologetic and willing to defend Bulbasaur and the rest of the assembled Pokémon from Team Rocket, he and his friends were allowed to leave peacefully demonstrating yokai's mercy for those who respect nature.

The "wild" nature of Pokémon is present consistently throughout the series. In the first episode, Pikachu refuses the confines of a pokéball and is obstinate toward Ash's orders, only listening to him once he "proves his worth" by sacrificing his well-being to protect the electricmouse Pokémon from the flock of Spearow who were angered by Ash's attempts to catch one of their members. In Episode Four, “The Challenge of the Samurai," Pokémon's natural wrath is once again demonstrated due to Ash and company's encroachment on the breeding ground of a hive of Beedrill (Bug-Type hornet Pokémon). Because their hive was threatened by humans, they attacked Ash, Misty, Pikachu, and Samurai - forcing them to hide in Samurai's mountain cabin until they calmed. Furthermore, in Episode Twenty-Five ("Primeape Goes Bananas"), the titular Primeape - a Fighting-Type monkey Pokémon - is extremely quick to anger and flies into a violent rage when James kicks it. Before this attack, however, Primeape was a Mankey, Primeape's first evolutionary form, having evolved at James' provocation. Previously, Mankey was playful toward Ash, Pikachu, Misty, and Brock, only stealing some food and teasing Ash by stealing his hat. Only when it was attacked by a human did it advance to its next evolutionary stage and attack Team Rocket violently. However, Ash was able to defeat it in a Pokémon battle and catch it - indicating that while direct human intervention is punishable, a duel with another Pokémon is worthy of respect.

The capricious nature of Pokémon is represented in other episodes as well. For example, in Episode Nineteen (“The Ghost of Maiden's Peak"), a Gastly (a Ghost-Type Pokémon) is 
revealed to be responsible for disguising itself as the "Maiden's Ghost" and hypnotizing Brock and James into falling in love with it. This is a rare case in which a Pokémon has human-like intelligence as it is able to speak fluent English (Japanese in the Japanese version, obviously). At the end of the episode, Gastly talks to the "real" Maiden's Ghost who thanks it for continuing its legend. Gastly replies that it enjoys keeping traditions and legends alive and that it profits from doing so, having sold Ash and company fake ghost-repelling amulets earlier in the episode. Here, the yokai-like characteristics of Pokémon as neither good nor evil manifest through Gastly as an entity who plays pranks on humans in order to keep the belief in tradition and mythology extant in their lives. Gastly's appearance as a floating purple incandescent orb resembles the folkloric sōgen-bi-a will o' wisp type creature said to be the fiery head of a wicked monk. Furthermore, Gastly's antics are similar to those of kitsune and bake-danuki (mythical raccoon dogs) who, traditionally, amuse themselves by disguising as humans and pranking people in a variety of ways.

However, while yokai (and Pokémon upon which they are clearly based), are oftentimes represented as wild, capricious beings, they are also able to be live peacefully amongst humans as companions. The yokai inugami (ghost dog) for example, is believed in Japanese mythology to be a spirit of a dog that has been summoned and bound to a family's bloodline as a familiar giving the bloodline better fortune in return for respect and offerings of food. The connections between Pokémon and these type of yokai are obvious here, as Pokémon are consistently portrayed to be friendly creatures under the ownership of Pokémon trainers. As another example, the Pokémon Meowth is a direct reference to Japanese "maneki neko" or "beckoning cat" that is thought to be a lucky talisman said to bring fortune to their owners. Furthemore, Meowth is represented with a gold coin on his forehead that closely resembles an ancient form of Japanese 
currency called "koban". Here, the image of Meowth is derived directly from Japanese history and myth.

In Episode Forty-Nine (“The Case of the K-9 Caper!"), humans' interactions with, and control of, the natural world and yokai is represented. Ash and company visit a K-9 police unit school where the Pokémon Growlithe are trained to become police dogs. In this episode, it is explained that Growlithe are raised from birth and bonded to Officer Jenny so that they are loyal, dependable, and capable officers. The Pokémon Growlithe - a type of dog Pokémon who can breathe fire - are controlled by human masters. In this case as well as in the Pokémon franchise as a whole, it is iterated that humans can tame the natural world and the spirits therein through the use of technology in conjunction with a respectful and benevolent disposition toward these creatures. Any behavior that is found to be disrespectful or abusive toward the world and its Pokémon is anathema and to be rebuked. For instance, Team Rocket trick the Growlithe into obeying their commands through voice modulation technology, which they use to deceive the Growlithe into betraying Officer Jenny. While this trick works initially, the Growlithe eventually wise up to the scheme with the help of Ash and Pikachu and attack Team Rocket. Team Rocket is therefore punished for using technology to interfere with the respectful relationship with humans and Pokémon.

Respect for the natural world and Pokémon is demonstrated throughout the series and the episodes analyzed. In Episode Fifty (“Pokémon Paparazzi”), for instance, a Pokémon photographer named Todd is passionate about taking pictures of Pokémon in their natural habitat, free from posing, manipulation, and other artifice. While Todd attempts to take pictures of Pikachu through the episode, it comes across as bothersome and obnoxious for the Pokémon in question. Later, Ash criticizes Todd seemingly out of his earshot for not "taking Pokémon's 
feelings into consideration." Todd takes this to heart at the end of the episode when he requests permission first before taking pictures of Pikachu and the other Pokémon. Furthermore, during the climax of the episode, Todd risks the safety of his camera to rescue Ash and Pikachu from a waterfall - sacrificing his camera in order to prevent harm from coming to his new friends. The lesson of this episode, then, is that in order to appreciate nature "properly," one must respect the natural world's "feelings." Additionally, this sometimes comes at the cost of sacrifice particularly technology in this case.

Japanese culture was represented in Season 1 of Pokémon primarily through visual emblematic images. The food, architectural, clothing, and folkloric traditions of Japan were consistently extant in the episodes analyzed. However, these images lacked distinct, concrete connection to Japanese culture. Other than brief background flashes of the Japanese war-time "Rising Sun" flag in Episodes Twelve and Twenty-Five ("Here Comes the Squirtle Squad!" and “Primeape Goes Bananas!” respectively), there was never any mention of Japan or Japanese culture made by characters. To a Japanese audience, these images, behaviors, and traditions would be familiar and salient as Japanese without exposition, however, to other audiences, these images may not be obviously Japanese. Chopsticks, for example, are not exclusively Japanese as they are used by other Asian cultures as well. In these cases, the inherently Japanese symbols are exoticized - not because of their explicit association with Japan, but because of their implicit association with the Pokémon world. However, the conjunction of each of these images in proximity to stereotypically Japanese symbols (e.g. samurai and ninja outfits) presents opportunities for non-Japanese audiences to "connect the dots" between the stereotypical meanings and the "floating" non-obviously Japanese symbols previously, and solely, associated with Pokémon. 


\section{Diegetic Text}

Diegetic text refers to the words on screen within the "world" of the television program. In contrast to subtitles, which are added after production, diegetic text is any instance where text is represented in the context of scenes. In contrast to captions and subtitles, diegetic text is meant to be perceived as inherently part of the scene. This includes, but is not limited to, words on billboards, books, letters, magazines, and signs. Diegetic text is usually used to give context to the scene or enhance the exposition of a television show's narrative. Rather than complicate matters with competing definitions, for this paper, diegetic text here refers broadly to any and all linguistic symbols suggestive of a textual script that appears on screen in order to distinguish between this on-screen text and the textual object that I am examining.

While editors typically left the visual symbolic representations of Japanese culture unaltered in Pokémon, the diegetic (“in-world”) text present on objects such as books, signs, and doors was often altered from its original Japanese. In some cases, this text was directly replaced by English. However, in many other instances, the Japanese was erased altogether without replacement. This was usually the case where Japanese lettering was in the periphery of a scene. In this section, I briefly trace these patterns of alterations to the diegetic text in the first season in order to determine how editors reduced or otherwise managed the cultural "odor" of the episodes.

During the first scenes of the show, three Pokémon appear on Ash's television screen with diegetic text indicating their Japanese names (Zenigame, Hitokage, and Fushigidane) under their respective portraits. In the next scene, however, after the camera had zoomed in on their individual portraits sequentially and zoomed back out, the text had disappeared. This was not the only case of disappearing Japanese text in the episode, though, as later when Ash is to choose his 
first Pokémon to go on his journey with him, the Japanese text originally on the pokéballs in their initial, introductory shot disappears in subsequent shots. In this first episode, the editors are inconsistent with their decisions to keep or edit out aspects of "Japanese-ness" from the show. This inconsistency occurs elsewhere in the season as in Episode Nineteen ("The Ghost of Maiden's Peak"), where the audience is afforded glimpses at unedited Japanese on a Shinto shrine in some cases. Elsewhere, Japanese text is altered and removed from the English version of the episode. However, on this Shinto shrine, there are several instances where kanji still appear on the paper ofuda talismans placed upon the shrine as well as on the shrine itself.

Another interesting case where the Japanese "odor" was not replaced in this season occurs in Episode Fifty-One ("The Ultimate Test"), during a scene where Ash is answering questions for the titular test. As the test is entirely "True or False" answering, Ash has two options to choose from on a keyboard - a red button with a maru "correct" circle and a blue button with a batsu "incorrect" "X." Here, the red button signifies "true" and the blue button "false." This is at odds with conventional English-speakers' understanding of color associations as the color red usually indicates "wrong," or "false," with green symbolizing "correct," or "true." In Japan, however, the common assumption is that the circle indicates something that is true and the "X" something false. Furthermore, as Ash verbalizes his answers "True" and "False" while pressing the corresponding buttons, it seems to an English-speaking audience that he is pressing the incorrect buttons. In this case, the Japanese "odor" is left alone by editors. This, then, may have confused English-speaking audiences about why Ash was pressing a red-button for "true" answers and the blue-button for "false" answers. However, read a different way, it may have also built connections between the maru and batsu symbols and their respective relation to true or false questions. While the editors scrubbed the obviously "Japanese" aspects of this 
episode, namely the diegetic text, some cultural "odor" remains extant in the visual symbols.

Another instance where Japanese text was left "as is" was in Episode Four ("Challenge of the Samurai!"), where a small name tag on Ash's sleeping bag reads: "Satoshi." The inclusion of this in the English version suggests that the editors were not diligent in their analysis of episodes that needed "deodorization" and inadvertently kept the Romanized spelling of Ash's original Japanese name. American audiences would have little to no frame of reference to what "Satoshi" signified, nor would they have any audio accompaniment to the text- the word would not indicate any "Japanese-ness" to them. It merely serves as a "leftover" bit of cultural odor from the original version of the show. Furthermore, the lack of distinctly Japanese text within this episode was apparent as there was very little evidence of "covering up" or erasure of text on screen during this episode.

Inconsistencies in "managing' the presence of Japanese currency are also common throughout the first season. In Episode Five ("Showdown in Pewter City"), in a scene where Ash receives a bill for his and Misty’s lunch, the check totals " $\$ 1150$ " with the two meals being "550" and "600" (with no currency symbols present), respectively. If read as an amount in dollars, this bill is quite hefty for a simple lunch for two people. However, as it is translated from Japan’s currency the yen, it makes more sense as “ $¥ 1150$ ” which would be the equivalent of about nine dollars and fifty-eight cents in American currency in 1998. In the Japanese version, there are some kanji indicating that this slip of paper is a bill and katakana on the bottom indicating the name of the restaurant - "Restaurant Nibi" - Nibi being the Japanese name of the town featured in this episode. In the English version, however, the yen symbols are replaced with dollar signs, the kanji erased, and the katakana replaced with a "Thank You" script.

In line with the decision not to adjust the yen prices of the aforementioned lunch bill, the 
editors also chose not to change price tags on other objects in Episode Five. For example, the prices on the rocks in a "rock souvenir" shop were left as " 120, , "600," "1000," etc. To US audiences, this would indicate that simple, singular rocks are priced at an extraordinarily high amount. However, to the Japanese where 120 yen would be approximately the equivalent of an American dollar, these souvenir stones would be around the equivalent of one, six, and ten dollars, respectively.

In this case, Japanese specificity with regard to pricing again "slipped through" editing to convey a sense of dissonance between image and value. Here, then, US viewers became aware of a different pricing system potentially unknown to them at that time. This price system, however, serves as another point in which the "strangeness" of the Pokémon world takes shape in US audiences' minds while the "familiarity" of a Japanese reading grounds the show to the Japanese context. The price numbering on the rocks and on the lunch bill in Episode Five indicate that the events in this anime do not take place in America.

However, in other episodes, the nationality of the currency used in the Pokémon world is ambiguous. In Episode Forty-Nine (“Case of the K-9 Caper”) American dollar signs on money bags are represented briefly in a Team Rocket fantasy-scene wherein they imagine stealing Pokémon to use in heists. In the original version of this episode, these bags also had dollar signs, suggesting that the American symbol has become globally understood as a signifier of currency and possibly wealth. However, in Episode Nineteen (“The Ghost of Maiden’s Peak"), Japanese paper and coin currency are in a cash register. As the paper yen count up to "1000" and "5000" with 100 and 500 yen coins, these images contradict previous representations of American dollar signs in the episode. However, without the cultural knowledge of what Japanese yen actually look like, English-speaking audiences would potentially perceive this currency as merely a 
product of the Pokémon world or the Kanto region. On the other hand, if this currency is correlated with the representation of many other particularly Japanese objects in the episode (shrines, ofuda, yukata, taiko drums, etc.) the currency may then be perceived as Japanese. It is questionable, though, the extent to which these objects would be "Japanese" rather than "Pokémon-ese."

While there are moments of inconsistency with leaving Japanese text in scenes in the first season, the majority of the episodes are edited with the use of a slightly different shade of paint to cover over the Japanese -and, at times, replace it with English. This editing suggests that editors intentionally sought to delete references to Japanese culture wherever possible in the first season. In order to "Americanize" the show, editors decided to exclude Japanese-specific text in order to prevent this culture from interfering from interfering with editors' preferred readings of the show.

Erasure. There were many cases where the original Japanese text within the episodes was erased entirely from the English version. In Episode Fifty ("Pokémon Paparazzi"), for example, text within a page featuring the Pokémon photographer Todd is completely expunged. In the Japanese image, the text presumably explains the profile of Todd as it has his Japanese name - Tohru - in katakana beneath his photo. However, in the English version this context is removed entirely - depriving the book and "Todd" of their Japanese identities. Furthermore, in the English version, the title of the book on the front cover is erased as well as the text underneath a photograph of Ash being carried away by the flying dinosaur Pokémon Aerodactyl (a situation that occurred in an earlier episode). In each of these cases, the Japanese was erased entirely and not replaced by English. Rather than "re-odorizing" the edits with an Englishspeaking tint, the editors opted to merely erase the text and rely on dialogue exposition to convey 
the context of the features of the book. What was left, then, was an English translation of the Japanese dialogue which may or may not have accurately conveyed the same information from the original. This erasure occurs elsewhere in the season as well. In Episode Nineteen ("The Ghost of Maiden's Peak"), much of the Japanese text present on street vendor signs and on Japanese uchiwa hand fans was removed entirely, keeping the symbolic Japanese-ness of the objects in question but deleting the linguistic markers delineating them as such.

The most egregious example of diegetic textual Japanese deletion occurred in episode Fifty-One ("The Ultimate Test"). While Ash takes the test, every one of the test's questions and answers have been scrubbed of the Japanese language and the answers replaced with a pictograph representing the correct answer to the question. In addition to these erasures, the results of the test on a scoreboard in the examination building's lobby were also altered from the Japanese version. This erasure obfuscates the intention of the scoreboard. In the Japanese version, each column on the scoreboard along with the test-takers' photos and identification numbers were categorized according to how well they did on the test with the far-left column being those who scored the highest and those on the right the lowest. However, the words indicating these categories were erased entirely from the English version, thereby reducing both the amount of contextual information in the scene and the cultural "odor" present in the episode.

Similarly, in Episode Fifty-Two ("The Breeding Center's Secret"), in the opening shots of the scene, many tall buildings have signs adorning their structures. In the Japanese version of the episode, these signs are filled with Japanese hiragana and kanji alongside images of Pokémon. In the English version, these signs are almost completely erased, leaving only the images of Pokémon and the occasional English lettering. This gives the impression that signs and billboards in the Pokémon world are mostly letter-less decorative adornments for buildings rather 
than advertisements that offer services. This editing to minute aspects of the episode's symbology represents an intent to de-odorize the anime through the erasure of even the most insignificant cases of Japanese text.

This editing is not limited to wide-shots of the city, however, but also occurs in close-up shots of shop signs as well. In the same episode, a close-up of the store-front of the breeding center where the action of the episode takes place has a sign consisting only of the word "Pokémon" in the English version. However, in the original, the sign also contains Japanese words presumably indicating the name and purpose of the center in question. Likewise, a placard to the side of the building has also had its Japanese erased completely. This shot, along with the other shots of the city, indicates to a US audience that there is very little, if any, use for signs as anything more than decoration as they do not convey any information other than the buildings' relation to Pokémon.

This occurs again on a restaurant that Ash and the others visit. This restaurant, in both versions of the show, is named "Restaurant Hungry" as indicated by lettering on the building's canopy. In the Japanese version, this name exists alongside Japanaese katakana characters. However, in the English version, the canopy has only this name written on it. The strange name of the restaurant, then, is the only indication that the building is a restaurant and even then, one that has been titled in an odd manner by English standards. While the letters are perceptibly English, the syntax as well as the connotation of "restaurant" and "hungry" in that order are unfamiliar, giving the sense that the person in charge of the decision to name the restaurant is only vaguely familiar with the English language. This remaining English alongside the removal of the Japanese text causes the scene to "float" in its representation of a strange nationality that is not quite familiar to an English-speaking audience. 
Replacement. The replacement of Japanese text with English is prevalent throughout the first season. In some cases, the diegetic text provided important contextual and expositional cues for the audiences, so it is understandable that these cases would be translated. There are, however, many cases where minor text in the background of shots or hitherto unimportant to the story is removed or translated. What follows are brief examples where originally Japanese texts and equivalents are replaced by their English equivalent.

In Episode Forty-Eight (“Bulbasaur’s Mysterious Garden”), an alteration to a pokécenter emergency room sign was translated to provide the context that Ash's ill Bulbasaur was being held in an operating room for treatment. Also, in Episode Fifty-One ("The Ultimate Test"), the Japanese text on a placard Pikachu holds indicating that the episode is transitioning to a new scene is replaced with the English "Exam \#1." The same technique was also applied to subsequent scenes with "Exam \#2" and "Exam \#3." These replacements provide value as contextual accompaniment to their respective scenes and were therefore translated accordingly.

However, there were often scenes where the on-screen Japanese was minimally related to the story or at least unimportant for understanding the story. In a scene in the first episode where Ash departs on his journey, a crowd of people hold up a supportive banner that says, "Go Ash Go" that - due to a mismatched color palette - has clearly been edited. In the original version, the sign says "Ganbaru Satoshi" which translates to "Do your best, Satoshi." While the meaning of the sign contains similar sentiments between the versions, the Japanese "odor" of the banner has been directly replaced with English text. However, this odor is not completely de-odorized due to the presence of Japanese hachimaki headbands. The context of the scene - cheering Ash along on his journey - is clear. Nevertheless, editors saw fit to de-odorize the banner through translation, while leaving intact the visual symbols of Japanese-ness as they may have been more 
difficult to edit.

Another example where diegetic Japanese specificity was erased and replaced by a pictograph exists in Episode Five ("Pewter City Showdown”) where a shop sign owned by who is later revealed to be Brock's father - Flint (Munō in the Japanese version) - is altered. The Japanese language on the store sign indicating the store's status as a souvenir shop was changed to a picture of a rock with the English script "Rocks for Sale" underneath. Here the kanji and hiragana are deliberately covered by a picture accompanied by English text. In another scene, the text on the Pokémon gym indicating its status as a gym was originally, in the Japanese version, the Romanized "Nibi Gym." Although the text itself in this case was not Japanese, it did not "fit" with the established convention of Westernizing the anime by naming each major town in Kanto after a color (e.g. Cerulean City, Fuchsia City, Celadon City, etc.). Therefore, the text was overwritten with "Pewter Gym" by the editors. The English distributors' intention to remain consistent with the naming convention therefore overshadowed any intention to allow cultural specificity to remain. However, this cultural specificity could not be entirely erased in this episode as evidenced earlier where scenes in which Japanese imagery and objects were tangible.

Whether replaced or erased entirely, Japanese diegetic text in the first season is consistently altered for English-speaking audiences. At times, the translation of this text served to enhance the viewing experience of these audiences as certain objects provided important contextual properties that contributed toward the understanding of the episode's plot. At other times, the removal of Japanese text was done solely to prevent the Japanese "odor" from being apparent or to keep the episode in line with the English conventions associated with characters' and places' names in the anime. In each of these cases, the Japanese cultural specificity of the program was managed in such a way to keep the anime "exotic" as a unique cultural product to 
entice viewers to watch the show but not "too Japanese" so as to prevent accessibility for children.

\section{Names and Puns}

The alteration of characters' original Japanese names further contributes to the "deodorization" of the Pokémon anime. Along with diegetic text, the names of characters in the first season were also altered to be more in line with English naming conventions. The vast majority of main and minor characters' names as well as names of cities and towns were changed in the first season to presumably to be more in line with these conventions. This was a major way in which distributors and editors "de-odorized" the Japanese culture from the anime as many of the characters' have particularly "Japanese" names in the anime. For instance, Ash Ketchum was originally "Satoshi," Misty "Kasumi," and Brock "Takeshi." These alterations served a dual purpose: to Anglicize the characters and to attribute puns to them based on their character (e.g., Ash Ketchum is based on the English version's slogan, "Gotta Catch 'Em All!" and Brock on the characters' proclivity to use Rock-Type Pokémon). These characters' names would therefore be easier to pronounce for American children as they are one or two syllables rather than that Japanese's three-syllable names and easier to remember due to the connection between the characters' profiles and their names. Naming conventions based on puns and other wordassociations are present throughout the first season. The names of towns, for example, are all based on a color palette, with "Pallet Town" ("Masara Town" in Japan) being the origin of Ash's journey and him travelling through places such as Viridian City, Pewter City, Fuchsia City, and Saffron City. While the original Japanese names of these towns approximate to similar colors Tokiwa (Viridian City) equates to an evergreen color, for example - they were nevertheless translated, deodorizing the anime of some of its Japanese specificity. 
While there were puns in the Japanese-versions of the episodes, they were altered to "fit" into English-language. For example, in Episode Four (“Challenge of the Samurai!”), Ash catches a Caterpie (a Bug-Type caterpillar Pokémon) which offends Misty as she is disgusted by BugType Pokémon. While screaming at Ash for catching a "mushi" (a bug), she repeats the word several times in disgust and anger. In reaction to this, Ash dons a cow costume in a reaction shot and, while grinning, questions "ushi?" - seemingly mishearing her exclamations. In Japanese, the word "ushi" means "cow," therefore Ash's costume makes sense in this context. However, in the English version of the episode, Misty exclaims "gross" instead of "mushi," or alternatively, "bug" and Ash replies with a rhetorical question: "Misty, are you grossed out by a Cow-terpie?" Here, while the structure of the pun remains similar, the reference to cows feels forced, making it a sort of "half-pun" wherein the linguistic specificity of the pun had to be left behind in order for the visuals of the scene to "fit." These alterations to puns occur throughout the first season, which indicates that the editors had to expend significant effort in adapting the show for Englishspeaking audiences. However, the editors nevertheless attempted to keep the humor of these puns as much as possible which kept some aspects of Japanese-style wordplay humor but adapting it to an English-speaking audience.

Puns are also embedded in minor characters' names. Professor Oak was originally Doctor Ookido (Orchid), Gary - Ash's Rival - was initially Shigeru, and Officer Jenny - the Pokémon police officer - was Junsara. Here, the same effort to localize the anime was afforded to minimal, tangential characters in order to erase nominal Japanese-ness from the show's first season. Here, not only did editors remove Japanese "odor," they also added American "odor" to give the show a more familiar, recognizable feel for US audiences. This, along with the Japanese visual symbols present in the anime, blended cultural schema together to create a "mixed" text. 
Furthermore, the names of Team Rocket - Jessie and James - were originally Musashi and Kojirou in the Japanese version. While the alliterative English names were coined after the notorious American outlaw Jesse James, their Japanese names were based on of Miyamoto Musashi and Sasaki Kojirou - two famous swordsmen rivals in Japan's Edo period. Here, the cultural odor was transliterated from Japanese myth and history to American myth and history, maintaining some of the original version's referential intent. However, this - like the main character's names mentioned above - was also done so as to allow English speaking children to remember the names more easily. A similar technique was employed for the Team Rocket members "Butch" and "Cassidy" in Episode Fifty-Two. Originally, these characters were named Kosaburō and Yamato, - two distinctly Japanese names referring to a typical name for a family's second oldest son and a battleship, respectively. These characters' names were changed to reference a notorious American outlaw.

However, there was a particularly poignant exception to this alteration of minor characters' names. In the fourth episode ("Challenge of the Samurai!"), the featured character of that episode, "Samurai," retained his name in both the Japanese version and the English version. There are several possible reasons why his name was not "Americanized." The most obvious potential reason was that due to Samurai's samurai outfit, the editors saw little reason to alter the character as it would be difficult to erase or minimize his Japanese-ness in the first place. Additionally, the word "samurai" may have been more familiar to American children than "Satoshi" or "Musashi" and therefore it remained as a semi-common referent in the Englishspeaking lexicon. The familiarity of samurai to an English-speaking world likely informed editors' permission for his name to remain as is. However, the connection between Samurai and his attire as well as with the Japanese landscape and the rest of the Japanese symbols extant 
within the season reduces the gap between audience's familiarity with Japanese culture and the non-immediately obvious Japanese symbols. Producers' and editors' potential intentions with Pokémon were to first and foremost create a profitable product, though it may be argued that there the implicit familiarization of audiences with Japanese culture facilitated this end through the presentation of the "exotic" Japanese aspects of the show.

However, as samurai are distinctly Japanese in nature, the maintenance of Samurai's identity between versions indicates an intention to exoticize one of the first Pokémon trainers Ash encounters. Furthermore, as Samurai was a bug-catcher with Bug-Type Pokémon, he was further embedded in Japanese cultural specificity as Satoshi Tajiri has stated that Pokémon is based on the Japanese hobby of bug-hunting and catching in the forests and mountains of rural Japan. While a Japanese audience would read both aspects of this specificity, the American audience may only be familiar with the samurai references. This reduction of the "cultural odor" of Samurai serves to Orientalize his status as a Japanese person through symbols of samurai. To American audiences, he was presented as an "exotic" image of Japan's feudal history. To Japanese audiences, he was a kid playing dress-up in armor for protection from bugs as he takes part in a familiar hobby many kids enjoy in Japan.

In the case of Samurai, the cultural specificity of Japan may not have been reduced due to the editor's (4Kids Entertainment) intention, but by their potential unfamiliarity with Japanese culture and pastimes. Samurai was presented as a formal boy in samurai garb who believed in honor and fair play. A Japanese audience would be able to connect these symbols to their own socio-historic experiences. However, the American audiences may be aware of samurai and the related concepts of honor and such, but it is through a filtered, orientalized understanding of Japan, the Japanese, and their history that had been informed by other media and representations 
that reinforce a shallow reception and perception of these.

Additionally, some Pokémon keep their original Japanese name in the first season of the anime. Pikachu, the mascot for the series, retains its name internationally. However, Pikachu's name is of Japanese origin - consisting of two onomatopoeia "pika" and "chu," with "pika" representing the sound of the glinting of light on metal and "chu" as the sound a mouse makes. Other Pokémon like Meowth ("Nyaarth") retain their approximate meaning in both versions as "nyaa" is the Japanese onomatopoeia for "meow." For the most part, however, Pokémon names differ wildly between the English and Japanese versions. Charmander's Japanese name "Hitokage" approximates to "fire shadow" and Bulbasaur's "Fushigidane" equates to the colloquialism "isn't it strange?"

These alterations to the names of people, places, and Pokémon indicate an intentional strategy to "de-odorize" the identity of these representations. All of these examples began as having a particularly Japanese nominal origin that editors "smelt" and subsequently "dealt" with in order to increase the potential profitability of the series by replacing these identities with identities that are more familiar to an English-speaking audience, thereby reducing the amount of "Japanese" cultural specificity within the anime.

In the first season of Pokémon, then, producers and editors managed the cultural "odor" in several ways. Producers represented Japanese culture through symbols of clothing, food, architecture, and other assorted forms of cultural knowledge. However, these Japanese symbols were never explicitly connected to Japan or Japanese-ness. As most of these physical representations remained unedited in the translation of the show to English-speaking audiences, these objects signify an unspecified, unfamiliar culture that may be associated more with Pokémon instead of Japan. Other visual images such as Japanese landscapes and matsuri 
festivals inform Japanese audiences about Kanto's Japanese setting. To English-speaking audiences, however, these settings are "exotic" and without ethnic, national, or cultural specificity due to these audiences' lack of cultural schema that would familiarize them with these images.

The edits made to Japanese text within the anime further cause the anime to "float" culture-less for English-speaking audiences. Most of the time, Japanese text was edited out and replaced with English text. Occasionally, the Japanese text was edited out without replacement leaving a blank space on objects where text previously existed. There were, however, instances where Japanese text was left in the English version. This inconsistency in editing permitted some aspects of Japanese linguistic specificity to "slip through" to English audiences.

The linguistic symbols of Japanese culture led the first season to be edited to be less Japanese-specific. This was amplified by editors' alterations to characters' names. Editors of the first season's script changed characters' names to be less Japanese and more American in nature. Rather than keep the "Japanese-ness" of these characters' identities, editors altered them to be more familiar to English naming conventions thereby making them more American. These edits are the most egregious example of editors "deodorization" of Japanese culture in the anime as names are inherently tied to identities. The conjunction of this editing along with the editing to Japanese linguistic text coalesce as an intentional attempt to stifle the show's Japanese-ness. However, the visual representations of Japanese culture allowed certain aspects to remain within the program, though hidden by the "exoticness" of Pokémon's world. The fantastic visuals of Pokémon further maskthe Japanese odor by correlating the Japanese visual symbols to the Pokémon world. Therefore, rather than these images being "Japanese" in the minds of Englishspeaking audience, they are "Pokémon-nese." 
In the next section, I examine Season Twenty's visual and linguistic symbols to determine whether the same strategies used in the first season were employed. In doing so, I compare the two seasons' cultural "odor" to conclude how the management techniques in the latest season differ from those in the first season if they differ at all.

\section{Background of Season Twenty}

Inspired by the real-world Hawaii, the region featured in Season Twenty of Pokémon is Alola, a tropical archipelago comprised of four main natural islands. With beach resorts, humid jungles, arid mountains, and volcanos, the region is a direct analog to the Polynesian islands of the Pacific Ocean. In this setting, Ash once again sets out on adventure.

In this season, Ash and his mother Delia win a trip to Alola as a prize from a lottery machine. While on vacation, Ash explores Melemele Island, meets new Pokémon and encounters the "Pokémon School," a school where children learn how to become better trainers. Additionally, during an encounter with Melemele Island's guardian Pokémon Tapu Koko, Ash receives a "Z-Ring" bracelet permitting him to take Alola's "Island Challenge." The Island Challenge is a competition similar to the Pokémon League in that trainers face off against island "Captains" and "Kahunas" (the functional equivalent of Kanto's gym leaders) in various sorts of trials testing their capability as Pokémon trainers. To take part in this challenge, Ash decides to stay in Alola and study at the Pokémon School while his mother returns to their home in Kanto. In this Polynesian context, Ash travels from island to island on his adventures, though always returning to Melemele Island's Pokémon School. Furthermore, Team Rocket continue their schemes from Season One and follow Ash to Alola in order to steal rare Pokémon for their leader. 
In Alola, Ash and Pikachu meet a new cast of reoccurring characters. Three of these characters (Lillie, Sophocles, and Lana) are of ambiguous ethnicity but have pale skin. Lillie is a blond girl who is afraid of touching Pokémon. Sophocles is a rotund boy with a penchant for gadgetry and Electric-Type Pokémon while Lana is a short girl with blue hair who enjoys fishing in the ocean and Water-Type Pokémon. Four other re-occurring characters have tanned skinned presumed to signify their Polynesian ethnicity. Professor Kukui, the instructor at the Pokémon School, is a laid-back academic who wears his lab coat open, revealing his chest. Similarly, Kiawe, a Fire-Type Pokémon enthusiast, has dark skin and wears no shirt. Mallow, on the other hand, is a green-haired aspiring chef whose father runs the local restaurant. With the exception of Professor Kukui, of these characters are students at the Pokémon School alongside Ash.

In Season 20, many of Pokémon's Pokémon characters are "revamped" variants of their respective original forms. Additionally, a human character from the first season - Professor Samuel Oak - has an Alolan cousin named Samson Oak who also studies Pokémon. Samson has tan skin, longer hair, and wears a Hawaiian shirt, shorts, and sandals in contrast to Samuel's formal lab attire. Here, the producers of Pokémon have "re-tooned" Samson to be more exotic compared to his cousin, Samuel.

There are also new versions of Pokémon originally released/debuted in the first generation of the video game and the first season of the anime. Raichu, for example, has a new "Alolan Variant" that has browner fur and Psychic-Type powers in addition to its original Electric Typing. Some Pokémon were re-presented with new versions based on Polynesian tradition. For example, Marowak - originally introduced as a Ground type Pokémon that wields a bone as a club - has a new Ghost/Fire form that resembles a Hawaiian fire dancer. In this Alolan version, its club is now a staff that resembles a Samoan Siva Afi ("fire knife") with fire 
on each end that it spins as it attacks and dances. Plant-based Pokémon are also reimagined. Some of them, like the coconut-tree Pokémon Exeggutor "adapted" to the Alolan environment by growing ten feet taller as a tree to better blend in with the archipelago's flora. Originally a Grass and Psychic type Pokémon, Exeggutor in its Alolan form is instead a Grass/Dragon Pokémon.

In the next sections, I examine episodes of Season 20 for evidence where producers and editors chose to "de-odorize" Japanese specificity from the anime. In doing so, I focus on the backdrop of the Alolan setting as well as the cultural aspects of objects present in these episodes. By tracing the patterns of "deodorization" used in this season, I analyze how producers and editors of the anime have managed the cultural odor of Pokémon twenty years following its initial broadcast.

\section{Analysis of Episodes}

\section{Landscape}

The Pokémon who inhabit Alola are inspired by the flora and fauna of the tropical climate. The Flying-Type Pokémon Toucannon, for instance, is analogous to toucan birds, Komala to koala, and Crabrawler to crabs. Other Pokémon based upon real-world animals include those based on Hawaiian birds (the Bug-Type Oricorio), small Asian mongoose (the Normal-Type Yungoos), and bee fly (Ribombee, another Bug-Type). Here, the original Japanese-influenced Pokémon and humans were interspersed with an exoticized image of Polynesian plants and animals.

This is further compounded by the fact that Hawaiian-inspired landscapes such as jungles, volcanoes, and oceans are prominent throughout the twentieth season. In contrast to the mountain forests of Kanto, Alola's geography is rich with lush jungles and vast oceans with an 
occasional volcanic mountain in the background. While these volcanoes resemble the mountains in the first season, Alola is for the most part absent of any Japanese scenery. Rather, the Polynesian-esque island-scape is filled with the naturalistic representations of island life such as palm trees, waterfalls, and beaches as well as symbols of Hawaiian-colonized tourist spots such as towering hotels and beach resorts. While these resorts are present primarily in background shots, they nonetheless reoccur throughout the first season. Furthermore, the initial plot of the season results from Ash's visit to an Alolan resort as a vacation from life in Kanto. Alola as a location is therefore represented as an exotic locale away from the "norm" of everyday life. Rather than the normalized Japanese landscape of Kanto, Alola is an exotic Polynesian archipelago filled with images of tropical island-life.

However, that is not to say that the twentieth season is completely absent of "Japaneseness." In the following section, I examine the "Japanese-ness" of images represented in the twentieth season, the Polynesian-ness of the images, and the diegetic text both present and erased, as well as the "odor" of the names of the characters and the locations within this season. This is then compared to the first season to see if there were any differences in the management of cultural "odor" between the two seasons. A discussion will follow considering the implications of this analysis.

\section{The Japanese-ness of Food, Clothing, and Architecture}

Food. In the twentieth season, Japanese food, utensils, or related objects are rarely present in the episodes analyzed. In Episode 979 ("Mallow and the Forest Teacher"), there is a brief shot of a table full of food including a bowl of ramen. In the 13 episodes that I examined from Season 20, this bowl of ramen is the only example of Japanese food noticeably present within the anime. This lack of Japanese cuisine suggests that Alola lies outside the boundaries of 
Japan. Furthermore, whenever characters eat food, they do so with knives and forks, unlike the regular occurrence of chopsticks in the first season. In addition to this lack of Japanese utensils, most if not all of the food present in scenes are fruit, vegetables, eggs, and barbecued meat. Here, Polynesian cuisine is the primary type of food represented in this season, though there are occasional instances of "Western" food such as doughnuts and mention of other, non-Japanese food like gratin and shish kebab. Additionally, In the same scene with the ramen, Chinese dumplings are also present on the table, representing other Asian cuisine alongside Japan's. The representation of food in this season is deliberately presented and acknowledged as part of the scenes in contrast to the first season where the food is minimized as tangential aspects of scenes. In any case, aside from the brief instance of ramen, there is very little mention, let alone representation, of Japanese food such as the onigiri rice balls and miso soup that are present in the first season.

Architecture. In addition to the lack of noticeably Japanese food representation in Season Twenty, there are also very few instances of Japanese architecture or interior design. Japanese architecture is only notably present in two scenes of the episodes analyzed.

The most notable instance of Japanese architecture is in Episode 940 ("Yo, Ho, Ho! Go, Popplio!"). In this episode, Lana brings Ash, Pikachu, Professor Kukui, and the rest of the class on a fishing trip. The night before the trip, Ash visits Lana's home to pick out a fishing rod he can borrow for the trip. Here, her home's interior and exterior are of traditional Japanese wooden design complete with tatami mats in the living room. Furthermore, brief exterior shots of Lana's neighborhood reveal other Japanese-style homes as well. This multiplicity of Japanese homes on the island is further pronounced in Episode 975 ("Balloons, Brionne, and Belligerence!"). In several shots, Japanese homes are present in the backgrounds of the scenes. While brief, these 
scenes indicate a Japanese "settled" presence within Alola.

Clothing. Just as the dearth of representations of Japanese food indicate that Pokémon has been "de-odorized" of a strong Japanese presence in Season Twenty of the anime, so too have other traditionally Japanese objects. In addition to the deficiency of representation of Japanese food and architecture, Alola also lacks Japanese fashion. Clothing-wise, only two noticeable representations of Japanese culture are found in the episodes analyzed. In Episode 975 (“Balloons, Brionne, and Belligerence!"), a minor character named Ida is introduced. Ida is a musical performer who wears an outfit that is similar to a kimono crossed with a dress and accompanies her Pokémon while they do circus-like talents and maneuvers. Furthermore, while she performs with her Pokémon, she plays a biwa - a Japanese stringed instrument. In the same episode, Ida's boyfriend Kanoa - a man with tanned skin who wears a shell necklace, surfboards, and dives for treasure - wears a haori, a traditional Japanese overcoat. Here, the Pacific-Islander image typified by Kanoa is correlated to Ida's approximate "Japanese-ness" as a blend of the two cultures.

Although this season held very few representations of Japanese clothing, Japanese-ness was nevertheless exoticized by occasional exposition such as in Episode 975 ("Balloons, Brionne, and Belligerence!'). In a scene in this episode, Ida and Kanoa explain that they're travelling "Sea Folk" who search for treasure and perform circus stunts to make ends meet. Here, although their clothing is Japanese, this clothing does not seem to culturally "match" the lack of firm structure that they have in their lives which seems to be closer to that of Polynesian or Romani cultures. Here, although Japanese clothing was present, it was part of the dress of the "Sea Folk" - ancillary characters who appeared in only one episode.

Overall, in the twentieth season, Japanese clothing attire was associated more with the 
"exoticness" of happy, free-spirited characters rather than directly connected to Japanese culture. This contrasts with the first season's representation of Japanese clothing wherein characters were often seen wearing Japanese clothing without explicit connection to Japanese culture. Instead, the implicit nature of this Japanese clothing is present to Japanese audiences but this connection is intentionally left out of the English version of the anime. However, in the twentieth season, Japanese clothing is explicitly connected to the "Sea Folk." Here, Japanese culture is exoticized through the intentional displacement of Japanese clothing articles onto fictional representations of Polynesian sea-farers.

\section{Japanese Cultural Knowledge}

Representation of Japanese cultural knowledge is also rare in Season Twenty. With the exception of a few notable instances of objects, social customs, and mythology, there are not as many depictions in this season as there as there are in the first season. The most prevalent example of "Japanese-ness" is the continued ubiquity of the gashapon-esque pokéballs outlined above. However, while Japanese cultural specificity is not as prevalent as it is in the first season, there are several examples indicating that there remains some Japanese-ness continually produced and represented within the anime series.

In a flashback scene in the first episode of the twentieth season for example (Episode 936: "Alola to New Adventure!"), Ash and his mother win a vacation to Alola from a Japanese lottery machine. This machine is a ten-sided wooden wheel that is operated by turning a handle to spin it several times before it "spits out" a random ball signifying a certain prize contingent upon the operator's rules. In this case, Ash and his mother receive a rare ball signifying a trip to Alola. In the same scene, the machine's operator wears a Japanese happi jacket, suggesting that Ash and his mother are at a matsuri festival when they win the prize, grounding the scene in 
Japanese culture. It is also notable that they are presumably in the more-Japanese Kanto region when they win this trip, indicating that the lottery machine is connected to Kanto culture because it is never present in Alola. The confluence of these symbols makes this scene the most "Japanese" out of any other scene in Season Twenty, although there is another instance where Japanese culture and related cultural knowledge is present.

The one other instance of a Japanese cultural object is in Episode 939 ("First Catch in Alola, Ketchum-style!"). Here, a Flying-Type owl Pokémon named Rowlet carries back a Japanese wind chime fuurin to its adopted Flying-Type Pokémon family of Pikipek (woodpecker), Trumbeak (small toucan) and Toucannon (large toucan) because it mistakes it for a piece of fruit. While it remains a relatively minor aspect of the episode, it does build Rowlet's character development in that it accentuates Rowlet as not quite "fitting in" with the rest of the tribe. In any case, the deficiency of Japanese cultural objects in Alola suggests that Alola exists apart from Kanto's “Japanese-ness.”

Alongside these objects, there is a Japanese cultural-specific tradition present in Episodes 977 and 978 (respectively, “Alola, Kanto!” and “When Regions Collide!”). In Japan, a shügakuryoko is a school field trip that happens once in a student's secondary schooling career when they go to an "exotic" locale, most commonly the islands of Okinawa or Hokkaido if they live on the mainland, but sometimes to foreign regions such as Korea, Taiwan, or Hawaii if the school is wealthy enough. Furthermore, shügakuryokō is a consistent episode theme in many other anime, representing the school trip experiences of its primary demographic (junior high to high school aged adolescents). In Pokémon's twentieth season, Ash, his instructor, and his classmates go on a shügakuryokō to the "exotic" Kanto region. Here, the Japanese producers of the anime facilitate a recursive exoticization by re-presenting Kanto (Japan) as the exotic "other" 
in comparison to Alola and the Alolan natives' experiences. This is represented most clearly when the Alolan characters are amazed at the "Kanto versions" of their familiar Alolan Pokémon. The taken-for-granted assumption of Kanto and its related Pokémon as being the original and therefore the primary culture of Pokémon is turned on its head when viewers are forced to reconcile perspectives from another culture's point of view in the Pokémon world. Furthermore, the one thing that remains constant between Pokémon seasons (besides Ash and Pikachu) is Pokémon and their implicit association with yokai. This cultural knowledge, then, is a constant between Season One and Season Twenty indicating that although other types of visual symbols consistent with Japanese culture are reduced between the airings of these seasons, the implicit connection between Pokémon and Japanese folkloric tradition remains unbroken.

Another aspect of Japanese cultural knowledge present in the twentieth season is the connection of Pokémon to yokai. In Episode 975 ("Balloons, Brionne, and Belligerence!") when the main characters along with the Sea Folk Ida and Kanoa are out at sea seeking sunken treasure, the Pokémon Dhelmise guards the sunken ship holding the treasure - the "Mystic Water" - an amulet made from enchanted sea water. Dhelmise is a Ghost and Grass-Type Pokémon resembling a giant ship's anchor and steering wheel with a single eye that looks like a compass. Kanoa notes that Dhelmise is hyper-protective of anything within its territory and that they should therefore take care in diving to retrieve the treasure. Of course, Team Rocket, unaware of this information, disturbs and consequently enrages Dhelmise with their submarine trying to get to the treasure before the others. After Dhelmise disposes of Team Rocket with its thrashing, it is subsequently placated with the help of Lana's Popplio - a Water-Type Pokémon that resembles a circus seal. Dhelmise is therefore represented as a territorial guardian of nature that should not be disturbed lest it unleash its wrath. Furthermore, the resolution of this plot 
suggests that when the natural world is disrespected and disturbed by technology, it can only be returned to its natural state through the help of natural forces.

Furthermore, in Episode 939 ("First Catch in Alola, Ketchum-style!"), that status of Pokémon as respected yokai is represented by a flock of Pikipek and a Rowlet who take fruit from street vendors' carts and bring it back to their nest. As the vendors smile and wave at the bird Pokémon, it suggests that this fruit is presented as an offering in return for the birds' happiness, well-being, and their protection. The flock's capriciousness presents itself, however, when a Trumbeak scolds Rowlet for bringing back the wrong thing (the fuurin mentioned above). This occurs again when the flock steal a load of fruit from the hoard of a Bewear, a Pokémon that resembles a large stuffed bear. However, as Team Rocket had made friends with this Bewear, they seek to steal back the fruit from the tribe and return it to its "rightful" owner. Here, the ethical ambiguity of wild Pokémon, and therefore yokai, is presented as indicative of their inherent nature.

A poignant example of wild Pokémon as forces of protection and benevolence is in Episode 974 ("Mallow and the Forest Teacher"). In this episode, Mallow runs away into the jungle from her father's restaurant as she feels she is not receiving the recognition she deserves as a cook. Along the way, she trips, falls unconscious and is rescued by an Oranguru - a Psychic and Grass-Type orangutan Pokémon known for its intelligence. At its hut, Oranguru brews "Pinap" Juice from the Pinap Berries it has gathered nearby and gives it to Mallow when she wakes up as she recounts her frustrations toward her father. Later in the episode, Oranguru shields Mallow from Team Rocket and forces them to flee with its psychic abilities. Furthermore, when Ash, Mallow's dad, and the rest of Mallow's friends find her, Mallow's dad reveals that Oranguru taught him how to first make his famous Pinap Juice which led to his 
success as a restaurant owner. Oranguru is additionally noted to be a positive influence in Melemele Island's community as a "therapist" for the townspeople who bring it Pinap Berries in return for the Pinap Juice it makes, along with listening to them while they vent about their troubles. Oranguru's hut is additionally mentioned to have been built by the townspeople in recognition and thanks for Oranguru's help, likening it to the shrines found throughout Japan that were built in celebration and deference to the guardian spirits of Japan.

Here, the benevolence and protection from yokai in return for the community's respect is featured as a guiding lesson of the episode. Oranguru's shamanistic nature is cemented by its solitary habitation of a hut within a tropical jungle. Furthermore, the animism of Japanese yokai and Polynesian beliefs in protective guardian spirits cross paths through cultural proximity. This connection is never explicitly made present, however, so while Japanese- and Polynesianaudience readings may make this connection due to their implicit cultural schema, other audiences may merely attribute Oranguru and other Pokémon's behavior to the quirky personalities of "Pocket Monsters."

This cross-cultural proximity is further exemplified by Tapu Koko - the guardian Pokémon of Melemele Island. Tapu Koko presents a direct connection to Hawaiian culture through its Hawaiian totem pole appearance as well as its Polynesian-sounding name stemming from "tapu" - a Hawaiian word signifying something that is sacred. As the guardian deity of Melemele Island, it protects people and Pokémon from threats and decides who is allowed to take the Island Challenge. It also resembles yokai in its mannerisms as Lillie tells Ash that it likes to play tricks on people if it deems it "necessary." Polynesian mythology concerning guardian spirits and their connection to nature is therefore made present through the character design of Pokémon such as Tapu Koko, and the cultural proximity of animistic traditions is 
pronounced in Tapu Koko's behavior in conjunction with its Polynesian appearance.

\section{Polynesian-ness}

Season Twenty of Pokémon held very few instances of apparent Japanese cultural specificity. Rather than merely eliminating the Japanese "odor" of Season Twenty, however, producers of Pokémon instead replaced this "odor" with that of Hawaiian culture. In doing so, they exoticize a "new" culture in place of Season One's presentation of the "exotic" Japanese culture. Just as Season One's Kanto setting resembled that of the Kanto region in Japan, the very setting of "Alola" as well as select other representative features coalesce to form an exoticized visual representation of Hawaii. In this season, elements of Hawaiian food, architecture, clothing, and other signifiers of Hawaiian culture are consistently found within the analyzed episodes.

For instance, much of the food extant in this season resembles that typically found in tropical climates. Fruit with spikes resembling pineapples and dragonfruit were most present but barbecued meats and salads were also consistently represented. Architecturally, most of the buildings in Alola resembled those of Western origin. However, there were some that resembled Polynesian buildings. For instances, Oranguru's thatched hut woven with reeds and straw and lifted off the ground by wooden planks is similar to buildings typically associated with native “islanders." Additionally, the Pokémon School Ash attends resembles a Polynesian bungalow comprised of several buildings raised on the water and conjoined by walkway bridges.

The stereotypical relaxed nature of island life is represented in the clothing of three reoccurring characters: Samson Oak, Professor Kukui, and Kiawe. Samson bears a strong resemblance to his cousin as an older man with tan skin, but in contrast to Samuel Oak, Samson has long white hair and wears white cargo shorts, purple flip-flops, and a light-blue button-up 
shirt decorated with images of fish. His relaxed, good-natured attitude is additionally signified by a loose top-button on his shirt that exposes his neck. Another character, Professor Kukui, is similarly dressed as he wears a pair of bicycle shorts underneath a pair of board shorts, shoes without socks, and a laboratory jacket that is completely open, revealing his chest and emblemizing his care-free attitude. Kiawe, a dark-skinned teenager, resembles indigenous Polynesian peoples through the way he dresses. As Kiawe prefers, and is partnered with, FireType Pokémon, his character profile is associated with that of fire with its red and brown hues. Additionally, his red and black hair resembles both a flame and an erupting volcano, further associating Kiawe with fire and island topography. Furthermore, Kiawe wears a necklace made of seashells and bone with a gold amulet adorned with red gems. The confluence of these factors - along with his dark skin tone and lack of shirt - suggests that Kiawe is native to the Alolan archipelago.

Rather than the consistent presence of Japanese clothing and cultural objects found in the first season, the producers of the twentieth season instead represented Polynesian culture. In doing so, they exoticized the "Alolan" locale through stereotypical symbols of Hawaiian island life such as fire-dancers, shirtless surfers, and indigenous (sometimes tribal-looking) main characters.

\section{Conclusion}

The Pokémon Company and 4Kids Entertainment, through their respective production and editing of the show, balanced the Japanese cultural specificity of the first season in order to appeal to multiple audiences. For international audiences who may be "turned off" by the foreign-ness of a Japanese cartoon, 4Kids erased and replaced instances of Japanese linguistic text. This erasure and replacement was inconsistent, however, as there were several instances 
where Japanese text was seen in the English version of the episodes. However, 4Kids was not able to easily edit the Japanese-specific symbols. Japanese architecture, clothing, food, and other assorted cultural knowledges manifested within the show's symbols were therefore left unaltered. Although these symbols persisted in the English version, they were never explicitly associated with Japanese culture. International audiences are therefore presented with symbols emblematic of Japanese culture without their articulated meanings to Japanese-ness. Instead, these symbols are neutralized artifacts of the "everywhere but nowhere" context of Kanto. While Kanto is a recognizable location to Japanese audiences, international audiences may interpret the region as culturally ambiguous location. Here, audiences may attribute the context of the show to whichever culture with which they are most familiar or interpret the region as an exotic, culturally-neutral place.

However, this neutralized interpretation may be mediated by potential connections to Japan made by audiences who are aware of stereotypical connotations of certain Japanese symbols (e.g., ninja, samurai). For those who are cognizant of the Japanese-ness of these symbols, the first season may present opportunities to become aware of other symbols relevant to, and indicative of, Japanese culture. The balancing act The Pokémon Company performed in the first season in including only some Japanese symbols without making the show "too foreign" for international audiences permitted associations to Japanese culture to be made. Furthermore, the fact that 4Kids was inconsistent, and at times amateurish, with their edits to Japanese linguistic text expanded on these associations. The variance in erasure and replacement permitted some Japanese diegetic text to be present in the anime, potentially indicating to international audiences the cultural origin of the anime by mediating the culturally-neutral aspects of the program. 
In the twentieth season, however, the "everywhere but nowhere" context of the show was replaced with one that was recognizably Hawaiian. Instead of presenting the exoticness of a culturally ambiguous Pokémon world, The Pokémon Compnay instead exoticized aspects of Polynesian culture. Rather than producers and editors erasing the Japanese cultural odor of Pokémon in its twentieth season, they intentionally included Hawaiian cultural odor to overwrite its Japanese specificity. While there was the occasional Japanese-specific symbol present in an episode, it was overshadowed by the saturation of Hawaiian symbols omnipresent within the season. Therefore, The Pokémon Company included explicit associations to Hawaiian culture, potentially in order to make the anime seem "fresh" in its twentieth season. 


\section{CHAPTER V: DISCUSSION}

In Season One, editors managed the Japanese cultural "odor" of the program through selective edits to diegetic text within the episodes. This cultural odor is defined by Iwabuchi (2002b) as the stereotyped features of products positively associated with their respective countries of origin. Iwabuchi applies this concept to the features of Japanese products, which often include representations of samurai, geisha, and ninja. While the linguistic cultural odor was often erased and replaced in the first season, visual symbolic images emblemizing Japanese culture (e.g., ninja, samurai) remain unaltered, allowing representations of Japanese-ness - and consequently its cultural odor - to "slip through." As these images are commonly associated with Japan, global audiences are therefore more likely to associate Pokémon - and its non-obviously Japanese imagery - to Japanese culture. Here, such stereotypes as ninja and samurai provide a sort of "Rosetta Stone" toward interpreting the cultural specificity of the Pokémon anime as scholars such as Akita (2006) and Nishihara (2005) note the orientalized representations of Japan and Japanese culture in media through images of geisha. Furthermore, Sorenson (2008) argues that anime that are internationally successful (most notably, Hayao Miyazaki's Spirited Away) portray "neo-orientalist, quasi-religious mysticism" in conjunction with traditional "Japaneseness" to produce a form of exoticism of Japanese identity within an animated medium (p. 190). Here, Pokémon presents symbols of Japanese culture that have served as stereotypical markers of orientalist perceptions toward Japan.

The editing of the linguistic text was furthermore inconsistent as there were several examples where Japanese hiragana, katakana, and kanji were present in scenes. This inconsistency further associated the Japanese language with the "foreign" images on screen potentially facilitating the reception of Japanese culture for an English-speaking audience. 
Additionally, the names of characters and places were altered from the original Japanese to be more "Western" in reference. Characters' identities were therefore deliberately changed to be less Japanese in this season. As none of the main characters' names went unchanged, it suggests that editors attempted to eliminate all traces of Japanese "odor" whenever possible In doing this, 4Kids Entertainment managed the "threat" of Japanese-ness. Per Ivy (1997), "the foreign - because of its very threat - must be transformed into a manageable sign of order, a transformation indicated most clearly by...internationalization" (p. 2-3). Though mediated images and metaphors, the "West" was able to rhetorically manage anxiety concerning Japan and the Japanese in film, television, and novels. With the exception of "Samurai," no characters had English names recognizably associated with Japanese culture signifying a management of the threat by Westernizing these characters' identities. Samurai exists in the first season as a familiar stereotype that provides a locus of orientation for audiences to read Pokémon as Japanese, though not too Japanese.

In the twentieth season, however, the producers and editors of Pokémon reduced the evident Japanese-ness even further. While some Japanese artifacts remain interspersed in the occasional scene, the twentieth season was mostly "scrubbed" of visual symbols suggestive of Japanese “odor." This was further enabled through the replacement of Japanese and English diegetic text with a new, "Alolan" language. This language exoticized the anime through its contextualization of the geographic setting as a place where familiar written language conventions do not apply. In this case, the Alolan language became its own, alien form of cultural "odor" as a symbol for a culture that is not English, nor Japanese..

Rather than the apparent Japanese odor that was present in the first season, Season Twenty contains representations of Polynesian and Hawaiian culture that coalesce into a 
substituted cultural "odor." This substitution subsequently exoticizes tropical Polynesian island life through the representation of associated stereotypical images such as landscapes, clothing, food, and other assorted cultural objects and knowledge. Therefore, the producers of Pokémon in its twentieth season managed the Japanese cultural "odor" by primarily replacing it with a Polynesian "odor." The implications of these management techniques are discussed in the following chapter.

Essentially, the task of the producers and editors of the Pokémon anime was tailoring the first season to as broad of a base as possible while retaining cultural specificity to keep it relevant to the Japanese market. This aligns with Kraidy's (1999) definition of glocalization as a "concept that takes into account the local, national, regional, and global contexts of intercultural communicative processes" (p. 472). To do this, they had to balance several types of audience in mind: the initial Japanese audience toward whom the anime was first broadcast toward and who held expectations for how anime represents Japanese culture, the non-Japanese anime-fan audience who were tangentially aware of Japanese cultural specificity, and the international audience for whom Japanese culture would be unfamiliar outside of certain stereotypes.

The challenge for producers and editors for this first season, then, was to produce Pokémon in such a way that it could appeal to each of these audiences simultaneously. For foreign audiences, they needed to account for children's general ability (and inability) to comprehend foreign products and foreign information, yet retain enough of the Japanese-ness to make it a unique "cartoon" thereby inviting these children to explore its uniqueness. Similarly, producers needed to account for the tastes of non-Japanese anime fans who had come to expect certain aesthetic and symbolic qualities of anime and for whom these qualities were attractive. In order to appeal to these demographics, editors left in much of the Japanese-specific visual 
symbols indicative of Japanese cultural specificity, yet translated or outright removed much of the Japanese linguistic text present in episodes. Here, Iwabuchi's (2002a) conception of globalization as a tailorization of products to "the demands of the local market" is made evident (p. 46). The Pokémon Company, however, also maintained the presentation of the Pokémon as a distinctly Japanese anime through the inclusion of Japanese imagery emblematic of its culture. By doing this, they were able to retain elements of "subtle" Japanese-ness that anime fans familiar with some of these symbols could recognize but, because of the edits made to the episodes, children unfamiliar with Japanese culture could also comprehend these episodes' features. Furthermore, the remaining aspects of Japanese "odor" became the markers of a unique product - and culture - for US audiences. Therefore, in the creation and distribution of the first season of Pokémon, producers and editors had to carefully manage the Japanese cultural "odor" present in episodes in order to appeal to each of these audiences

In the first season, producers and editors struck a balance between keeping the particularly Japanese symbols visually present in the episodes, but, for the most part, removed or replaced Japanese linguistic text that discernibly linked the Pokémon world to Japan and Japanese culture. Editors removed most of the diegetic Japanese text present in episodes in order to "de-odorize" the anime of this Japanese specificity. The lack of text anchoring Kanto to a specific culture therefore caused it to "float" as a fantastical world lacking association to any particular nation for non-Japanese audiences.

The inconsistency of doing away with (most) Japanese diegetic text but retaining Japanese cultural objects lent the first season toward a reading that suggests to English-speaking audiences that the Pokémon anime portrays an unfamiliar, culturally-ambiguous "floating world." While the Japanese text was replaced by English text, this English-ness was mediated by 
the visual symbols representing Japanese culture - symbols that are dissonant with Englishspeaking audiences' experiences with what constitutes North American culture. Therefore, to these audiences, Kanto lies neither in Japan nor the United States but "floats" between them depending on the viewers' cultural experiences. While a Japanese person would read Pokémon's first season as taking place in Japan due to the multitude of symbols and linguistic markers suggesting this interpretation, audiences from the United States would recognize it more as "notAmerican." With the exception of Japanese symbols and the occasional dialogue making references to familiarly American food and culture (e.g. doughnuts) and "American" names (e.g. Jessie, James, Jenny), the first season of Pokémon primarily consisted of "odorless" symbols non-specific to any particular culture. As these audiences in the United States would not have the same understanding of the connotations these symbols have in reference to Japanese culture along with the fact that these symbols are never directly connected to Japanese "odor," they thereby "float," unbound by recognizable cultural specificity. This caused Kanto to seem like an “everywhere but nowhere" place.

Furthermore, the replacement of characters' Japanese names with “Americanized” names further supports the conclusion that the editors of the first season wished to "de-odorize" the anime as much as possible in order to better appeal to US audiences. As "Satoshi," "Kasumi," and "Takeshi" are all inherently Japanese, editors most likely replaced them, respectively, with "Ash Ketchum," "Misty," and "Brock" for the dual purpose of making the show more “American" and "cartoony.” Additionally, editors simultaneously “de-anime'd” and "cartoonified" the show through English-language puns and naming conventions that assembled the context of the show as a fantastical land. For example, the color-coordinated convention of 
re-naming the locations of the first season (e.g. "Pallet Town," "Viridian City," "Fuchsia City") made Kanto seem to be outside the realm of familiarity in terms of town and city names.

However, there were several instances where Japanese text "slipped past" the editors. The occasional glimpses of Japanese text in conjunction with both the stereotypical and nonstereotypical images of Japanese-ness further grounded the first season in Japanese specificity, providing yet another "hint" towards its Japanese origin for non-Japanese audiences. Furthermore, the name "Kanto" directly refers to the Kantō region in Japan, suggesting that though it is a real place - the editors thought it "exotic" enough to sound like a land where magical monsters lived thereby orientalizing Japan through the show.

In the first season, there were instances where Japanese cultural symbols were "scrubbed" of their cultural odor by editors. As in the case where editors translated Jessie's kimono fitting profession as a "costume designer," editors intentionally replaced dialog signifying the Japanese specificity for the purpose of familiarizing the on-screen symbols to US audience's experiences. However, this "costumification" implicitly orientalized kimono as a mere costume rather than exploring its status as a traditional form of Japanese attire.

The presentation of culture therefore has as much to do with the verbal dimension (how symbols are noted and talked about) as it does about the visual dimension (what symbols are seen and how they are presented spatially). In the case of Jessie's kimono, as it was translated as a costume, it was therefore reduced in the minds of the US audience to a costume and not a traditional garment significant in Japanese culture. This same audience, potentially unfamiliar with Japanese artifacts, may then unquestioningly assume this costume is native to that of the Pokémon world and not the real world, further disconnecting kimono from Japan. 
This stereotypical orientalization is mediated by actual, culturally-salient representations of Japanese culture. Replete with images of Japanese landscapes, architecture, clothing, and other assorted cultural artifacts, the first season held representations of Japanese-ness that intrinsically connected the show to Japanese culture. The saturation of this first season of the anime with images of Japanese culture may imply several things. Japanese producers may not have expected Pokémon to be a worldwide hit and therefore chose not to limit the visual "Japanese-ness" in the first season. On the other hand, this may also be read as an intentional conveyance of Japanese cultural representation to foreign audiences. This potentially intentional conveyance may be read as a calculated move to portray an exoticized Japan made fantastic through the influence of Pokémon. Furthermore, through the representation of stereotypically Japanese images of ninja and samurai alongside the not-so-obvious Japanese representations of cultural artifacts such as zabuton pillows and Shinto shrines, Japanese producers correlated these objects. This correlation thereby (intentionally or unintentionally) furthered associations between the show and Japanese culture through the introduction of "new" Japanese representations to foreign audiences.

The representation of stereotypically Japanese images (e.g. ninja and samurai) invite nonJapanese viewers to recognize the Japanese-ness of the first season of Pokémon. If these audiences recognize these stereotypes then they may be likely to associate the show with Japan, Japanese culture, and then, subsequently, associate other unfamiliar symbols with Japanese culture as well. While these images may not explicitly teach audiences about Japanese culture, they at least make these audiences aware that there is more to Japanese culture than the stereotypical images that have been repeatedly represented and codified in media. The "exotic" qualities of the Pokémon world in the first season may influence audiences to follow through 
with attending to other anime with similar representations of Japanese culture. In this way, the first season of Pokémon, through its aesthetic qualities, offered an opportunity for audiences to become aware, and potentially appreciative, of Japanese culture.

The interpretation of this inclusion of Japanese visual "odor" as an unintended side-effect of the show being produced in Japan is corroborated by editors' penchant to edit away or replace Japanese diegetic text in this first season. While this diegetic "scrubbing" was at times inconsistent, it was nevertheless noticeable through their amateurish methods of covering up the text with mismatched paint tones. However, intentional or not, it nevertheless remains that global audiences were introduced to non-stereotypical representations of Japanese culture through not only their existence within the episodes, but also through their proximity to Japanese cultural objects that were obviously and stereotypically Japanese. It may be argued that these previously non-stereotypical objects could become stereotypical through correlation with stereotypical objects. However, as stereotypes become such through reductive repetition, there is little danger of these objects in this instance doing so as these objects were never explicitly tied to Japanese culture nor were they oft repeated in a manner that reduced their status to that of caricature. Instead, these images were normalized as part of the first season's scenes as a taken-for-granted aspect of Kanto's culture by characters. Furthermore, as anime programs in the US have been, and continue to be, rather rare in broadcast, there have been few opportunities for these images to become caricaturized through reductive and shallow representation. These representations then, instead of existing as stereotypical representations of Japanese culture, endure as opportunities through which non-Japanese audiences can learn more about Japanese culture through their representation in anime. 
Although it may not be said that these symbols actively teach people about Japanese culture, they nevertheless exist as gateways through which people can begin to explore the culture's uniqueness. And while it cannot be said that this proximity "teaches" Japanese culture nor does it necessarily influence people to learn more about Japanese culture, the conjunction of these images at least facilitates thought that Japanese culture is more than the stereotyped ninja and samurai. Potentially, however, for those who have developed an interest in Pokémon, may seek further representation of these symbols in other anime as well. Pokémon therefore presents aesthetic opportunities for people to become cognizant and appreciative of other cultures through its representation of Japanese cultural symbols.

Cognizant of the audience's desires for novelty, producers of Pokémon may have intentionally included Japanese cultural "odor" within the first season as an "exotic" selling point to differentiate this anime from Western cartoons. This aligns with Ning's (1997) conception of the Orient as a "mysterious" and "attractive" locale due to its position of being outside of the hegemonic "imperial center" (p. 58). As, according to Ito (2005) manga and anime "reflect[s] the reality of Japanese society, along with the myths, beliefs, rituals, tradition, fantasies, and Japanese way of life" as well as "social phenomena... social order and hierarchy, sexism, racism, ageism, [and] classism" (Ito, 2005, p. 456). Here, anime is inherently Japanese as a cultural commodity. Due to this, there exist certain attributitive and aesthetic differences between anime and cartoons from the United States. While a delineation of these features falls outside the parameters of this paper, it is reasonable to conclude that anime and US cartoons, at the very least, essentially look different. Japanese producers additionally accentuated this visual difference through the representation of Japanese cultural artifacts through the visual symbols within the first season. As Japanese consumers and anime fans are aware of these differences and 
these symbols, they come to expect certain features to be present in anime. However, for US audiences unfamiliar with Japanese culture, the Japanese-ness of the aesthetics of anime is not immediately recognizable as Japanese, rather, they are associated with the familiar cartoons. The differences between these two media are nonetheless perceptible to US audiences and so symbolically Japanese artifacts may subtly clarify the cultural origin of anime and, therefore, Pokémon. Furthermore, the representation of stereotypically Japanese images such as ninja and samurai connect the "floating" foreign-ness of Pokémon to Japan.

In the twentieth season, however, producers and editors managed the Japanese cultural “odor” of Pokémon by removing it almost entirely. Instead of Japanese symbols, producers included in the Hawaii simulacrum images of Hawaiian culture. In contrast to the seemingly cultural-less "floating" Kanto, the Alola region is saturated with symbols and cultural artifacts emblematic of Hawaiian culture. As an established, and dominant, media franchise, Japanese producers of Pokémon no longer had to rely on the anime's Japanese "exoticness" as a selling point. They instead repositioned a Hawaiian cultural "odor" to re-exoticize the Pokémon world as a land worthy of attention and exploration.

As a land more or less physically situated between Japan and the United States, Hawaii exists as somewhat of a "middle-ground" between the two nations. Furthermore, the common representation of Hawaii as a desirable tropical locale in various media has exoticized it and its native culture. In the twentieth season of Pokémon, Hawaiian culture and its traditions are further represented in Alola through images of the island's landscape, along with the architecture, food, and clothing that characters wear. Additionally, as Hawaii has significant populations of people from both the United States and Japan, it exists as a cultural meeting point between these places. With Hawaii's population totaling 1.3 million, Japanese citizens account for approximately 22\% 
of the entire population of Hawaii as there are approximately 300,000 Japanese in Hawaii, making them the third-largest ethnicity in Hawaii above that of even Native Hawaiians (State of Hawaii Department of Business, Economic Development \& Tourism, 2012). The migration of Japanese people to Hawaii suggests that this state is a desirable destination for them to live. In the twentieth season of Pokémon, the representation of Alola as a stand-in for Hawaii furthered these perceptions through the symbolic images associated with Polynesian island-lifestyles.

Therefore, instead of the "exotic" Japanese images found in the first season, producers reproduced the exotic, desirable qualities of Hawaii and Hawaiian culture in the twentieth season. By doing this, producers were able to reproduce the first season's "exoticness" felt by US audiences toward the images of Japan - but for Japanese audiences toward the images of Hawaii. Furthermore, although US audiences are familiar with Hawaii, it nevertheless remains an "exotic" destination thereby keeping some of the "exotic" qualities US audiences felt toward the Japanese Kanto in the first season. The replacement of Japanese cultural "odor" with a Hawaiian "odor" suggests an intent to scrub the Japanese-ness in order to be more appealing toward international audiences while retaining an exotic "fresh" odor that audiences are tempted to orient toward through the desirable images of Hawaii. In the process, this "re-odorization" fetishizes Hawaii, and subsequently Hawaiian and Polynesian cultures, as novel and desirable.

Alola is much more grounded in symbolism familiar to audiences in the United States compared to Kanto. Replete with images of island resorts, tiki torches, tropical fruit, and Polynesian fire-dancers, this season is closely associated with stereotypically Hawaiian cultural artifacts. Rather than "floating" as an ambiguous culture like Kanto, to English-speaking audiences, Alola reflects a familiar Hawaiian culture. Furthermore, the representation of these images is rather pronounced and seem to be especially intentional on the parts of the producers 
of the show. While the first season held glimpses of Japanese culture in subtle ways through the occasional representation of cultural artifacts, there were very few instances of this Japaneseness in the twentieth season. The representation of Hawaiian cultural symbols completely overshadows the few instances of Japanese symbols thereby "de-odorizing" Japanese culture almost entirely from the program and "odorizing" Hawaiian culture in the process.

In contrast to Kanto’s subtle Japanese-ness that piqued international audiences' interest toward Japanese culture, Alola's aesthetic is obviously and profoundly inspired by that of Hawaii and Polynesian culture. Instead of wondering where Pokémon took place in the first season, audiences may likely be aware of stereotypical images of Hawaii and Hawaii's inspiration of Alola culture. Through the representation of beach resorts, surfers, volcanos, palm trees, and the like, Alola was firmly anchored to Hawaiian cultural symbolism. Kanto, on the other hand, had no such anchoring. Instead, the first season took place in an "everywhere but nowhere" land where ambiguous mountains and simple, rural towns backgrounded the season's narrative. Furthermore, there were very few stereotypical representations of Japanese people or culture in the first season. While there were images of samurai and ninja, they were confined to single episodes and not omnipresent like the Hawaiian cultural "odor" in the twentieth season. Furthermore, these images coincided with other, non-stereotypical representations of Japanese culture to suggest that there was more to Japanese culture than the stereotypical imagery. The abundance of Hawaiian imagery overshadowed any instance of Japanese specificity stereotypical or otherwise - present in this season. As such, audiences may attend more to the overwhelmingly Hawaiian images of the season rather than the few instances of Japanese "odor." Here, the exoticization of Hawaii through Alola saturated the inherent Japanese-ness present in Pokémon in such a way that readings of this Japanese "odor" became much less apparent. This 
was further exacerbated by the intentional reduction of Japanese cultural objects in the new, "foreign" land of Alola. Through this reduction, producers and editors avoided active management of the cultural "odor" in the twentieth season. Instead, this management became "passive" through the images present on screen that overshadowed any sense of Japanese-ness.

As a cultural commodity heavily embedded in, and influenced by, Japanese culture, anime presents a unique case where this Japanese-ness is represented in media on a global stage. Hayao Miyazaki and Studio Ghibli are held up as exemplar producers of Japanese cinema, having been awarded many international awards for such anime films as Spirited Away and My Neighbor Totoro (Boyd \& Nishimura, 2004; Darling-Wolf, 2016; Denison, 2015; Hagiwara, 2006; Napier, 2005b; Wu, 2016). Pokémon and its success demonstrate that this Japanese-ness can be, and is, managed by producers and editors in order to make programs more appealing to international audiences. These international audiences' understanding of Japanese culture presented in media is therefore moderated by how much cultural "odor" producers and editors allow within the program. In Pokémon's case, producers of the show's first season included many instances of Japanese cultural specificity through visual symbols and diegetic text. This diegetic text, however, was managed through several ways by editors, diluting the Japanese cultural "odor" within the international version of the anime. This "odor" was further diluted in the twentieth season of Pokémon where there were very little instances of Japanese culture represented. Through these processes of “deodorization," international audiences' understanding of Japanese culture represented through anime is impacted by the choices made by producers and editors to include and exclude Japanese specificity. There nevertheless remain occasional artifacts representative of Japanese culture present in these seasons, however, allowing some odor to remain regardless of these choices. These moments of extra-cultural novelty allow 
audiences to pick up on some of the Japanese specificity present thereby presenting them with opportunities to learn more about Japanese culture through media representations.

\section{Implications}

As Ito (2000) states, for Japanese children and adults, anime are "influential...because they 'teach' the readers the roles, expectations, rights, duties, taboos, and folkways of Japanese society whether the reader is aware of it or not" (p. 14). The themes and values represented within anime therefore provide cultural information of Japanese culture to Japanese people. It stands to reason, then, that this cultural information - represented through anime's symbols may be interpreted by international audiences as well - though potentially to a lesser extent.

Pokémon is a unique example of a cultural commodity that became a worldwide phenomenon through much more than just its anime. Several sociohistorical and institutional factors led to the franchise's ubiquity. As a transmedia franchise, Pokémon is comprised of video games, comic books, toys, trading cards, and other accoutrements that assisted in its success. Furthermore, Japan's unique history in developing animation as a cultural commodity for further export allowed for greater success in generating Pokémon as a commercial hit. These factors amongst others make it difficult to apply this project's conclusions toward anime's management of cultural "odor" and its introductive properties toward any other culture's television programming.

In terms of the facilitation of intercultural awareness, interest, and sensitivity, there are several strategies that producers should consider when creating a text and marketing it worldwide. Background linguistic text left in the program can help anchor ambiguously cultural contexts to specific cultures. Rather than erasing and/or replacing ancillary text non-significant to the narrative or otherwise non-expository in nature, producers can facilitate intercultural 
awareness by keeping these linguistic elements unedited. As some of a culture's inherent identity is tied to their language system it follows that erasing this language from representation in television programs dissociates (to a certain degree) the culture from the program. Therefore, whenever possible, background text should be kept in the program.

Furthermore, visual representations of cultural commodities, artifacts, and traditions can bridge the gap between unfamiliarity with the represented culture and a piqued interest in that culture. Represented "naturally" in television, these images can instigate cognitive processes of inquiry in which audiences may seek to elaborate on the unfamiliar nature of these images. In the case of Pokémon's first season, the conjunction of unfamiliar Japanese symbols with stereotypical images and leftover Japanese linguistic text worked associatively to expound upon the former's Japanese origin. Care should be taken not to reductively represent these images as stereotypes, however. While the images of samurai and ninja are stereotypical images of Japan, they are nevertheless culturally significant as professions deeply embedded in Japanese history. Therefore, whenever possible, "familiar" images of cultures should be associated with "unfamiliar" images in order to facilitate more familiarity; however, these "familiar" images should not be employed reductively, condescendingly, or stereotypically. Rather, attention should be focused on developing nuance to these "familiar" images as well as presenting the unfamiliar symbols as "natural" within the context of the program. Producers should therefore present cultural "odor" within programs as taken-for-granted aspects of characters' lives and not "wacky" or "exotic" novelties presented in a shallow manner.

The narrative features of the program should also be amenable to the natural inclusion of cultural “odor." As Pokémon's first season took place in a "strange," ambiguous land with a variety of locales, the inclusion of unfamiliar cultural symbols was not out of place as they 
became associated with the Pokémon world. The explorative aspect of the show's plot allowed viewers to explore the world alongside Ash - priming viewers to learn something about the Pokémon world each time they watched. Here, the transmedia features of Pokémon facilitate cultural learning by the franchise's inherent nature of exploring, capturing, and collection. With these features in mind, producers of programs who have cross-cultural education in mind should produce shows that emphasize these characteristics alongside "natural," nuanced, nonstereotypical representations of unfamiliar cultures in order to introduce audiences to cultures that they themselves can "explore" for themselves.

It may be argued that profit-driven motives to make the program as broadly appealing as possible through "deodorization" heavily influence the decision to do so. However, it should be made clear that not only can cultural attributes make a program more appealing to certain audiences, but it can also develop further interest in this culture and subsequent investment in other programs - boosting profits in these programs in the process. Cultural "odor" can therefore be the appeal of programs if carefully employed with the above considerations in mind.

\section{Future Research}

This study focused primarily on the representation of cultural "odor" within two seasons of the Pokémon anime. While this holds implications for cross-cultural entertainment and cultural awareness, the study can be developed and expanded upon in several directions. Most immediately obvious is the development of a project that is more longitudinal. As this study only examined the first and twentieth seasons of the program, there is ample room to further explicate the methods in which producers managed the cultural "odor" of the Pokémon anime over its twenty-year history. Furthermore, a more comprehensive comparison between the Japanese and English versions of episodes may elucidate clearer implications for just how much producers and 
editors removed, edited, or otherwise managed the cultural "odor" across the anime's broadcast history.

In 2006, The Pokémon Company International (TPCi) decided to bring the localization in house for the ninth season of Pokémon. Therefore, an examination to the methods through which TPCi localized may be examined to see what immediately changed in the aftermath of this determination. An examination to the franchise's other products such as the trading card game, the videogame series, and other paraphernalia may provide more robust conclusions concerning the management of cultural odor in Pokémon.

The representation of Hawaiian culture in the twentieth season may also be explored more fully in an examination of how Pokémon melded Hawaiian culture into an amalgamation of Japanese, Hawaiian, and Western cultures into a formulation that still appeals to audiences of each of these cultures separately but simultaneously.

Furthermore, this study did not take into account the episodes that aired in Japan but were subsequently banned from broadcast in the US. Further studies should examine the cultural factors influencing the refusal to air such episodes. Doing so may clarify the underlying Japanese values and cultural schema present in these episodes that were not in alignment with those of the United States.

A more in-depth study examining audiences' reception of cross-cultural images might delve into how attributes of a program may prime audiences to learn, explore, or otherwise gather information about another culture. This may be accompanied by research into whether transmediated franchises' tendency to facilitate the collection and internalization of new information as part of being a fan can also lead to cross-cultural awareness and sensitivity. 
Additionally, an examination toward anime or other programs similar to Pokémon that never reached its level of acclaim may be researched as to whether it had anything to do with cultural representation or "deodorization." Other anime programs that gained popularity in the US may similarly be examined as well. Japanese anime such as Dragon Ball Z, Digimon, and $Y u-G i-O h !$ may be compared to see if any similar "odor" management strategies were present in these programs.

\section{Conclusion}

In this project, I have traced the patterns of cultural odor management in which producers and editors of the anime engaged in order to invite several types of audiences to view Pokémon as both a distinctly Japanese product as well as a "de-odorized" cartoon. While editors attempted to erase the "Japanese-ness" of Pokémon as much as possible in the first season, this cultural "odor" nevertheless undergirded the "everywhere but nowhere" setting of the show through representative Japanese symbols. Furthermore, because this "odor" was conflated with the fantastical setting of Pokémon, an avenue of becoming sensitive toward Japanese culture was made available through the exposure toward Pokémon culture.

While editors attempted to scrub the first season of Pokémon of its cultural "odor" through the selective editing of Japanese specificity in dialog, linguistic text, and character/place names, it still retained aspects of Japanese-ness. The balance struck between its symbolic representative status as a distinctly Japanese product and its cultural odorless-ness helped lead to its unique accomplishment as a cultural commodity that achieved worldwide acclaim. Because producers and editors balanced the cultural "odor" in such a way that appealed to multiple audiences simultaneously, Pokémon was able to succeed internationally. In the twentieth season, however, the vivid and ubiquitous representations of Hawaiian culture overshadowed instances 
where Japanese culture was apparent. Here, in contrast to the careful balancing act of symbolic representation and diegetic editing observed in the first season, the producers and editors of Pokémon took on a more passive role in managing the Japanese "odor" of the anime, letting the images of the Hawaiian Alola supersede those of Japanese-ness.

The results of this study suggest that cultural specificity within television entertainment programs can be introductive toward the cultures in which they are embedded. While anime produced primarily for entertainment purposes may not necessarily teach audiences about foreign cultures, they can serve as prompts to facilitate interest in discovering more about the cultures. This is mediated, however, by producers' and editors' management of the cultural "odor" embedded in these products. If the production staff deems it necessary to remove or stifle cultural specificity, it becomes difficult for audiences to be introduced to these specificities. Because of Pokémon's ability to appeal to multiple types of audiences around the world, however, inconsistencies in the editing of Season One permitted some forms of cultural "odor" to slip through to the finished product thereby potentially introducing audiences unfamiliar with Japanese culture to some Japanese symbols.

While it is disappointing that producers of Pokémon have hidden away its Japanese specificity in its twentieth season, it is not surprising. Since Pokémon has become a global phenomenon and the largest media franchise in history, it no longer has to rely upon its cultural novelty to sell its products. Instead, each iteration needs to be just different enough from its previous iteration in order to sell more products. In Season 20, this was executed through the application of a Hawaii-like atmosphere to the world of Pokémon. In following seasons, it is likely that other filters will be overlaid on Pokémon for the sake of continued audience investment. 
There are potentially positive benefits from studying Pokémon's cultural "odor" management, however. Pokémon provides a unique opportunity toward understanding how cultural commodities peripheral to the United States' ubiquitous entertainment industries can intrude upon this hegemony. Through Pokémon's representation of Japanese culture alongside novel fantasy, audiences became more familiar with the symbolic images of Japanese culture in the anime's first season. The phenomenal pervasiveness of Pokémon at the turn of the millennium exposed millions of people around the world to these Japanese symbols. These symbols alongside anime's aesthetic properties developed further interest in Japan and Japanese products. Media companies such as Netflix, Crunchyroll, Funimation, and other streaming services who present anime rely on the Japanese-ness of these shows to increase, and retain, the subsets of their respective audiences who are interested in these shows. In Crunchyroll and Funimations' cases, anime is the product that they're distributing, proving not only is there a demand for Japanese products, but that the Japanese-ness of these programs are the key desired quality. Not only can programs' cultural specificity develop cross-cultural awareness and sensitivity toward other cultures, it can also develop interest in these cultures' products - thereby incentivizing media producers to publish and distribute these cultural products globally. This, in turn, can facilitate the aforementioned awareness of, and sensitivity toward, other cultures. The cycle of incentivizing media producers to distribute unique products can therefore increase intercultural exposure provided that these distributors do not scrub these products of their cultural "odor.' 


\section{REFERENCES}

4Kids Entertainment, Inc. (1999). Annual report 1999. Retrieved from http://yahoo.brand.edgaronline.com/displayfilinginfo.aspx?FilingID=498210-1238-

105389\&type $=$ sect $\&$ TabIndex $=2 \&$ companyid $=2289 \& p p u=\% 252$ fdefault.aspx $\% 253$ fcom panyid $\% 253 \mathrm{~d} 2289$

Adelia, S. C., \& Subiyanto, A. (2012). Rethinking, rewording, remaking: Analyzing the cultural adjustments in the English dubbed version of 'Cardcaptors'. Retrieved from http://jurnalonline.um.ac.id/data/artikel/artikel22A649E392681CA9702D2577853C4B82.pdf

Ahn, J. (2002). Animated subjects: On the circulation of Japanese animation as global cultural products. Spectator: The University of Southern California Journal of Film and Television, 22, 10-22. Retrieved from http://cinema.usc.edu/assets/098/15853.pdf

Akita, K. (2006). Orientalism and the binary of fact and fiction in 'Memoirs of a Geisha'. Global Media Journal, 5(9), 1-11. Retrieved from http://www.globalmediajournal.com/openaccess/orientalism-and-the-binary-of-fact-and-fiction-in-memoirs-of-a-geisha.pdf

Allison, A. (2000). A challenge to Hollywood? Japanese character goods hit the US. Japanese Studies, 20(1), 67-88. doi: 10.1080/10371390050009075

Allison, A. (2003). Portable monsters and commodity cuteness: Pokémon as Japan's new global power. Postcolonial Studies, 6, 381-395. doi: 10.1080/1368879032000162220

Allison, A. (2006). Millennial monsters: Japanese toys and the global imagination. Berkeley: University of California Press.

Anime News Network (1999). Pokemon TV show finds new home. Retrieved from https://www.animenewsnetwork.com/news/1999-01-27/pokemon-tv-show-finds-newhome 
Anime News Network (2016). Pokémon anime moves to Disney XD in U.S with Pokémon Sun and Moon. Retrieved from https://www.animenewsnetwork.com/news/2016-1117/pokemon-anime-moves-to-disney-xd-in-u.s-with-pokemon-sun-and-moon/.108938

Anime News Network (2018). Legends of VHS fansubs: Trackign down Miami Mike. Retrieved from https://www.animenewsnetwork.com/feature/2018-03-11/legends-of-vhs-fansubstracking-down-miami-mike/.128838

Arnold, M. (2004). Japanese anime and the animated cartoon. URL (consulted Feb 13 2018): http://www.midnighteye.com/features/animated_cartoon.shtml

Albrow, M. (1990) Introduction. In M. Albrow and E. King (Eds.), Globalization, Knowledge and Society. London: Sage.

Armour, W. S. (2011). Learning Japanese by reading 'manga': The rise of 'soft power pedagogy'. RELC Journal, 42(2), 125-140. doi: 10.1177/0033688211405181

Armour, W. S., \& Iida, S. (2014). Are Australian fans of anime and manga motivated to learn Japanese language? Asia Pacific Journal of Education, 36(1), 31-47. doi: $10.1080 / 02188791.2014 .922459$

Bainbridge, J. (2014a). ‘Gotta Catch ‘Em All!' Pokémon, cultural practice and object networks. IAFOR Journal of Asian Studies, 1(1), 1-15. doi: 10.22492/ijas.1.1.04

Bainbridge, J. (2014b). 'It is a Pokémon world': The Pokémon franchise and the environment. International Journal of Cultural Studies, 17(4), 399-414. doi:

$10.1177 / 1367877913501240$ 
Bakonyi, K. (2010). The influence of Japanese animation on 'Avatar: The Last Airbender.' Animatrix: A Journal of the UCLA Animation Workshop, 8, 27-38. Retrieved from http://connection.ebscohost.com/c/articles/79553380/influence-japanese-animationavatar-last-airbender

Barnlund, D. C. (1975). Public and private self in Japan and the United States. Tokyo: Simul Press, Inc.

Baudrillard, J. (1994). The system of collecting. In J. Eisner \& R. Cardinal (Eds.) Cultures of collecting (pp. 7-25). London: Reaktion Books.

Befu, H. (2001). Hegemony of homogeneity: An anthropological analysis of nihonjinron. Melbourge: Trans Pacific Press.

Benedict, R. (1946). The Chrysanthemum and the sword. Boston, MA: Houghton Mifflin Harcourt.

Borbély, P. (2014). Japanese comics lost in translation. Language transitions and the (mis)interpretation of the translated material. International Journal of Language, Literature, and Culture in Education, 113-122. Retrieved from http://files.jolace.webnode.sk/200001286-4b8a84d808/LLCE\%202014\%20-\%2011.pdf

Boyd, J. W., \& Nishimura, T. (2004). Shinto perspectives in Miyazaki's anime film "Spirited Away." Journal of Religion and Film, 8(3), 1-14. Retrieved from http://digitalcommons.unomaha.edu/jrf/vol8/iss3/4

Bresnahan, R. (1983). Islands in our minds: The Pacific Ocean in the American literary imagination. In W. I. Cohen (Ed.) Reflections on orientalism: Edward Said, Roger Bresnaham, Surjit Dulai, Edward Graham, and Donald Lammers (pp. 3-14). East Lansing, MI: Michigan State University 
Brienza, C. E. (2009). Books, not comics: Publishing fields, globalization and Japanese manga in the United States. Pub Res Q, 25, 101-117. doi: 10.1007/s12109-009-9114-2

Bromley, H. (2004). Localizing Pokémon through narrative play. In J. Tobin (Ed.) Pikachu's global adventure: The rise and fall of Pokémon (pp. 211-225). London: Duke University Press.

Buckingham, D. \& Sefton-Green, J. (2004). Structure, agency, and pedagogy in children's media culture. In J. Tobin (Ed.) Pikachu's global adventure: The rise and fall of Pokémon (pp. 12- 33). London: Duke University Press.

Buntilov, G. (2016). Common narratives in discourses on national identity in Russia and Japan. Asian Philosophy, 26(1), 1-19. doi: 10.1080/09552367.2015.1136199

BusinessWire (2005, December 23). Pokemon USA Moves Licensing In-House in 2006; 4Kids Entertainment to Transition Its Representation of Pokemon. BusinessWire. Retrieved from https://www.businesswire.com/news/home/20051223005061/en/Pokemon-USAMoves-Licensing-In-House-2006-4Kids

Carlson, R. \& Corliss, J. (2011). Imagined commodities: Video game localization and mythologies of cultural difference. Games and Culture, 6(1), 61- 82. doi: $10.1177 / 1555412010377322$

Chalaby, J. K. (2003). Television for a new global order. International Communication Gazette, 65(6), 457-472. doi: 10.1177/0016549203065006003

Chen, L. (2014). What's the cultural difference between the West and the East? The consumption of popular "cute" games in the Taiwanese market. New Media and Society, 16(6), 1018-1033. doi: 10.1177/1461444813497555 
Ching, L. (1998). Yellow skin, white masks: Race, class and identification in Japanese colonial discourse. In Kuan-Hsing Chen (Ed.) Trajectories: Inter-Asia cultural ctudies (pp. 5675). London: Routledge.

Cho, B., Kwon, U., Gentry, J.W., Jun, S., \& Krop, F. (1999). Cultural values reflected in theme and execution. Comparative study of U.S. and Korean television commercials. Journal of Advertising, 28(4), 59-73. doi: 10.1080/00913367.1999.10673596

Clark, A. M., \& Clark, M. T. G. (2016). Pokémon Go and research: Qualitative, mixed methods research, and the supercomplexity of interventions. International Journal of Qualitative Methods, (January-December), 1-3. doi: 10.1177/1609406916667765

Clements, J. (2013). Anime: A history. London: BFI Publishing.

Condry, I. (2009). Anime creativity: Characters and premises in the quest for 'Cool Japan.' Theory, Culture \& Society, 26(2-3), 139-163. doi: 10.1177/0263276409103111

Condry, I. (2013). The soul of anime: Collaborative creativity and Japan's media success story. London: Duke University Press.

Consalvo, M. (2006). Console video games and global corporations: Creating a hybrid culture. New Media \& Society, 8(1), 117-137. doi: 10/1177/1461444806059921

Consalvo, M. (2007). Visiting the floating world: Tracing a cultural history of video games through Japan and America. Proceedings of DiGRA 2007 Conference, 736-741. Retrieved from http://www.academia.edu/20516362/Visiting_the_Floating_World_Tracing_a_Cultural_ History_of_Games_Through_Japan_and_America

Corbett, A. (2009). Beyond 'Ghost in the Human Shell'. Journal of Evolution and Technology, 20(1), 43-50. Retrieved from https://jetpress.org/v20/corbett.htm 
Crane, D. (2002). Culture and globalization: Theoretical models and emerging trends. In D. Crane, N. Kawashima, \& K. Kawasaki (Eds.) Global culture: Media, arts, policy, and globalization (pp. 1-28). New York: Routledge

Cwiertka, K. J. (2006). Modern Japanese cuisine: Food, power and national identity. London: Reaktion Books

Daliot-Bul, M. (2009). Japan brand strategy: The taming of 'Cool Japan' and the challenges of cultural planning in a postmodern age. Social Science Japan Journal, 12(2), 247-268. doi: $10.1093 /$ ssjj/jyp037

Darling-Wolf, F. (2000). Texts in context: Intertextuality, hybridity, and the negotiation of cultural identity in Japan. Journal of Communication Inquiry, 24(2), 134-155. DOI: $10.1177 / 0196859900024002003$

Darling-Wolf, F. (2006). The men and women of non-no: Gender, race, and hybridity in two Japanese magazines. Critical Studies in Media Communication, 23(3), 181-199. doi: $10.1080 / 07393180600800734$

Darling-Wolf, (2016). The "Lost” Miyazaki: How a Swiss girl can be Japanese and why it matters. Communication, Culture \& Critique, 9(4), 499-516. doi: 10.1111/cccr.12122

Davis, D. W., \& Yeh, E. Y. (2008). East Asian screen industries. London: BFI

DeKeseredy, W. S., Muzzatti, S. L., \& Donnermeyer, J. F. (2014). Mad Men in bib overalls: Media's horrification and pornification of rural culture. Critical Criminology, 22(2), 179197. doi: $10.1007 / \mathrm{s} 10612-013-9190-7$

Denison, R. (2007). The global markets for anime: Miyazaki Hayao's Spirited Away. In A. Phillips and J. Stringer (Eds.) Japanese cinema: Texts and contexts, (pp. 308-322). New York: Routledge. 
Denison, R. (2014). Franchising and failure: Discourses of failure within the Japanese-American ‘Speed Racer’ franchise. Mechademia, 9(2014), 269-281. doi: 10.1353/merc.2014.0011

Denison, R. (2015). Anime: A critical introduction. London: Bloomsbury

Drazen, P. (2003). Anime explosion! The what? Why? \& Wow! Of Japanese animation. Berkely, CA: Stone Bridge Press.

Du Gay, P., Hall, S., Janes, L., Mackay, H., \& Negus, K. (1997). Doing cultural studies:

ThesStory of the Sony Walkman. London: Sage.

Eco, U. (2003). Mouse or rat? Translation as negotiation. London: Phoenix.

Esser, A. (2010). Television formats: Primetime staple, global market. The International Journal of Media and Culture, 8(4), 273-292. doi: 10.1080/15405702.2010.514176

Featherstone, M. (1996). Undoing culture. London: Sage.

Ferguson, M. (1995). The mythology about globalization. European Journal of Communication, 7(1), 69-93. doi: 10.1177/0267323192007001004

Ferreira, C., \& Fernandes, H. (2014). Transmedia storyworlds: Digital games, transmedia, and cross-media. A case study of 'Prince of Persia.' Videojogos, Conferência de Ciências e Artes dos Videojogos, 1-10. Retrieved from http://web.ipca.pt/videojogos/Papers/videojogos2014_submission_9.pdf

Fiske, J. (2011). Television culture. London: Routledge.

Foster, M. D. (2008). Pandemonium and parade: Japanese monsters and the culture of yokai. California: University of California Press.

Fujita, Y. (2004). Young Japanese 'cultural migrants' and the construction of the imagined West. Westminster Papers in Communication and Culture, 1(1), 23-37. doi: 10.16997/wpcc.201 
Gerbert, E. (2001). Images of Japan in the digital age. East Asia, 19(1-2), 95-122. doi: $10.1007 / \mathrm{s} 12140-001-0003-3$

Giddens, A. (1990). The consequences of modernity. Standford, CA: Stanford University Press. GoBankingRates (2017, December 6). 'Pokken Tournament' and Pokémon's $\$ 1.5$ billion brand. Retrieved from https://www.huffingtonpost.com/gobankingrates/pokken-tournament-andpok_b_9501260.html

Graham, E. (1983). The "Imaginative Geography" of China. In W. I. Cohen (Ed.) Reflections on orientalism: Edward Said, Roger Bresnaham, Surjit Dulai, Edward Graham, and Donald Lammers (pp. 31-44). East Lansing, MI: Michigan State University.

Grigsby, M. (1988). 'Sailormoon': 'Manga (comics)' and 'anime (cartoon)' superheroine meets 'Barbie': Global entertainment commodity comes to the United States. Journal of Popular Culture, 32(1), 59-80. doi: 10.1111/j.0022-3840.1998.3201_59.x

Grossberg, L. (1984). Another boring day in paradise: Rock and roll and the empowerment of everyday life. Popular Music, 4, 225-258. Retrieved from https://www.jstor.org/stable/853365

Hairston, M. R. (1999). Manga, anime, and Miyazaki: Page 2. URL (consulted Mar. 20 2018): http://www.utdallas.edu/research/spacesciences/hairston/nausicaa_lecture_1_p2.html Hagiwara, T. (2006). Globalism and localism in Hayao Miyazaki's anime. International Journal of the Humanities, 3(9), 7-11. Retrieved from http://libproxy.lib.ilstu.edu/login?url=https://search.ebscohost.com/login.aspx?direct=true $\& \mathrm{db}=\mathrm{hlh} \& \mathrm{AN}=25038967 \&$ site $=$ eds-live $\&$ scope $=$ site 
Hall, S. (1975). Television as a medium and its relation to culture. Retrieved from https://www.birmingham.ac.uk/Documents/college-artslaw/history/cccs/stencilledoccasional-papers/9and25to37/SOP34.pdf

Hall, S. (1991). Old and new identities, old and new ethnicities. In A. King (Ed.) Culture, globalization and the world system (pp. 41-68). New York: Macmillan.

Hanada, T. (2003). Cultural diversity as social demand: The Korean minority and Japanese broadcasting. International Communication Gazette, 65(4-5), 389-400. doi: $10.1177 / 0016549203654005$

Hancock, Q., Jolls, T., \& Jolls, P. (2013). Racism and stereotypes in electronic media. Public Library Quarterly, 32, 333-344. doi: 10.1080/0161846.2013.848135

Hasegawa, Y., \& Hirose, Y. (2005). What the Japanese language tells us about the alleged Japanese relational self. Australian Journal of Linguistics, 25(2), 219-251. doi: $10.1080 / 07268600500233019$

Heemsbergen, D. (2016). "Eat your hamburgers, Apollo": A survey of Japanese video game localization methods and challenges. Arizona Journal of Interdisciplinary Studies, 5, 3146. Retrieved from https://journals.uair.arizona.edu/index.php/azjis/article/download/19419/19055

Held, D. (2006). Models of democracy ( $3^{\text {rd }}$ ed.). Cambridge, UK: Polity Press

Hill, M. (2000). 'Asian values' as reverse Orientalism: Singapore. Asia Pacific Viewpoint, 41(2), 177-190. doi: 10.1111/1467-8373.00114

Hills, M. (2002). Fan cultures. New York: Routledge.

Hirsch, P. M. (1972). Processing fads and fashions: An organization-set analysis of cultural industry systems. American Journal of Sociology, 77, 639- 659. doi: 10.1086/225192 
Hjarvard, S., \& Petersen, L. N. (2013). Mediatization and cultural change. MediaKulture: Journal of Media and Communication Research, 54, 1-7. doi:

10.7146/mediekultur.v29i54.8123

Horno- López, A. (2016). The particular visual language of anime: Design, colour and selection of resources. Animation Practice, Process \& Production, 5(1), 39-56. doi: 10.1386/ap3.5.1.39_1

Hoskins, C., \& Mirus, R. (1988). Reasons for the US dominance of the international trade in television programmes. Media, Culture and Society, 10, 499-515.

Huang, C., \& Archer, A. (2014) Fluidity of modes in the translation of manga: The case of Kishimoto's 'Naruto'. Visual Communication, 13(4), 471-486. doi: $10.1177 / 1470357214541746$

Hubka, D. (2002). Globalization of cultural production: The transformation of children's animated television, 1980 to 1995. In D. Crane, N. Kawashima, K., \& K. Kawasaki (Eds.) Global Culture: Media, Arts, Policy, and Globalization (pp. 233-255). New York: Routledge.

Iida, Y. (2000). Between the technique of living an endless routine and the madness of absolute degree zero: Japanese identity and the crisis of modernity in the 1990s. Positions: East Asia Cultures Critique, 8(2), 423-464. doi: 10.1215/10679847-8-2-423

Ito, K. (2000). The manga culture in Japan. Japan Studies Review, 4, 1-17. Retrieved from https://asian.fiu.edu/projects-and-grants/japan-studies-review/journal-archive/volume-iv2000/jsr-2000.pdf

Ito, K. (2005). A history of manga in the context of Japanese culture and society. Journal of Popular Culture, 38(3), 456-475. doi: 10.1111/j.0022-3840.2005.00123.x 
Ito, K. (2008). Manga in Japanese history. In M. W. MacWilliams (Ed.) Japanese visual culture: Explorations in the world of manga and anime (pp. 26-47). London: Routledge.

Ito, K., \& Crutcher, P. A. (2014). Popular mass entertainment in Japan: Manga, pachinko, and cosplay. Symposium: Signs, Symbols, and Semiotics, 51(1), 44-48. doi: 10.1007/s12115013-9737-y

Ito, M. (2002). Television and Violence in the Economy of Memory, International Journal of Japanese Sociology, 11, 19-34. doi: 10.1111/1475-6781.00015

Ito, M. (2007). Technologies of the childhood imagination: 'Yugioh', media mixes, and everyday cultural production. In J. Karaganis (Ed.) Structures of participation in digital culture (pp. 88-111). New York: Duke University Press.

Ivy, M. (1995) Discourses of the vanishing. Chicago, IL: University of Chicago Press.

Iwabuchi, K. (2002a). Recentering globalization: Popular culture and Japanese transnationalism. London: Duke University Press

Iwabuchi, K. (2002b). From Western gaze to global gaze: Japanese cultural presence in Asia. In D. Crane, N. Kawashima, \& K. Kawasaki (Eds.) Global culture: Media, arts, policy, and globalization (pp. 256 - 273). New York: Routledge

Iwabuchi, K. (2002c). "Soft" nationalism and narcissism: Japanese popular culture goes global. Asian Studies Review, 26(4), 447-469. doi: 10.1080/10357820208713357

Iwabuchi, K. (2004). How “Japanese” is Pokémon? In J. Tobin (Ed.) Pikachu's global adventure: The rise and fall of Pokémon (pp. 53-79). New York: Duke University Press.

Jenkins, H. (2006a). Convergence culture. New York: New York University Press.

Jenkins, H. (2006b). Fans, bloggers, and gamers: Exploring participatory culture. New York: New York University Press. 
Jensen, P. M. (2009). How media systems shape the localization of TV formats. In A. Moran (ed.) TV formats worldwide: Localizing global programs (pp. 163-186). Bristol, UK: Intellect Publishing.

Kaczmarek, L.D., Misiak, M., Behnke, M. Dziekan, M., \& Guzik, P. (2017). The Pikachu effect: Social and health gaming motivations lead to greater benefits of Pokémon Go use. Computers in Human Behavior, 75(October), 356-363. doi: 10.1016/j.chb.2017.05.031

Katsuno, H., \& Maret, J. (2004). Localizing the Pokémon TV series for the American market. In J. Tobin (Ed.) Pikachu's global adventure: The rise and fall of Pokémon (pp. 80-107). London: Duke University Press.

Kelts, R. (2007). Japanamerica: How Japanese culture has invaded the U.S. New York: Palgrave Macmillan.

Kim, S., \& Prideaux, B. (2012). A post-colonial analysis of bilateral tourism flows: The case of Korea and Japan. International Journal of Tourism Research, 14, 586-600. doi: $10.1002 /$ jtr859

Kinder, M. (1991). Playing with power in movies, television and video games: From 'Muppet Babies' to 'Teenage Mutant Ninja Turtles'. Berkeley: University of California Press.

Kovacic, M. (2014). The many faces of popular culture and contemporary processes: Questioning identity, humanity, and culture through Japanese anime. The IAFOR Journal of Arts and Humanities, 2(1), 1-19. doi: 10.22492/ijah.2.1.02

Kraidy, M. M. (1999). The global, the local, and the hybrid: A native ethnography of glocalization. Critical Studies in Mass Communication, 16(4), 456-476. doi: $10.1080 / 15295039909367111$ 
Kraidy, M. M. (2001). Between globalization and localization: Television, tradition, and modernity. In Y. R. Kamalipour and K. R. Rampal (eds.) Media, sex, violence, and drugs in the global village (pp. 261-272). Lanham, MD: Rowman \& Littlefield Publishers, Inc.

Kriesi, H. (2013). Intoduction: The new challenges to democracy. In H. Kriesi (Ed.) Democracy in the age of globalization and mediatization, (pp. 1-18). New York: Palgrave Macmillan

Kubo, M. (2000). "Sekai wo haikaisuru wasei monsuta Pikachu" (Pikachu Wandering over the World). Bungei Shunju special issue: Dodum? Donaru? Watashitachi, 21, 340-49.

Kuwuhara, Y. (1997). Japanese culture and popular consciousness: Disney’s 'The Lion King' versus Tezuka's 'Jungle Emperor.' Journal of Popular Culture, 31(37), 48-59. doi: 10.1111/j.0022-3840.1997.3101_37.x

Ladd, F., \& Denerof, H. (2009). 'Astro Boy' and anime come to the Americas. Jefferson, NC: McFarland \& Company, Inc.

Lam, P. E. (2007). Japan's quest for “soft power”: Attraction and limitation. East Asia, 24(4), 349-363. doi: 10.1007/s12140-007-9028-6

Lamarre, T. (2002). Between cinema and anime. Japan Forum, 14(2), 183-189. doi: $10.1080 / 09555800220136347$

Lamarre, T. (2009). The anime machine: A media theory of animation. Minneapolis: University of Minnesota Press.

Larkey, E. (2009). Transcultural localization strategies of global TV formats: The Office and Stromberg. In A. Moran (ed.) TV formats worldwide: Localizing global programs (pp. 187-202). Bristol, UK: Intellect Publishing.

Larkin, B. (1997). Indian films and Nigerian lovers: Media and the creation of parallel modernities. Africa, 67(3), 406-440. doi: 10.2307/1161182 
Lee, P. S. (2000) Television and global culture: Assessing the role of television in globalization. In G. Wang, J. Servaes, \& A. Goonasekera (eds). The New Communications Landscape: Demystifying Media Globalization (pp. 191-201). London: Routledge

Lee, J.W. (2012). Commodifying colonial histories: Korea versus Japan and the re/productions of colonial violence in the World Baseball Classic. Journal of Sport and Social Issues, 36(3), 231-244. doi: 10.1177/0193723512443245

Lee, J. (2017). Clothing the body, dressing the identity: The case of the Japanese in Taiwan during the Colonial Period. The Journal of Japanese Studies, 41(1), 31-64. doi: $10.1353 / \mathrm{jjs} .2017 .0003$

Levi, A. (1996). Samurai from outer space: Understanding Japanese animation. Chicago, IL: Open Court.

Levi, A. (2006). The Americanization of anime and manga: Negotiating popular culture. In C. Bolton (ed.) Cinema Anime (pp. 43-63). New York: Palgrave Macmillan.

Levi, A. (2013). The sweet smell of Japan: Anime, manga, and Japan in North America. Journal of Asian Pacific Communication, 23(1), 3-18. doi: 10.1075/japc.23.1.02lev

Lewis, R. D. (2006). When cultures collide: Leading across cultures. Boston, MA: Nicholas Bealey International.

Lewis, T. (2009). From global to glocal: Australianizing the makeover format. In A. Moran (ed.) TV formats worldwide: Localizing global programs (pp. 291-306). Bristol, UK: Intellect Publishing.

Lewis, L. (2004) 'Anime Attacks: As Disney Dithers, Toei Takes on the World', Japan, Inc. Retrieved from http://www.japaninc.com/article.php?articleID=1322 (6-21-2018 url consulted) 
Lie, J. (2001). Ruth Benedict's legacy of shame: Orientalism and Occidentalism in the study of Japan. Asian Journal of Social Science, 29(2), 249-261. doi: 10.1163/156853101X00064

Local Industry Standards Association, The (2011). Localization. Retrieved from https://web.archive.org/web/20110102074246/http://www.lisa.org/Localization.61.0.html (Accessed 10 June 2018).

Lorenzen, M. (2007). Internationalization vs. globalization of the film industry. Industry and Innovation, 14(4), 349-357. doi: 10.1080/13662710701543650

Loveday, P., \& Burgess, J. (2017). Flow and 'Pokémon Go': The contribution of game level, playing alone, and nostalgia to the flow state. E-Journal of Social \& Behavioural Research in Business, 8(2), 16-28. Retrieved from http://libproxy.lib.ilstu.edu/login?url=https://search.ebscohost.com/login.aspx?direct=true $\& \mathrm{db}=\operatorname{sih} \& \mathrm{AN}=127698492 \&$ site $=$ eds-live $\&$ scope $=$ site

Lu, A. S. (2008). The many faces of internationalization in Japanese anime. Animation: An Interdisciplinary Journal, 3(2), 169-187. doi: 10.1177/1746847708091893

Lu, A. S. (2009) What race do they represent and does mine have anything to do with it? Perceived racial categories of anime characters. Animation: An Interdisciplinary Journal, 4(2), 169-190.

Machiyama, T. (2004). Mondo Tokyo: Otaku. In P. Macias \& T. Machiyama (eds.) Cruising the anime city: An otaku guide to Neo Tokyo (pp. 13-15). Berkeley, CA: Stone Bridge Press. MacWilliams, M. W. (2014). Japanese visual culture: Explorations in the world of manga and anime. London: Routledge. 
Makuch, E. (2016). ‘Pokémon Go’ Becomes Most Popular Mobile Game in US History-Report, Gamespot (14 July 2016). https://www.gamespot.com/articles/Pokémon-go-becomesmost-popular-mobile-game-in-us-/1100-6441797/ (Accessed 10 July 2018.)

Manovich, L. (2001). The Language of new media. Cambridge, MA: The MIT Press.

Mandiberg, S. (2015). Playing (with) the 'Trace': Localized culture in 'Phoenix Wright'. Kinephanos: Journal of Media Studies and Popular Culture, 5, 111-141. Retrieved from https://www.kinephanos.ca/Revue_files/2015_Mandiberg.pdf

Matsuda, H. (2012). Becoming Japanese in the colony: Okinawan migrants in colonial Taiwan. Cultural Studies, 26(5), 688-709. doi: 10.1080/09502386.2012.697723

Matsui, T. (2009). The Diffusion of Foreign Cultural Products: The Case Analysis of Japanese Comics (Manga) Market in the US. Princeton University, Woodrow Wilson School of Public and International Affairs, Center for Arts and Cultural Policy Studies., Working Papers. 1-29. Retrieved from https://www.princeton.edu/ artspol/workpap/WP37Matsui.pdf

McGaha, J. (2015). Popular culture \& globalization: Teacher candidates' attitudes \& perceptions of cultural \& ethnic stereotypes. Multicultural Education, 23(1), 32-37. Retrieved from https://eric.ed.gov/?id=EJ1090398

McGray, D. (1 May 2002). “Japan's Gross National Cool.” Foreign Policy. Retrieved 13 May 2018 from http://www.douglasmcgray.com/cool-japan.html

McIntosh, W. D. \& Schmeichel, B. (2004). Collectors and collecting: A social psychological perspective. Leisure Studies, An Interdisciplinary Journal, 26(1), 85-97. doi: $10.1080 / 01490400490272639$ 
McKevitt, A. C. (2010). "You Are Not Alone!": Anime and the globalizing of America. Diplomatic History, 34(5), 893-921. doi: 10.1111/j.1467-7709.2010.00899.x

McLelland, M. (2008). 'Race' on the Japanese internet: Discussing Korea and Koreans on '2channeru.' New Media and Society, 10(6), 811-829. doi: 10.1177/1461444808096246

Miyao, D. (2002). Before anime: Animation and the pure film movement in pre-war Japan. Japan Forum, 14(2), 191-209. doi: 10.1080/09555800220136356

Monden, M. (2008). Transcultural flow of demure aesthetics: Examining cultural globalization through Gothic \& Lolita fashion. New Voices, 2, 21-40. doi: 10.21159/nv.02.02

Moon, Y. (2013). Immoral Rights: Korean Populist Collaborators and the Japanese Colonization of Korea, 1904-1910. American Historical Review, 118(1), 20-44. Retrieved from libproxy.lib.ilstu.edu/login?url=https://search.ebscohost.com/login.aspx?direct=true\&db= tfh\&AN $=85708757 \&$ site $=$ eds-live \&scope $=$ site.

Moran, A. (2008). Makeover on the move: Global television and programme formats. Journal of Media \& Cultural Studies, 22(4), 459-469. doi: 10.1080/10304310802189956

Moran, A. (2009). Global franchising, local customizing: The cultural economy of TV program formats. Journal of Media \& Cultural Studies, 23(2), 115-125. doi: $10.1080 / 10304310802706932$

Moran, A. (2009). When TV formats are translated. In A. Moran (ed.) TV formats worldwide: localizing global programs (pp. 39-54). Bristol, UK: Intellect Publishing.

Moran, A., \& Aveyard, K. (2014). The place of television programme formats. Journal of Media \& Cultural Studies, 28(1), 18-27. doi: 10.1080/10304312.2014.870869 
Mori, Y. (2011). The pitfall facing the 'Cool Japan' project: The transnational development of the anime industry under the condition of Post-Fordism. International Journal of Japanese Sociology, 20(1), 30-42. doi: 10.1111/j.1475-6781.2011.01146.x

Morley, D., \& Robins, K. (1995). Spaces of identities: Global media, electronic landscapes, and cultural boundaries. London: Routledge

Morton, W. S., \& Olenik, J. K. (2005). Japan: Its history and culture. New York: McGraw-Hill, Inc.

n.a. (2007, December 27) US platinum videogame chart. Retrieved from http://www.themagicbox.com/Chart-USPlatinum.shtml

n.a. (2017, December 31). Top selling title sales unites. Retrieved from https://www.nintendo.co.jp/ir/en/finance/software/3ds.html

n.a. (2017, March 31). Pokémon in figures. Retrieved from http://www.Pokémon.co.jp/corporate/en/services/

Napier, S. J. (2005a). Anime: From Akira to Howl's Moving Castle. New York: St. Martin's Griffin

Napier, S. J. (2005b). The problem of existence in Japanese animation. Source: Proceedings of the American Philosophical Society, 149(1), 72-79. doi: 10.2307/4598910

Napier, S. J. (2007). From Impressionism to anime: Japan as fantasy and fan cult in the mind of the West. New York: Palgrave-McMillan.

Naylor, A. \& Helford, E. (2014), Science fiction anime: National, nationless, transnational, post/colonial. Science Fiction Film and Television, 7(3), 309-314. doi: $10.3828 /$ sfftv.2014.18 
Ndlela, M. N. (2011). Global television formats in Africa: Localizing Idol. In T. Oren \& S. Shahaf (eds.) Global television formats: Understanding television across borders (pp. 242-259). New York: Routledge.

Neuhaus, D. (2016). Assimilating Korea: Japanese Protestants, "East Asian Christianity" and the education of Koreans in Japan, 1905-1920. Paedagogica Historica, 52(6), 614-628. doi: $10.1080 / 00309230.2016 .1224262$

Newitz. A. (1995). Magical girls and atomic bomb sperm: Japanese animation in America. Film Quarterly, 49(1), 2-15. Retrieved from http://www.jstor.org/stable/1213488

Ning, W. (1997). Orientalism versus occidentalism? New Literary History, 28(1), 57-67. Retrieved from http://www.jstor.org/stable/20057401

Nintendo Press Release (1999). 'Game Boy's Pokémon Unleashed on September 28!' Retrieved from https://web.archive.org/web/19990501171038/http://www.nintendo.com/corp/press/1002 98.html

Nishihara, D. (2005). Said, Orientalism, and Japan. Alif: Journal of Comparative Poetics, 25, 241-253. Retrieved from http://www.jstor.org/stable/4047459

Noh, S. (2016). Subversion and reification of cultural identity in global fandoms. Gnovis, 17(1), 25-37. Retrieved from http://hdl.handle.net/10822/1043000

Noriega, C. (1987). Godzilla and the Japanese nightmare: When "Them!" is U.S. Cinema Journal, 27(1), 63-77. doi: 10.2307/1225324

Nye, J. (1990). Soft Power. Foreign Policy, 80(Autumn), 153-171. Retrieved from http://www.jstor.org/stable/1148580_doi: 10.2307/1148580 
Ogletree, S. M., Martinez, C. N., Turner, T. R., \& Mason, B. (2004). 'Pokémon': Exploring the role of gender. Sex Roles, 50(11-12), 851-859. doi:

10.1023/B:SERS.0000029102.66384.a2

Olson, S. R. (2000). The globalization of Hollywood. International Journal on World Peace, 17(4), 3-17. doi: $10.2307 / 20753277$

Otmazgin, N. (2014). Anime in the US: The entrepreneurial dimensions of globalized culture. Pacific Affairs, 87(1), 53-69. doi: 10.5509/201487153

Ōtsuka, E., \& Steinberg, M. (trans.) (2010). World and variation: The reproduction and consumption of narrative. Mechademia, 5, 99-116. Retrieved from https://muse.jhu.edu/article/400552/summary?casa_token=EvadoehE2PUAAAAA:OP32 e60BSB03LNfx5OimaFzECjkC-n5GDLLxyufD8YOk-bAiJ0T3OyI8t9TeGkZEMuw_cXk-hem

Patrickson, B., \& Young, S. (2013). The transcultural transmedia media mix. JAST: Journal of American studies of Turkey, 37, 43-65. Retrieved from http://www.academia.edu/download/34050928/The_Transcultural_Transmedia_Media_ Mix-libre.pdf

Patten, F. (2004). Watching anime, reading manga: 25 years of essays and reviews. Berkeley, CA: Stone Bridge Press.

Paulk, C. (2011). Post-national cool: William Gibson's Japan. Science Fiction Studies, 38(November), 478-501. doi: 10.5621/sciefictstud.38.3.0478

Perez, S. (2016). 'Pokémon Go' passed 100 million installs over the weekend, Techcrunch, (1 August 2016). https://techcrunch.com/2016/08/01/Pokémon-go-passed-100-millioninstalls-over-the-weekend/ Accessed 10 July 2018 
Peters, M. (2018). 'Pokémon' is the highest-grossing franchise of all-time. Retrieved from http://comicbook.com/anime/2018/06/24/Pokémon-franchise-revenue-anime-media/

Pieterse, J. N. (1994). Globalistion as hybridization. International Sociology, 9(2), 161-184. doi: $10.1177 / 026858094009002003$

Pinnington, A. (2001). Yoshimitsu, Benedict, 'endo': Guilt, shame and the post-war idea of Japan. Japan Forum, 13(1), 91-105. doi: 10.1080/09555800020027692

Pogorel, G. (2000). The production and consumption of national and local cultural products in the age of global communication. In G. Wang, J. Servaes, \& A. Goonasekera (eds.) The New Communications Landscape: Demystifying Media Globalization (pp. 249 - 253). London: Routledge

Pointon, S. (1997). Transcultural orgasm as apocalypse: 'Urotsukidoji: The Legend of the Overfiend.' Wide Angle, 19(3), 41-63. Retrieved from https://muse.jhu.edu/article/36177 Pokémon Company International, Inc. (2018). About the Pokémon Company International. Retrieved from https://www.pokemon.com/us/about-pokemon/

Posadas, B. T. (2014). Remaking Yamato, remaking Japan: 'Space Battleship Yamato’ and SF anime. Science Fiction Film and Television, 7(3), 315-342. doi: 10.3828/sfftv.2014.19

Pusztai, B. (2015). Adapting the medium: Dynamics of intermedial adaptation in contemporary Japanese popular visual culture. Acta Univ. Sapientiae, Film and Media Studies, 10, 141152. doi: 10.1515/ausfm-2015-0031

Price, S. (2001) Cartoons from another planet; Japanese animation as cross-cultural communication. Journal of American and Comparative Culture, 24(1-2), 153 - 169. doi: 10.1111/j.1542-734X.2001.tb00040.x 
Ramirez, D., Saucerman, J., \& Dietmeier, J. (2014). Twitch plays 'Pokémon': A case study in Big G games. Proceedings of DiGRA (2014), 1-10. Retrieved from https://library.med.utah.edu/e-channel/wpcontent/uploads/2016/04/digra2014_submission_127.pdf

Robertson, R. (1992). Globalization: Social theory and global culture. London: SAGE Publications

Robertson, R. (1995). Glocalization: Time-space and homogeneity-heterogeneity. In M. Featherstone, S. Lash, \& R. Robertson (Eds.) Global modernities, (pp. 25-44). London: Sage.

Roedder, A. (2014). The localization of 'Kiki's Delivery Service'. Mechademia, 9, 254-267. doi: $10.1353 / \mathrm{mec} .2014 .0008$

Ruh, B. (2010). U.S. anime in the 1980s: Localization and longevity. Mechademia, 5(2010), 3149. Retrieved from http://www.jstor.org/stable/41510956

Ruh, B. (2012). Adapting anime: Transnational media between Japan and the United States (doctoral dissertation). Indiana University, Bloomington, Indiana.

Ruh, B. (2013). Producing transnational cult media: 'Neon Genesis Evangelion' and 'Ghost in the Shell in Circulation.' Intensities: The Journal of Cult Media, 5, 1-23. Retrieved from https://intensitiescultmedia.files.wordpress.com/2013/07/producing-transnational-cultmedia-neon-genesis-evangelion-and-ghost-in-the-shell-in-circulation-brian-ruh.pdf

Ruh, B. (2014). Conceptualizing anime and the database fantasyscape. Mechademia, 9, 164-175. Ryan, J. (2011). Super Mario: How Nintendo conquered America. New York: Portfolio/Penguin Said, E. (1978) Orientalism. London: Routledge \& Kegan Paul Ltd.

Said, E. (1985). Orientalism. Harmondsworth: Penguin. 
Saito, A. P. (2017). "Moe" and internet memes: The resistance and accommodation of Japanese popular culture in China. Cultural Studies, 23(1), 136-150. doi: 10.5130/csr.v23i1.5499

Saito, K. (2014). Magic, shōjo, and metamorphosis: Magical girl anime and the challenges of changing gender identities in Japanese society. The Journal of Asian Studies, 73(1), 143164. doi: $10.1017 / \mathrm{S} 0021911813001708$

Sato, K. (2003). More animated than life. Media in Asia. Retrieved from http://www1.udel.edu/History-old/figal/Hist372/Materials/animatedlife.pdf

Sato, K. (2004). How information technology has (not) changed feminism and Japanism:

Cyberpunk in the Japanese context. Comparative Literature Studies, 41(3), 335-355. doi: $10.1353 /$ cls.2004.0037

Sapach, S. (2017). 'Gotta Catch Em’ All': The compelling act of creature collection in Pokémon, Ni no Kuni, Shin Megami Tensei, and World of Warcraft. The Journal of the Canadian Game Studies Association, 10(16), 53-74. Retrieved from http://journals.sfu.ca/loading/index.php/loading/article/view/171/206

Sato, K. (1997). More animated than life. Media in Asia. Retrieved from http://www.kampo.co.jp/kyoto-journal/media/animated.html

Sato, K. (2004). How information technology has (not) changed feminism and Japanism: Cyberpunk in the Japanese context. Comparative Literature Studies, 41(3), 335-355. doi: $10.1353 /$ cls.2004.0037

Schaub, J. C. (2001). Kusanagi's body: Gender and technology in mecha-anime. Asian Journal of Communication, 11(1), 79-100. doi: 10.1080/01292980109364805

Schirato, T. (1994). The narrative of orientalism. Southeast Asian Journal of Social Science, 22, 44-52. Retrieved from http://www.jstor.org/stable/24491918 
Schodt, F. L (1988). Manga! Manga!: The world of Japanese comics. Tokyo: Kodansha International

Schodt, F. L. (1996). Dreamland Japan: Writings on modern manga. Berkeley, CA: Stonebridge Press.

Scolari, C. A., \& Ibrus, I. (2014). Transmedia critical: Empirical investigations into multiplatform and collaborative storytelling. International Journal of Communication, 8(2014), 2191-2200. Retrieved from http://ijoc.org/index.php/ijoc/article/view/3102

Semati, M. M. (2001). Sex, violence, and terrorism in Hollywood's international political imagery. In Y. R. Kamalipour and K. R. Rampal (eds.) Media, sex, violence, and drugs in the global village (pp. 235-260). Lanham, MD: Rowman \& Littlefield Publishers, Inc.

Sephazon, R. (2017, April 14). The Pokémon Company reports a 2016 retail revenue of $\$ 3.3$ billion. Retrieved from http://www.nintendolife.com/news/2017/04/the_Pokémon_company_reports_a_2016_ret ail_revenue_of_usd3_3_billion

Shin, H. (2010). Colonial legacy of ethno-racial inequality in Japan. Theory and Society, 39(3/4), 327-342. Retrieved from http://www.jstor.org/stable/40587538

Shirong Lu, A. (2008). The many faces of internationalization in Japanese anime. Animation: An Interdisciplinary Journal, 3(2), 169-187. doi: 10.1177/1746847708091893

Sørensen, L. (2008). Animated animism: The global ways of Japan's national spirits. Northern Lights, 6, 181-196. doi: 10.1386/nl.6.1.181/1 
State of Hawaii Department of Business, Economic Development \& Tourism (2012). Japanese Population by County, Island and Census Tract in the State of Hawaii: 2010 (Report No. 2010-6). Honolulu, HI: Hawaii State Data Center. Retrieved from http://www.ohadatabook.com/HSDC2010-6_Japanese.pdf

Steele, P. (2012). Memorializing colonialism: Images of the Japanese occupation of Indonesia in Japanese popular theatre. Asian Theatre Journal, 29(2), 528-549. doi: https://www.jstor.org/stable/23359528

Steinberg, M. (2006). Immobile sections and trans-series movement: 'Astroboy' and the emergence of anime, l(2), 190-206. doi: 10.1177/1746847706068903

Steinberg, M. (2012). Anime's media mix: Franchising toys and characters in Japan. Minneapolis, MN: University of Minnesota Press.

Stevens, C. S. (2010). You are what you buy: Postmodern consumption and fandom of Japanese popular culture. Japanese Studies, 30(2), 199-214. doi: 10.1080/10371397.2010.497578

Straubhaar, D. J. (2002). (Re)Asserting national television and national identity against the global, regional and local levels of world television. In M. G. Durham and D. M. Kellner (eds.) Media and cultural studies keyworks (pp. 681-702). Oxford: Blackwell.

Straw, W. (1997). Sizing up record collections. In S. Whiteley (ed.) Sexing the groove: Popular music and gender (pp. 3-17). London: Routledge

Tai, E. (2004). "Korean Japanese": A new identity option for resident Koreans in Japan. Critical Asian Studies, 36(3), 355-382. doi: 10.1080/1467271042000241586

Tang, A. K. Y. (2017). Key factors in the triumph of 'Pokémon GO'. Business Horizons, 60(5), 725-728. doi: 10.1016/j.bushor.2017.05.016

Te-jen, Y. (1967). The Japanese struggle for world empire. New York: Vantage Press. 
Thompson, C. J., \& Arsel, Z. (2004). The Starbucks brandscape and consumers' (anticorporate) experiences of glocalization. Journal of Consumer Research, 31(3). 631-642. doi: $10.1086 / 425098$

TIME (1999, November 22). The Ultimate Game Freak. TIME. Retrieved from http://content.time.com/time/magazine/article/0,9171,2040095,00.html

Tobin, J. (2004a). Introduction. In J. Tobin (Ed.) Pikachu's global adventure: The rise and fall of Pokémon. London: Duke University Press.

Tobin, J. (2004b). Conclusion: The rise and fall of the Pokémon empire. In J. Tobin (Ed.) Pikachu's global adventure: The rise and fall of Pokémon (pp. 257-292). London: Duke University Press.

Varley, P. (2000) Japanese culture. Honolulu: University of Hawaii Press.

Vasquez, V. (2003). What Pokémon can teach us about learning and literacy. Language Arts, 81(2), 118-125. Retrieved from Retrieved from http://www.jstor.org/stable/41484188

Wahab, J., Anuar, M. K., \& Farhani (2012). Global media product and construction of "Japanese Identity": A case study of anime on Malaysian television. Jurnal Komunikasi, 28(2), 119. Retrieved from http://www.ukm.my/jkom/journal/pdf_files/2012/V28_2_1-19.pdf

Waisbord, S. (2013). A metatheory of mediatization and globalization? Journal of Multicultural Discourses, 8(3), 182-189. doi: 10.1080/17447143.2013.822504

Waisbord, S., \& Jalfin, S. (2009). Imagining the national: Gatekeepers and the adaptation of global franchises in Argentina. In A. Moran (ed.) TV formats worldwide: Localizing global programs (pp. 55 - 74). Bristol, UK: Intellect Publishing. 
Wang, G., \& Servaes, J. (2000). Introduction. In G. Wang, J. Servaes, \& A. Goonasekera (eds.) The New Communications Landscape: Demystifying Media Globalization (pp. 1-18). London: Routledge.

Wei, L., Qian, J., \& Sun, J. (2017) Self-orientalism, joke-work and host-tourist relation. Annals of Tourism Research, 68, 89-99. doi: 10.1016/j.annals.2017.12.003

Wells, P. (2002) Animation and America. New Brunswick, Canada: Rutgers University Press.

Werning, S. (2014). Manga, anime and video games: Between adaptation, transmedia extension and reverse remediation. Mediascape, Retrieved from http://www.tft.ucla.edu/mediascape/Fall2014_MangaGames.html

White, M. I. (2007). Modern Japanese cuisine: Food, power, and national identity [Review of the book Modern Japanese cuisine: Food, power and national identity]. Journal of Japanese Studies, 34(2), 406-410. Available from Project MUSE Website https://muse.jhu.edu/article/241908

Wise, J. M. (2008). Cultural globalization: A user's guide. Malden, MA: Blackwell.

Wong, W. S. (2006). Globalizing manga: From Japan to Hong Kong and beyond. Mechademia, 1(May), 23-45. doi: 10.1353/mec.0.0060

Wu, C. (2016). Hayao Miyazaki's mythic poetics: Experiencing the narrative persuasions in 'Spirited Away,' 'Howl's Moving Castle,' and 'Ponyo.' Animation, 11(2), 189-203. doi: $10.1177 / 174684$

Yamato, E. (2012). Accumulating Japanese popular culture: Media consumption experiences of Malaysian young adults. Media Asia, 39(4), 199-208. doi:

$10.1080 / 01296612.2012 .11689938$ 
Yasumoto, S. (2011). Impact on soft power of cultural mobility: Japan to East Asia. Mediascape. Retrieved from http://www.tft.ucla.edu/mediascape/Winter2011_SoftPower.pdf

Yoshida, K. (2008). Animation and "Otherness": The politics of gender, racial, and ethnic identity in the world of Japanese anime. (Unpublished doctoral dissertation). University of British Columbia, Vancouver. doi: 10.14288/1.0067003 Retrieved from https://open.library.ubc.ca/cIRcle/collections/ubctheses/24/items/1.0067003

Yoshioka, S. (2008). Heart of Japaneseness: History and nostalgia in Hayao Miyazaki’s 'Spirited Away’. In M. W. MacWilliams (ed.) Japanese visual culture: Explorations in the world of manga and anime (pp. 256-273). London: Routledge.

Zsila, A., Orosz, G., Bőthe, B., Tóth-Király, I., Király, O., Griffiths, M., \& Demetrovics, Z. (2018). An empirical study on the motivations underlying augmented reality games: The case of 'Pokémon Go' during and after Pokémon fever. Personality and Individual Differences, 133(2018), 56-66. doi: 10.1016/j.paid.2017.06.024

Zykas, A. (2009). Nihonron and Japanese country image communication: The aspect of 'articulation' of national identity. Regioninès Studijos, 2009(3), 121-139. Retrieved from https://www.ceeol.com/search/article-detail?id=155680 


\section{APPENDIX: LIST OF EPISODES EXAMINED}

\section{Season One}

Episode 001: Pokémon, I Choose You!

Episode 002: Pokémon Emergency!

Episode 003: Ash Catches a Pokémon

Episode 004: Challenge of the Samurai

Episode 005: Showdown in Pewter City

Episode 019: The Ghost of Maiden's Peak

Episode 025: Primeape Goes Bananas

Episode 031: The Ninja-Poké Showdown

Episode 048: Bulbasaur's Mysterious Garden

Episode 049: The Case of the K-9 Caper

Episode 050: Pokémon Paparazzi

Episode 051: The Ultimate Test

Episode 052: The Breeding Center Secret

\section{Season Twenty}

Episode 936: Alola to New Adventure!

Episode 937: The Guardian's Challenge!

Episode 938: Loading the Dex!

Episode 939: First Catch in Alola, Ketchum-style!

Episode 940: Yo, Ho, Ho! Go, Popplio!

Episode 943: Lillie's Egg-xhilarating Challenge!

Episode 947: The Sun, the Scare, the Secret Lair! 
Episode 956: One Journey Ends, Another Begins...

Episode 974: Mallow and the Forest Teacher

Episode 975: Balloons, Brionne, and Belligerence!

Episode 976: Mounting an Electrifying Charge!

Episode 977: Alola, Kanto!

Episode 978: When Regions Collide! 